\title{
نحو إعادة التفكير في الأطر المفاهيمية لتحليل السياق الفلسطيني الآستعماري
}

\section{Re-thinking Conceptual Frameworks to Analyze the Palestinian Colonial Context}

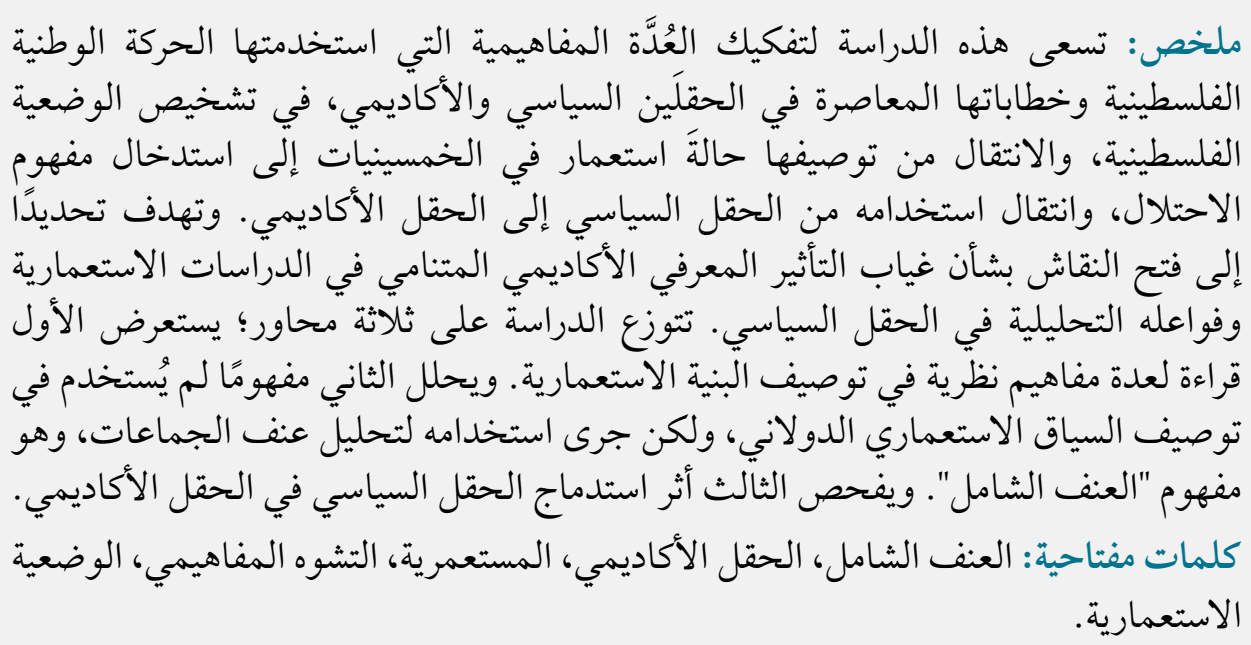$$
\text { الاستعمارية. }
$$

Abstract: This article deconstructs the conceptual tools employed by the Palestinian national movement to diagnose the Palestinian condition. It traces the transformations of contemporary political and academic discourses, from labeling the Palestinian condition as "colonialism" in the 1950s and then re-packaging it as "occupation" in post-Oslo era. Consequently, the article explains the impact of the absence of academic-epistemic frameworks in the field of colonial studies on the political field. To achieve this goal, the article is divided into three parts: Part I reads through theoretical frameworks to qualify colonial structure/ the structure of colonialism; Part II analyzes the concept of "Total Violence," that has been used to analyze communal violence but never to analyze colonial state violence; while Part III examines the impact of merging academia into the political realm.

Keywords: Total Violence, Academia, Coloniality, Conceptual Impotency, Colonial Context.

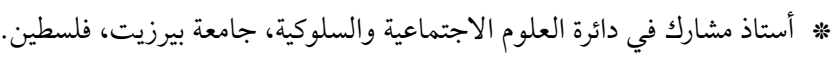




\section{مقدمة}

اجتهد كثيرون، ومازالوا، في محاولة تأطير مقاربة الحالة الاستعمارية الفلسطينية عبر استدعاء مرجعيات معرفية ذات طابع كوني، وعقد مقارنات أو نحت مفاهيم جديدة

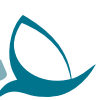

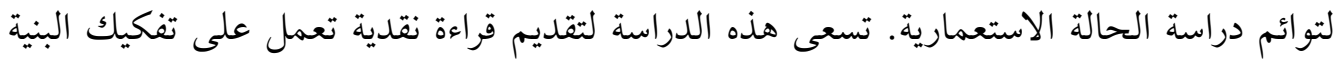
الخطابية لمجموعة من الأطر المفاهيمية في الحقلين السياسي والأكاديمي، عبر عملية تتبّع تاريخي

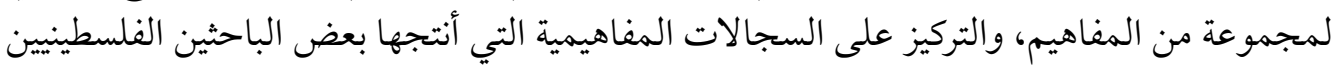

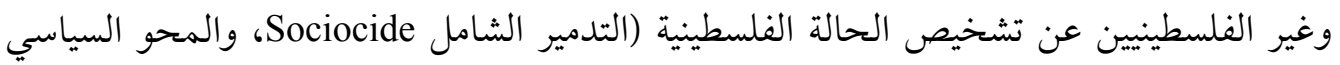

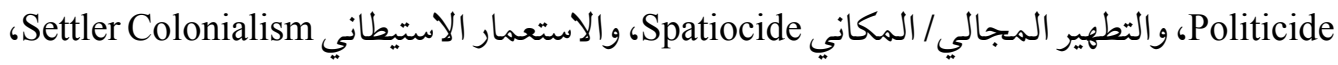
والأبارتهايد Apartheid). وفي هذا الإطار، تطرح الأسئلة التالية: لماذا لم تؤثّر هذه الأطر المفاهيمية وغيرها في مفردات الحقل السياسي الفلسطيني؟ بل لماذا يستخدم بعض الأكاديميين الفلسطينيين مفردات الحقل السياسي الفلسطيني؟ ولماذا لا تنسحب التحليلات الأكاديمية إلى الحقل السياسي

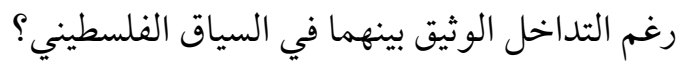

قبل البدء في عرض المحاولة، تجدر الإشارة إلى عدة صعوبات واجهتها هذه الدراسة. أولاها ذات

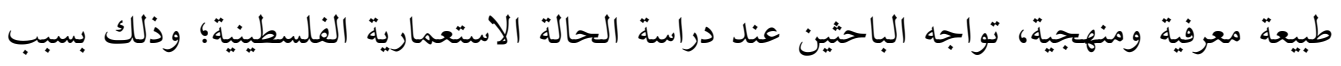

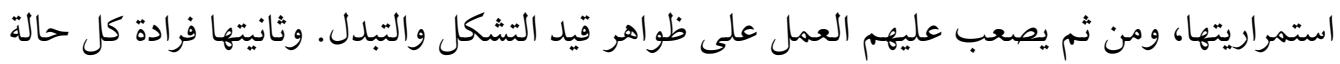
استعمارية وسياقها وشروطها وانعكاساتها؛ ما يجعل دراسة كل حالة استعمارية - مستعمَرية أشبه ولهيه بحالة المرور بحقل ألغام، بسبب عناصر الشبه والاختلاف بين الظواهر الاستعاسعمارية - المُستعمَرية.

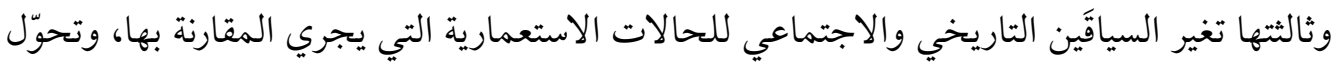

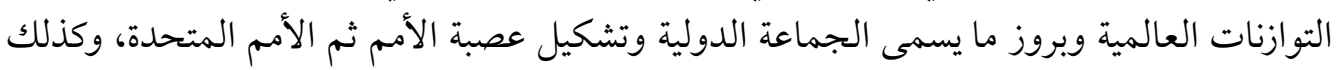
حدوث تغيرات أخرى جرت على مستوى العالم واختفاء الإمبراطوريات بالمعنى القديم.

بالنسبة إلى المفاهيم المستخدمة، يجتهد البعض في القول إن استخدام تعبير الاستعمار باللغة العربية

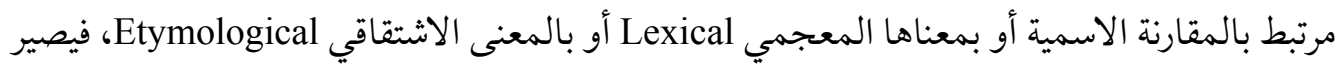

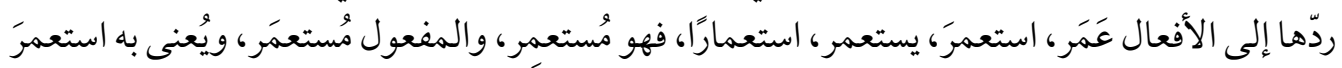

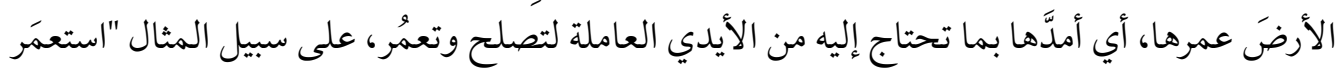

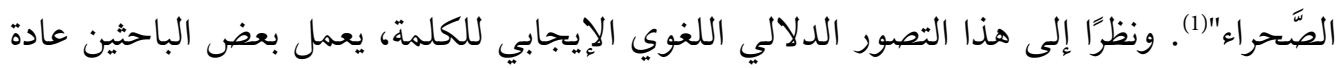

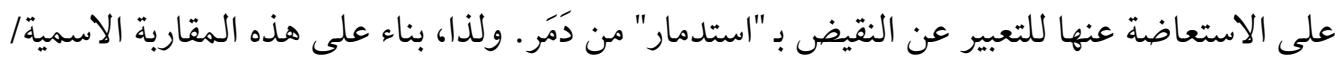

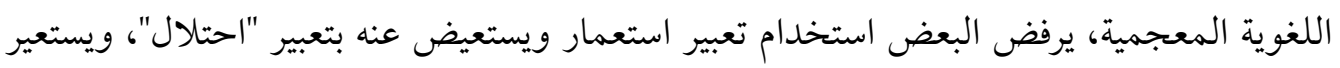
بعض آخر الكلمات اللاتينية "كولونيالية" وكولونيالي. وفي رأينا، هاتان المقاربتان إشكاليتان؛ لأن

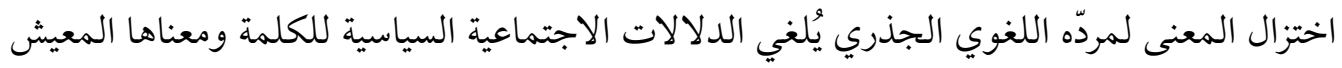

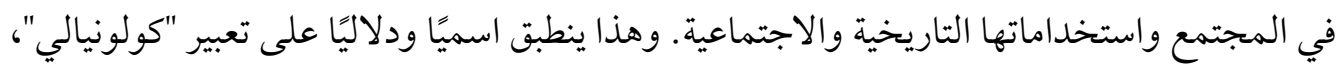


ففي بعض اللغات اللاتينية، كالإنكليزية والفرنسية، تعني كلمة كولونيالية، كما معناها أيضًا باللغة العربية، "تعمير" و"إجازة" و"توطّن" فمعنى "كولوني" Colonie/ Colony في القواميس الإنكليزية

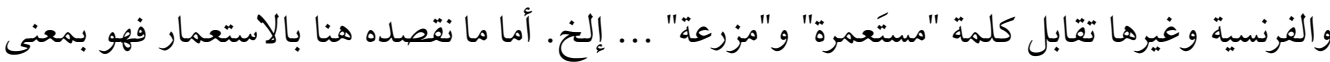
الاصطدام مع السكان الأصلانيين المرتبط بكل الأشكال الاستعمارية التي تعرّض لها أكثر من 84 في المئة من مساحة الكرة الأرضية من غزو أراضٍ والسيطرة على ممتلكات شعب الخب آخر . وهذا الاستخدام

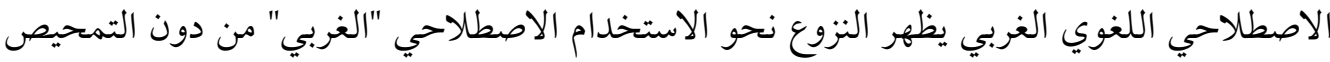

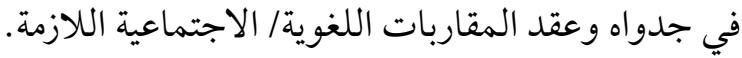

تقترح هذه الدراسة تسمية حالة الوقوع تحت الاستعمار بالحالة المُستَعَمَرية (نسبة إلى المُستَعمَرة)؛ وذلك لأن التوصيف الاستعماري ذو طابع تعميمي لا يميز بين الطرفين في الحالة الاستعمارية

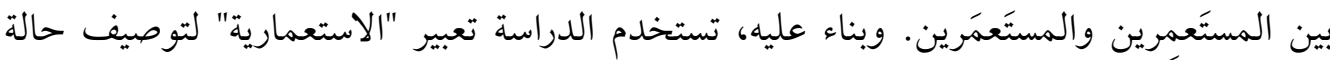

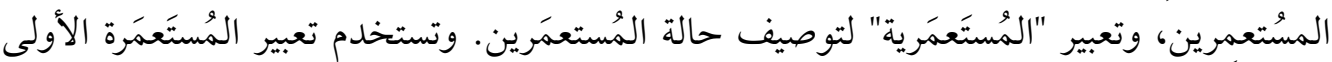

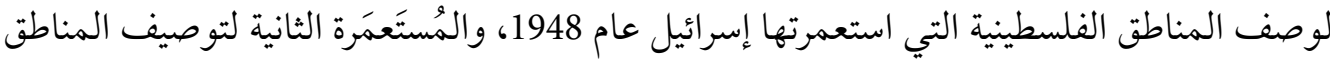

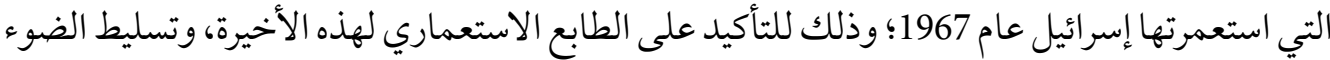

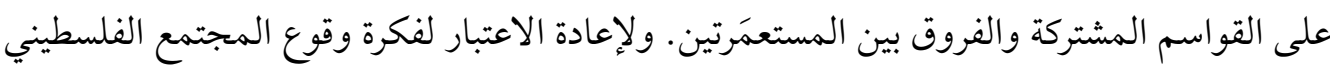
برمّته ويأجزائه المختلفة تحت مشروع استعماري استيطاني واحد، مع تباينات وفروق في طرائق إدارة

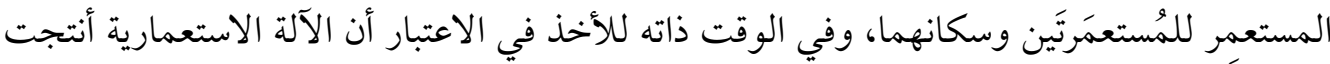
تصورات وممارسات وتمثلات وأوضاعًا مغايرة لدى المسُتعمَرين أنفسهم وبطرائق مقاومتهم للمشروع

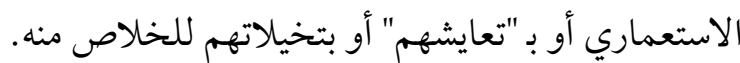

\section{أولا: مفهمة الإطار الاستعماري الاستيطاني: مقاربة تحليلية}

\section{1. إسرائيل بوصفها بنية استعمارية}

أنتج المشروع الاستعماري الصهيوني دولة إسرائيل التي كُتب عنها الكثير من الدراسات والأبحاث،

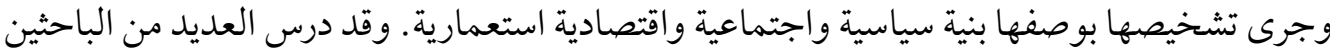

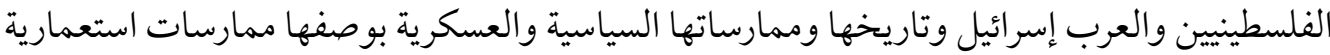
منذ ستينيات القرن الماضي (2). وشخّص إدوارد سعيد المشروع الصهيوني وعلاقته بالإمبريالية الغربية

(2) Elia Zureik, The Palestinians in Israel: A Study in Internal Colonialism (London: Routledge \& Kegan Paul, 1979); Edward Said, The Question of Palestine (New York: Times Books, 1979); Abdul-Wahhab Kayyali (ed.), Zionism, Imperialism, and Racism (London: Croom Helm, 1979); Fayez Sayegh, Zionist Colonialism in Palestine (Beirut: The Palestine Liberation Organization Research Center, 1965); Ibrahim Abu-Lughod \& Baha Abu-Laban (eds.), Settler Regimes in Africa and the Arab World: The Illusion of Endurance (Wilmette, IL: Medina University Press International, 1974);

عبد الوهاب المسيري، اليهودية والصهيونية وإسرائيل: دراسة في انتشار وانحسار الرؤية الصهيونية للواقع (بيروت: المؤسسة العربية 
وآثاره في ضحاياه (3)، ووصفه جميل هلال باعتباره الاستعمار الأخير في غرب آسيا(4)، ولاحقًا تناول نور

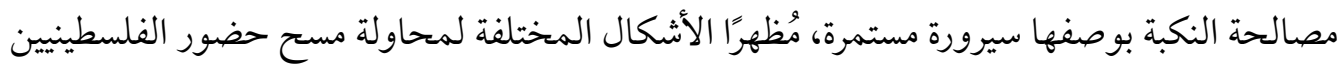

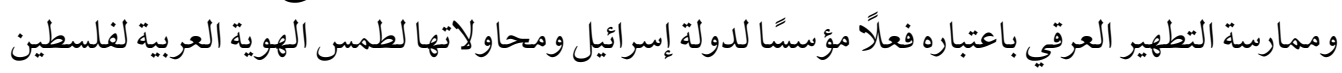

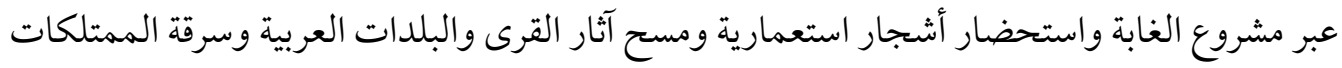

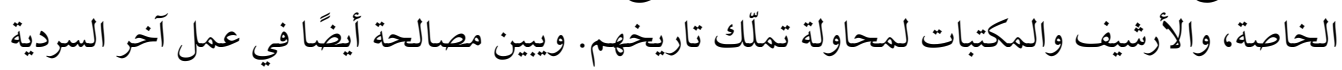

$$
\text { الاستعمارية والاستخدام التوراتي وعلاقتها بالآثار (5). }
$$

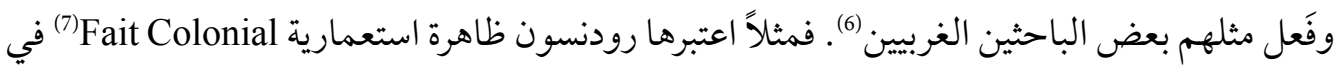

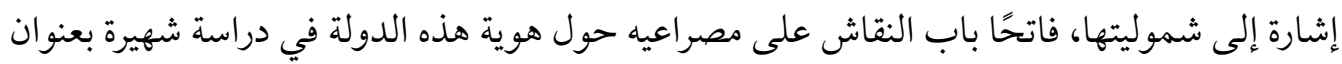

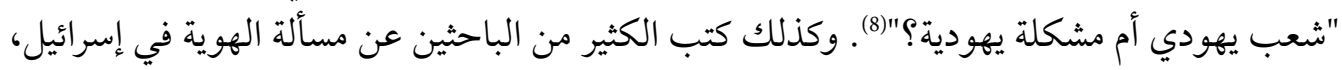

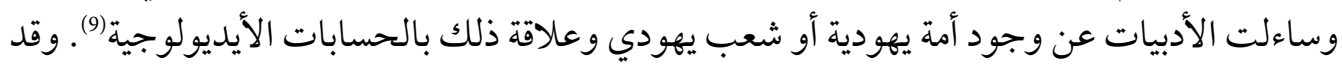

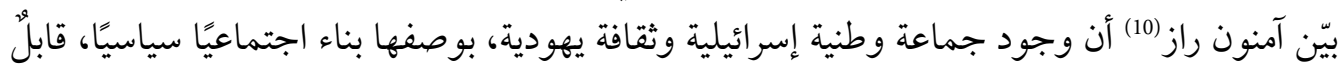

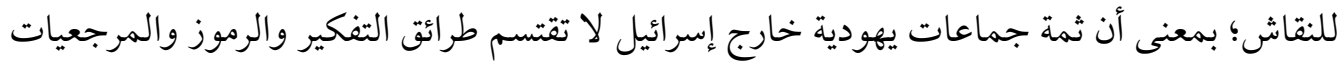

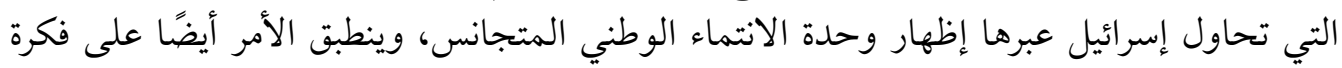
وحدة الشتات الإسرائيلي.

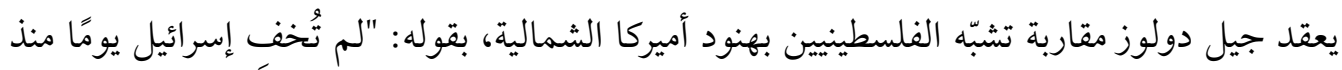

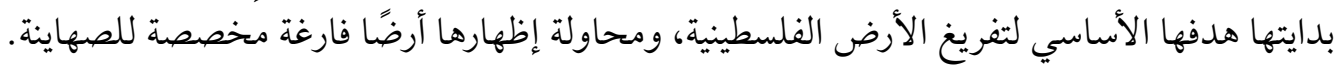

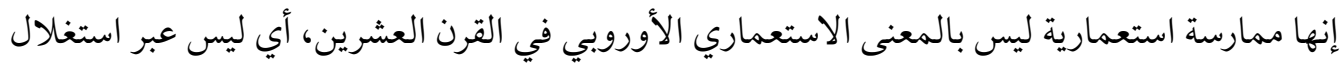

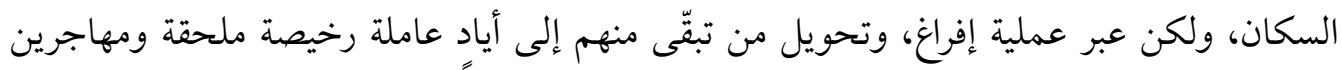

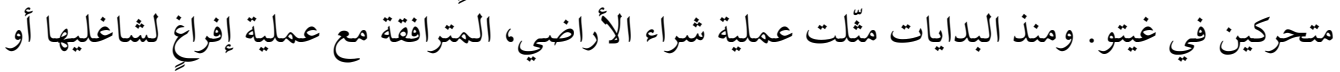

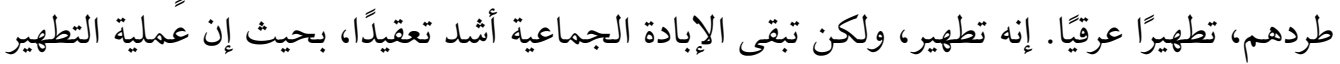

(3) Said, pp. 56-114.

(4) Hilal Jamil, "Imperialism and Settler-Colonialism in West Asia: Israel and the Arab Palestinian Struggle," Utafiti, vol. 1, no. 1 (1976), pp. 51-69.

(5) Nur Masalha, The Palestine Nakba: Decolonising History, Narrating the Subaltern, Reclaiming Memory (London/ New York: Zed Books, 2012), pp. 88-204; Nur Masalha, The Zionist Bible: Biblical Precedent, Colonialism and the Erasure of Memory (Durham: Acumen, 2013).

Arie Bober (ed.), The Other Israel: The Radical Case Against Zionism (Garden City, NY: Anchor Books, 1972); Uri Davis, Israel, Utopia Incorporated: A Study of Class, State, and Corporate Kin Control (London: Zed Press, 1977).

(7) Maxime Rodinson, "Israël, fait colonial?" Les Temps modernes, vol. 22, no. 253 (1967), pp. 17-88.

(8) Maxime Rodinson, Peuple juif ou problème juif? (Paris: François Maspero, 1981).

(9) Shlomo Sand, Comment le peuple juif fut inventé: De la Bible au sionisme (Paris: Fayard, 2008); Anthony D. Smith, Chosen Peoples: Sacred Sources of National Identity (Oxford: Oxford University Press, 2003).

(10) Amnon Raz-Krakotzkin, Exil et souveraineté: Judaïsme, sionisme et pensée binationale (Paris: La Fabrique, 2007), pp. 20-21. 
مرتبطة بالإفراغ الجغرافي وتحت شعار أنهم ليسوا سوى عرب فليعيشوا مع العرب الآخرين"(11). ثم ينتهي به نصه ليقول إن الفلسطينيين هم "هنود إسرائيل"(12). وعلى الرغم من أهمية هذه الكتابات، فإنه جرى تهميشها تدريجيًا لصالح مقاربات واصطلاحات أخرى ترى في المعضلة الاستعمارية

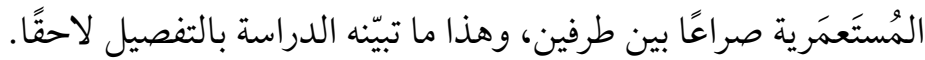

\section{2. الاستعمار الاستيطانن بوصغه حقلًا معرفيًا}

بالنظر إلى الأطر التحليلية لتشخيص الوضعية الاستعمارية المُستعمَرية، نشهد منذ خمسة عشر عامًا تزايذًا متصاعدًا في مفهمة الاستعمار الاستيطاني Settler Colonialism، واستخدامه لمقارنة حالات مشابهة بالاستعمار الصهيوني. تشترك دولة الاستعمار الإسرائيلي مع كل من كندا وأستراليا والولايات المتحدة الأميركية بكونها دولًا استعمارية استيطانية، أي إنها دول لمجتمعات سياسية قامت على

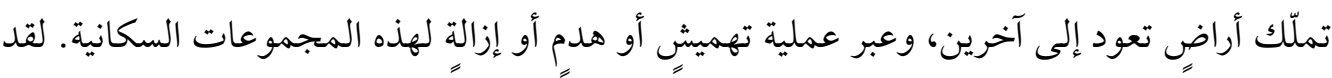
تزايد اهتمام الباحثين في العلوم الاجتماعية وسوسيولوجيا الاستعمار (13) عالميًا، بحقل الدراسات الاستعمارية الاستيطانية ومابعد الاستعمارية، وخاصة في الحقل الإيتين الأكاديمي الأنكلوسكسوني. وأنتج العديد من الباحثين الفلسطينيين من المُستَعمَرة الثانية والشتات كتابات جديدة عن الاستعمار الاستيطاني (14)، وأيضًا كتب باحثون من المُستَعمَرة الأولى عن الاستعمار الاستيطاني ومقاربته في سياق المُستَعمَرة الأولى (15). تقول صباغ - خوري إن الاهتمام بهذا الحقل قد تزايد مع تنامي عقد المقارنات بحالات استعمارية استيطانية مشابهة، وخاصة بعد فشل مشروع الدولتين وغياب مشروع جامع

(11) Gilles Deleuze, Les Indiens de Palestine Paru dans le recueil Deux régimes de fous (Paris: Minuit, 1983), pp. 222223.

(12) Ibid.

(13) Julian Go, "The 'New' Sociology of Empire and Colonialism," Sociology Compass, vol. 3, no. 5 (2009), pp. 775 788; Julian Go, "For a Postcolonial Sociology," Theory and Society, vol. 42, no. 1 (2013), pp. 25-55; Patrick Wolfe, Settler Colonialism and the Transformation of Anthropology: The Politics and Poetics of an Ethnograph Event (London: Cassell, 1999); Patrick Wolfe, "Settler Colonialism and the Elimination of the Native," Journal of Genocide Research, vol. 8, no. 4 (2006), pp. 387-409; Lorenzo Veracini, Settler Colonialism: A Theoretical Overview (New York: Palgrave Macmillan, 2010).

(14) Rashid Khalidi, The Hundred Years' War on Palestine: A History of Settler Colonialism and Resistance, 1917-2017 (New York: Metropolitan Books, 2020); Maya Mikdashi, "What is Settler Colonialism? (For Leo Delano Ames Jr.)," American Indian Culture \& Research Journal, vol. 37, no. 2 (2013), pp. 23-34.

(15) Ahmed Sa'di, "Colonialism and Surveillance," in: Kirstie Ball, Kevin Haggerty \& David Lyon (eds.), Routledge Handbook of Surveillance Studies (London: Routledge, 2012), pp. 151-158; Magid Shihade, "Settler Colonialism and Conflict: The Israeli State and Its Palestinian Subjects," Settler Colonial Studies, vol. 2, no. 1 (2012), pp. 108-123; Nadera Shalhoub-Kevorkian, "Human Suffering in Colonial Contexts: Reflections from Palestine," Settler Colonial Studies, no. 4, no. 3 (2014), pp. 277-290; Raef Zreik, "When Does a Settler Become a Native? (With Apologies to Mamdani)," Constellations, vol. 23, no. 3 (2016), pp. 351-364;

الفلسطينيون في إسرائيل: قراءات في التاريخ والسياسة والمجتمع، نديم روحانا وأريج صباغ - خوري (محرران) (حيفا: مدى 
للمكونات الفلسطينية المختلفة(16). وفي رأيها، سيشهد هذا الحقل تناميًا متزايدًا واهتمامًا من أفراد

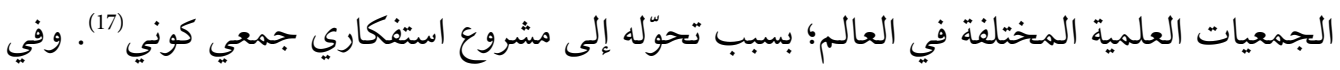

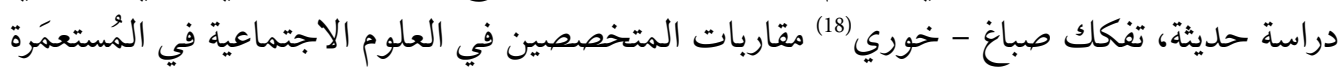

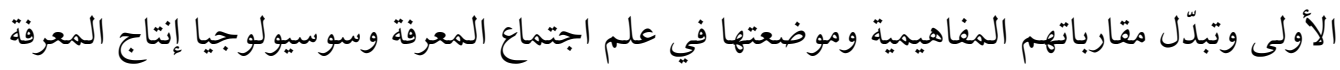

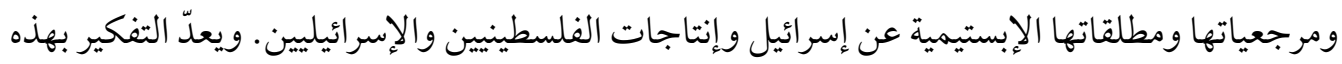

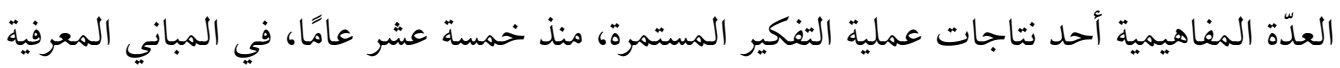

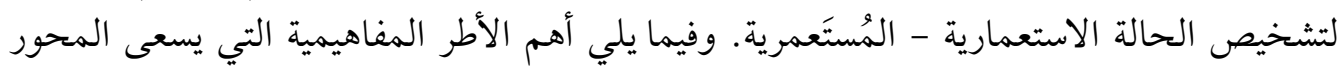
الثاني لعرضها وتقديم مقاربة مفاهيمية جديدة.

\section{3. عُدّة مغاهيمية لدراسة الحالة الاستعمارية الغلسطينية}

يقدّم العديد من الباحثين مقاربات مفاهيمية مهمة لتشخيص الحالة الاستعمارية، عبر استخدام

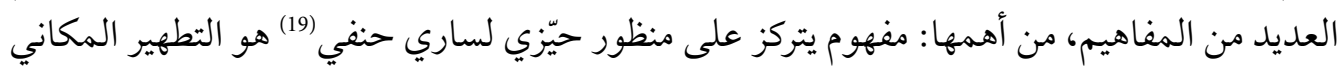

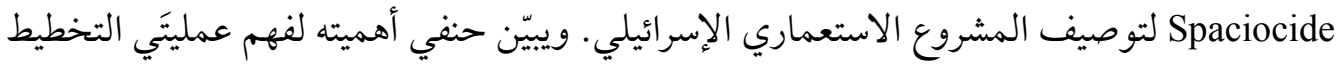

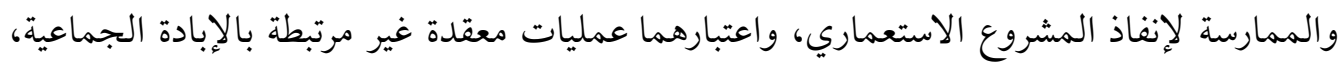

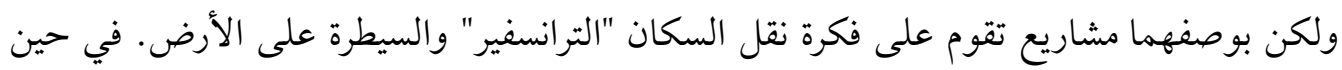

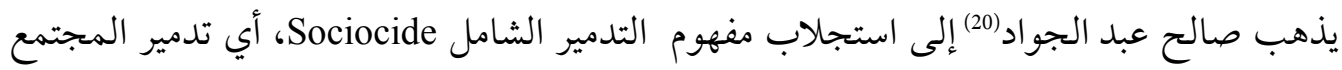

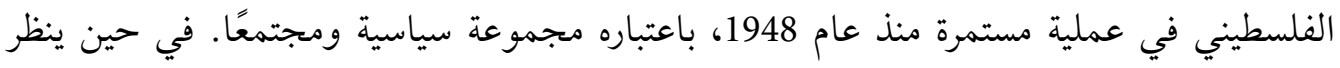

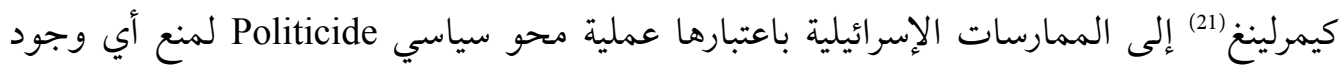

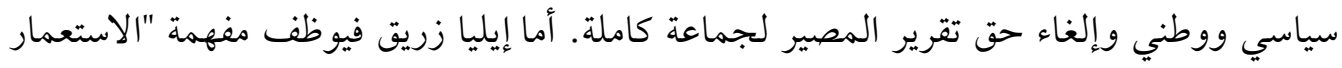

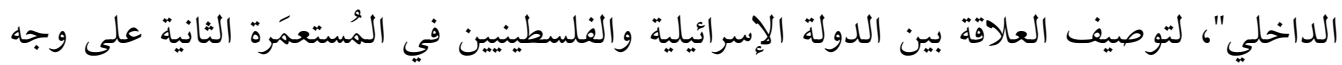

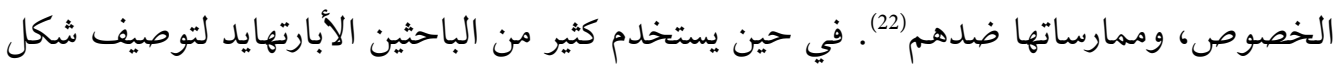

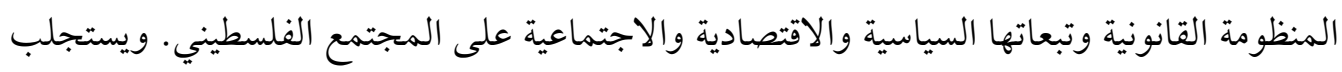

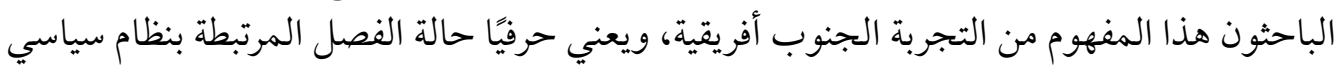

(16) Areej Sabbagh-Khoury, "Tracing Settler Colonialism: A Genealogy of a Paradigm in the Sociology of Knowledge Production in Israel," Politics \& Society (2021), p. 15.

(17) Ibid., p. 29.

(18) Ibid., pp. 14-17.

(19) Sari Hanafi \& Linda Taber, "Spatio-cide, réfugiés, crise de l’État-nation," Multitudes, vol. 4, no. 18 (2004), pp. 187-196.

(20) Saleh Abdeljawad, "La politique israélienne envers le peuple palestinien," Inprecor, no. 517 (Mai 2006), accessed on 10/1/2022, at: https://bit.ly/3JUy4sx

(21) Baruch Kimmerling, Politicide: Les guerres d'Ariel Sharon contre les Palestiniens (Paris: Éditions Agnès Viénot, 2003), p. 10.

(22) Elia Zureik, Israel's Colonial Project in Palestine: Brutal Pursuit, Routledge Studies on the Arab-Israeli Conflict (Abingdon: Routledge, 2015). 
تُمأسس للفصل العرقي ولتراتبيات إثنية. ويعرّف إليكيا مبوكولو "الأبارتهايد بوصفه سياسة جديدة

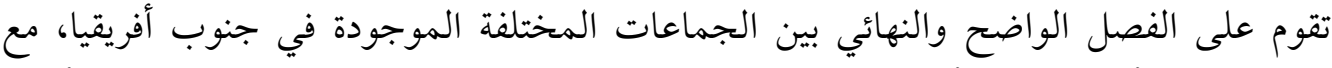

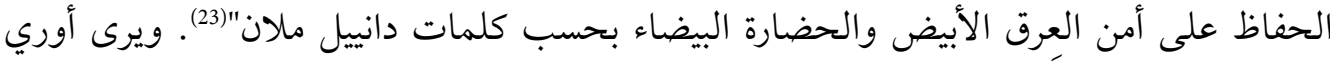

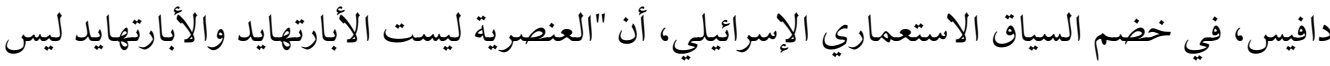
العنصرية، بل هو نظام سياسي يسمح بإنفاذ العنصرية على نحو قانوني عبر مأسسته برلمانيًا، ومن لئن

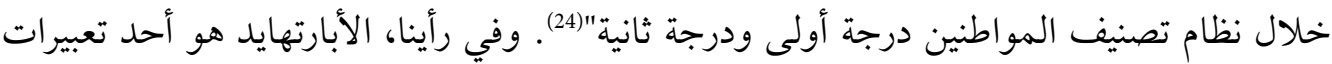

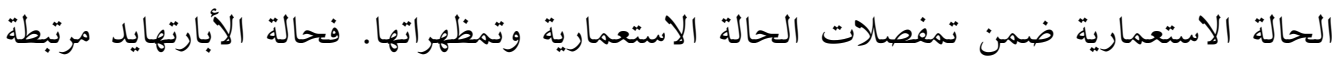
بالتكوين السياسي والأخلاقي لإسرائيل، تشابه حالة دولة جنوب أفريقيا. ويحرز المفهوم ومقاربته

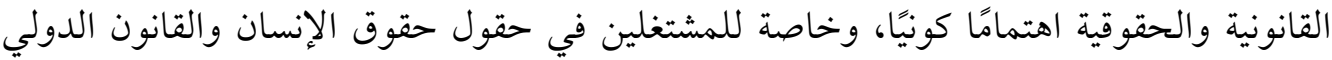

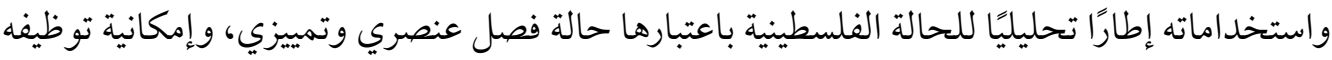
وسيلةً لاسترداد الحقوق ومحاولةً لردع الدولة الاستعمارية.

عاد مفهوم الأصلانية إلى الصدارة في الحقل الأكاديمي في العلوم الاجتماعية، وخاصة في الدراسات

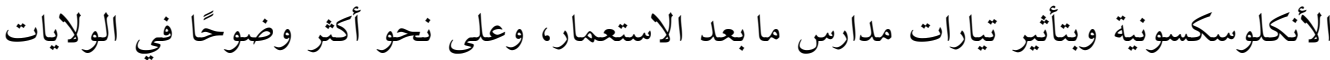

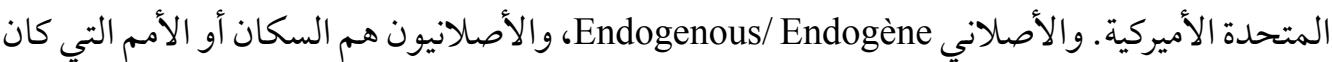
لها تاريخ متصل قبل الاستعمار والغزو الاستعماري. واستخدامات المفهوم عبر هذه التسمية متعددة: فبعضها يعني التعبير عن هوية عابرة للأجيال متناقلة ضد هوية المهيمن والغازي، ويجريك ولمي عادة إعادة

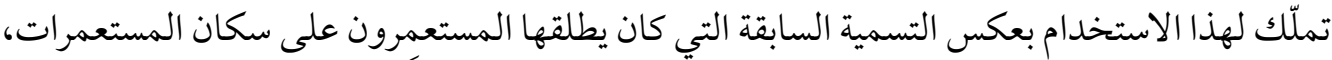

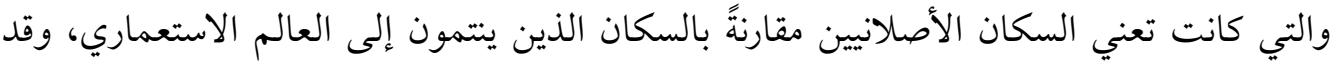
تكون مقابل البيض. تستخدم هذه العدة المفاهيمية الأصلانية لعقد المقارنات بالحالة الاستعمارية

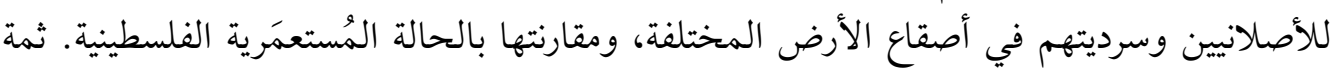

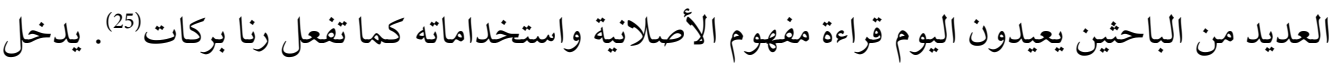
مفهوم الأصلانية في العدة المفاهيمية لتحليل الإطار الاستعماري الاستيطاني في السياق الفلسطيني

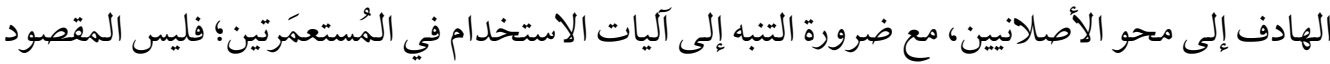

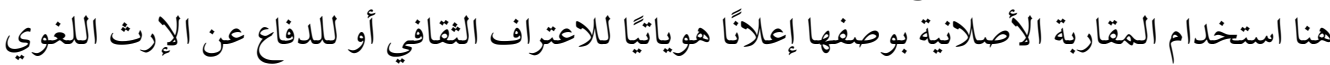

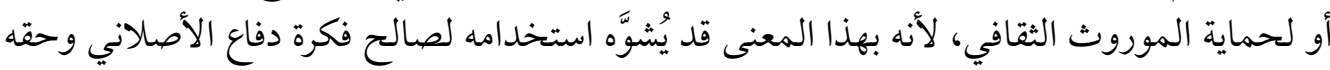
في العيش في ظل اعترافه بالسلطة الاستعمارية والدفاع عن حقوق مدنية وإنسانية وثقافية وهوياتية. وترى يارا هواري وأحمد أمارة أن نموذج الأصلانية "يفكك اعتبار المشروع الصهيوني مشروعًا فريدًا ومتميزًا لحالة فلسطين، ويضعه في السياق العالمي للمشاريع الاستعمارية الاستيطانية الأخرى.

(23) Elikia M'Bokolo, "Les pratiques de l'apartheid," in: Marc Ferro (dir.), Le livre noir du colonialisme (Paris: Robert Laffont, 2003), p. 469.

(24) Uri Davis, Apartheid Israel, Possibilities for the Struggle Within (London/ New York: Zed Books, 2003), p. 88.

(25) Rana Barakat, "Writing/ Righting Palestine Studies: Settler Colonialism, Indigenous Sovereignty and Resisting the Ghost(s) of History," Settler Colonial Studies, vol. 8, no. 3 (2017), pp. 349-363. 
يتيح هذا للفلسطينيين أن يعززوا علاقات التضامن مع الشعوب الأصلية الأخرى وأن يدركوا شبكات الاضطهاد المتشابكة" (26).

\section{ثنانيًا: استخدامر مفهومر جديد لمقاربة الحالة الاستعمارية -

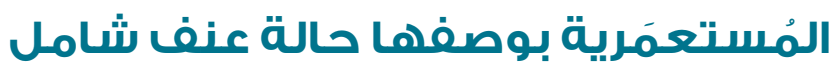

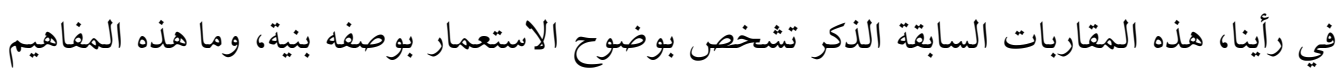

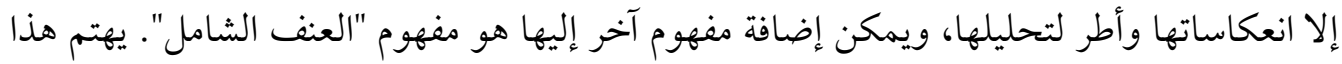

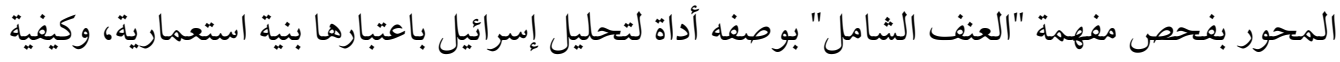

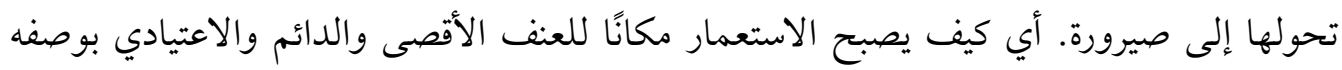

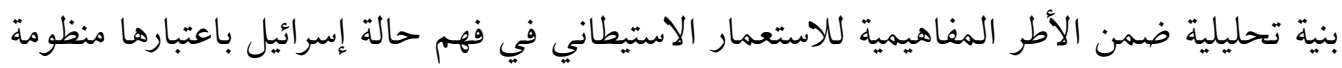

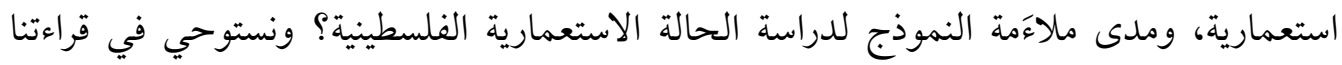

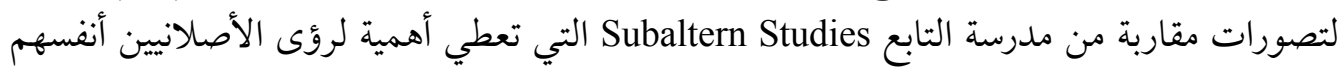

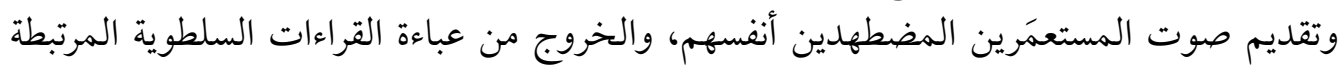
بالهيمنة.

\section{1. مغهمة العنف الشامـل بوصفه أداة تحليلية}

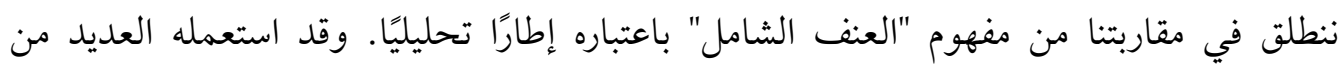

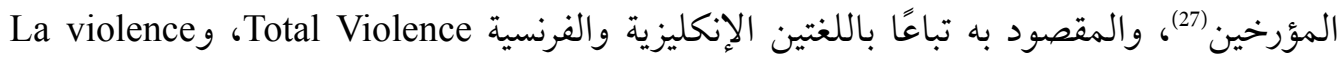

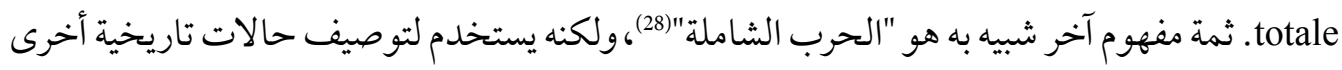

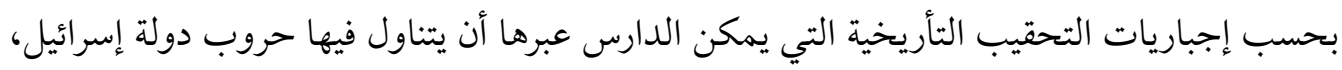

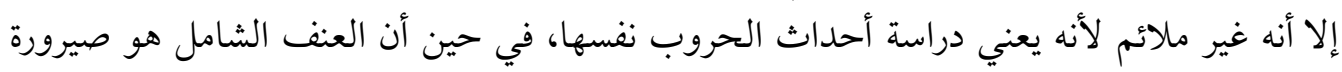

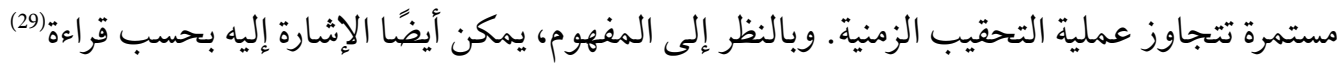

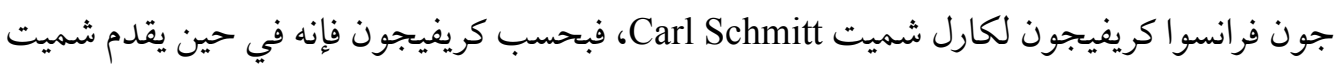

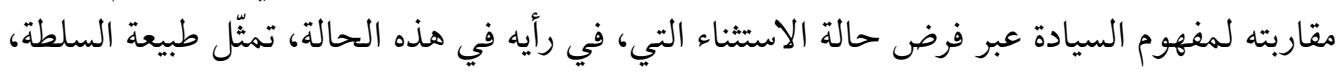

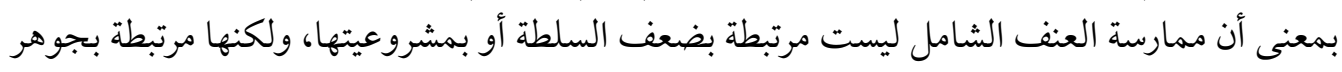
(26) أحمد أمارة ويارا هواري، "توظيف الأصلانية في النضال التحرّري الفلسطيني"، شبكة السياسات الفلسطينية، 2019/8/8،

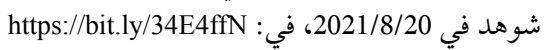

(27) Jean-Clément Martin, "Révolution française et 'violence totale'," Inflexions, vol. 31, no. 1 (2016), pp. 73-79.

(28) Jean-Yves Guiomar, L'Invention de la guerre totale (Paris: Le Félin, 2004); Gabriella Gribaudi, Guerra Totale: Tra bombe alleate e violenze naziste: Napoli e il fronte meridionale, 1940-44 (Torino: Bollati Boringhieri, 2005); David Bell, The First Total War: Napoleon's Europe and the Birth of Warfare as We Know it (New York/ Boston: Houghton Miflin Company, 2010).

(29) Jean-François Kervégan, Que faire de Carl Schmitt? (Paris: Gallimard, 2011); Giorgio Agamben, État d'exception: Homo Sacer II (Paris: Seuil, 2003). 
الدولة الشاملة نفسها، يعتبر جان كليمون - مارتن "أن المشاريع الاستعمارية المدعمة بالتقدم التقاني للغرب الذي يؤكد التحولات [...] عبر إشاعة ممارسات عنصرية، متجاوزين كل الاعتبارات الدينية

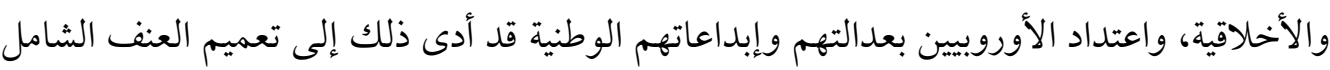
على أصقاع الأرض، الذي هو أساس الاستعمار "(30).

يستخدم بعض الباحثين مفهوم "العنف الشامل" للإشارة إلى عدد الضحايا الرقمية، كما يحدث عادة

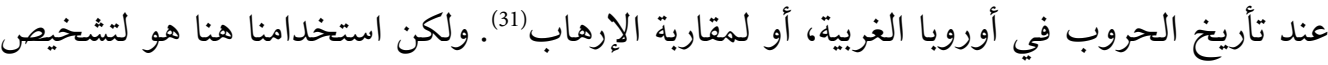

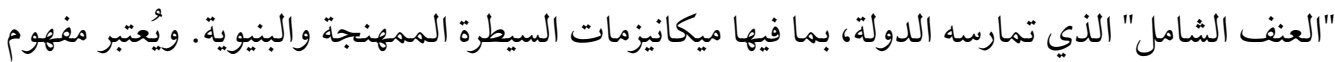
العنف الشامل مفهومًا مركزيًا لفهم نوعية العنف الذي تمارسه الدولة، وقد يمارسه الأفراد أيضًا، ولكنينا

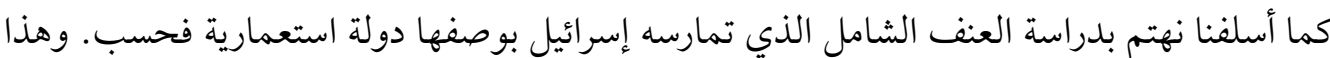

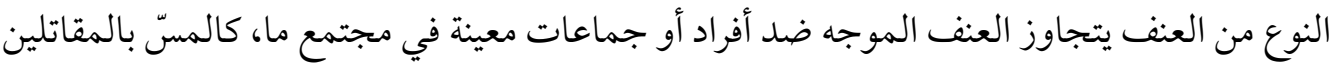
أو بجماعات محددة؛ في حين أن ماتقوم به دولة الاستعمار الصهيوني هو ممارسة استخطاطية مقصودة للمسّ بالمكونات الكلية في المجتمع الفلسطيني في كل الحيوات السياسية والاقتصادية

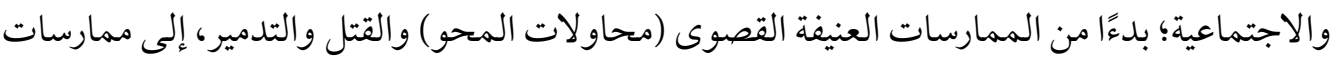

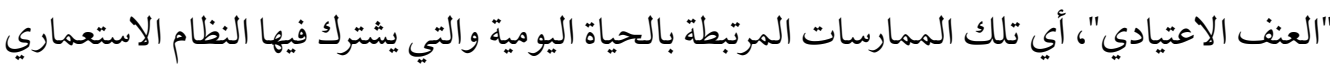

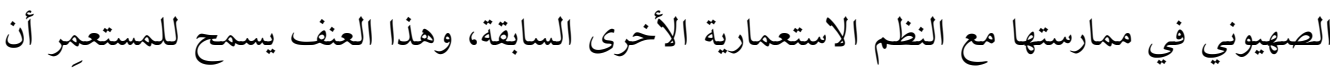

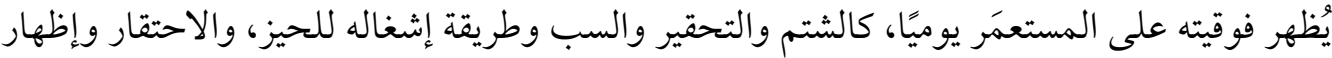
البطش، وقتل الفلسطيني لأي سبب كان مع الإبقاء على نظام يسمح بضبط الجنود، لأن قتل الفلسطيني

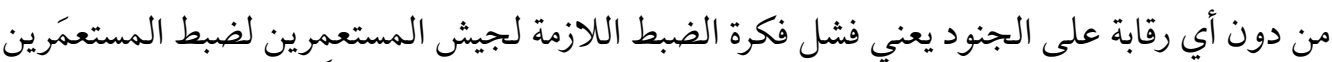

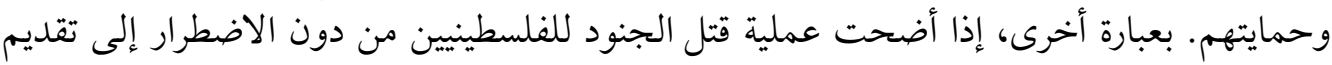
الأسباب (المبررات الشكلية)، حتى إن كانت صورية، فسيؤدي ذلك إلى تحفيز الفلسطينيين على رفع إنى

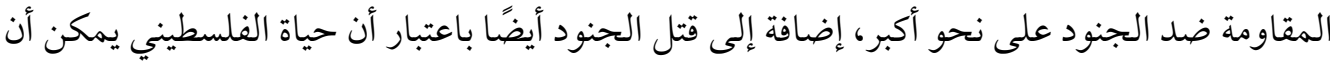

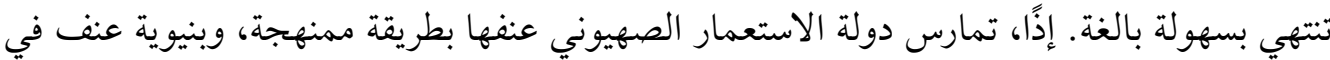

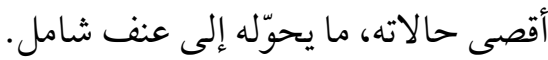

\section{2. العنف الشـامـل في الوضعية الاستعمارية}

يُسمي جورج بالاندييه (32) الشروط الاجتماعية والسياسية والاقتصادية للمستَعَمَين بـ "الوضعية الاستعمارية". ويعني جوهر العنف استخدام القوة الفيزيائية بهدف إيقاع خسائر جسمانية/ مادية أو

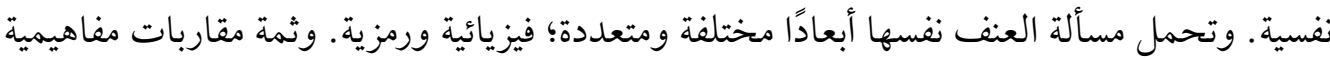

(30) Martin, pp. 73-79.

(31) Isabelle Sommier, "Du 'terrorisme' comme violence totale?" Revue internationale des sciences sociales, vol. 4, no. 174 (2002), pp. 525-533.

(32) Georges Balandier, "La situation coloniale: Approche théorique," Cahiers internationaux de sociologie, vol. 11 (1951), pp. 44-79. 


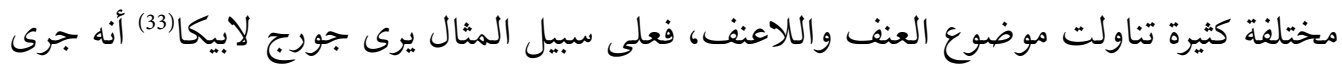

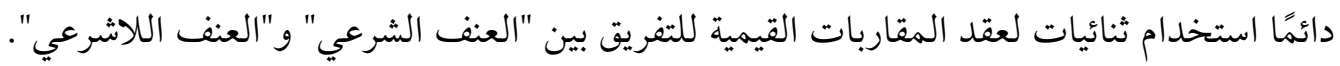

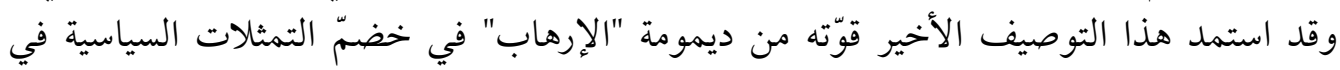

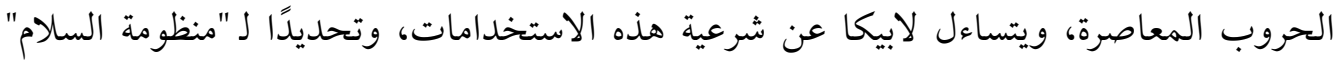

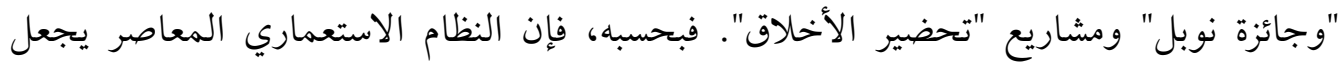

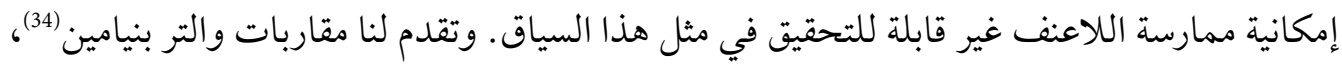

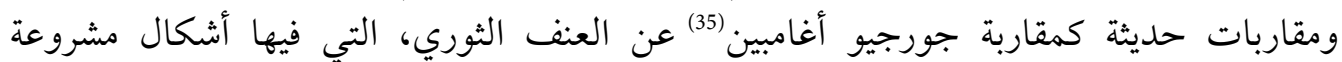

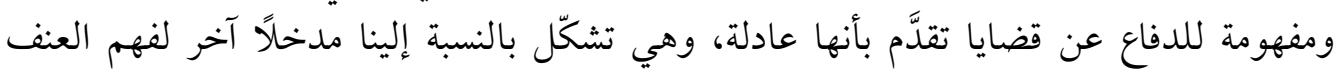
الشامل في الحالة الفلسطينية. ويمكننا أن نختصر المقاربة لدراسة الحالة التهائ الفلسطينية عبر استعارة

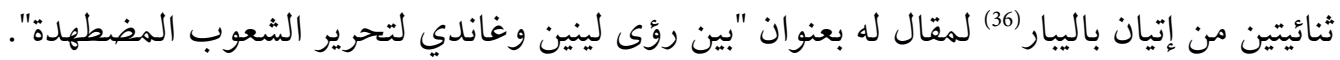

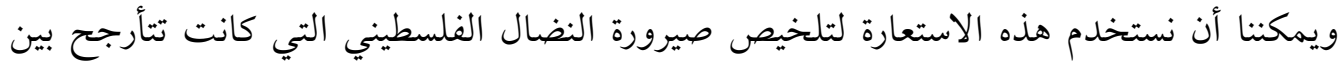

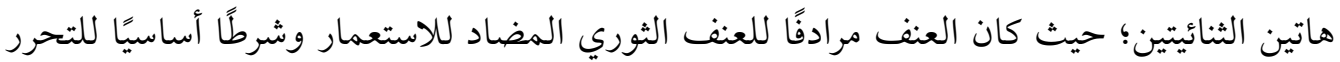

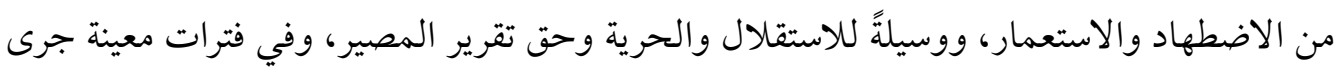
استحضار النموذج الغاندي "اللاعنفي".

جاء جزء كبير من الاستراتيجيات الفلسطينية للمقاومة، للرد على سردية المستعمِر التي تعبّر عنها

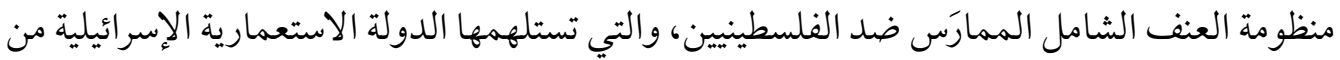

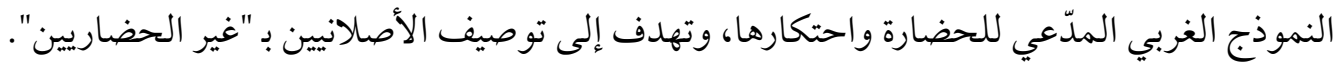

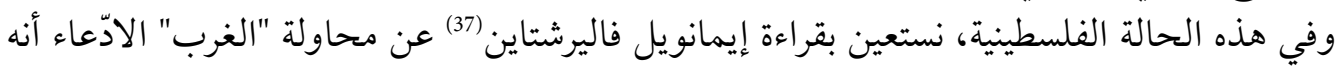

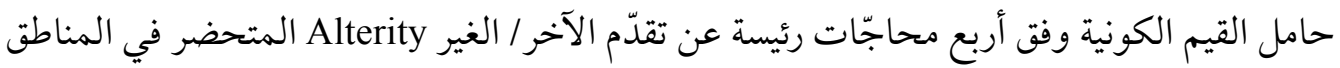

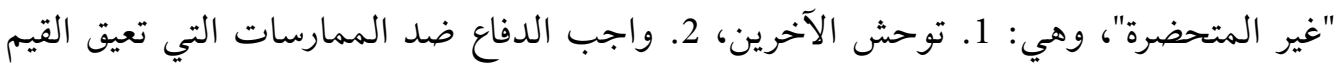

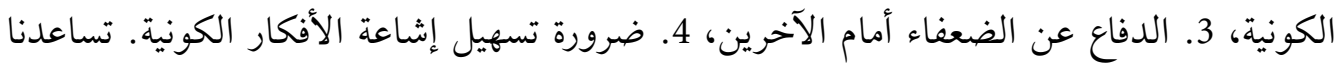

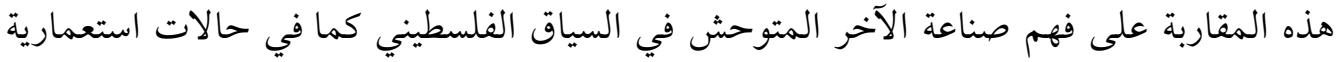

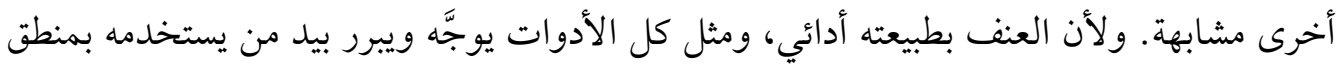

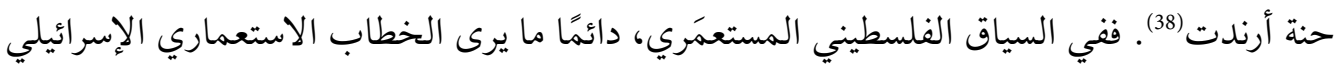

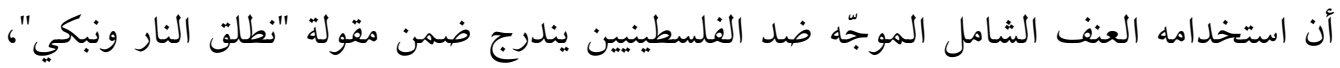

(33) Georges Labica, Théorie de la violence (Paris: Vrin; Napoli: La Citta del Sol, 2008).

(34) Walter Benjamin, "Critique de la violence," in: Rainer Rochlitz (dir.), Walter Benjamin: Critique philosophique de l'art (Paris: Gallimard, 2000 [1921]), p. 242.

(35) Agamben, p. 90.

(36) Étienne Balibar, "Lénine et Gandhi, Une rencontre manquée?" Alternative Roma, no. 6 (2005).

(37) Immanuel Wallerstein, L'universalisme européen: De la colonisation au droit d'ingérence (Paris: Demopolis, 2008), pp. 15-16.

(38) Hannah Arendt, Du mensonge à la violence: Essai de politique contemporaine, Guy Durand (trad.) (Paris: Calmann-Lévy, 1972), pp. 150-157. 


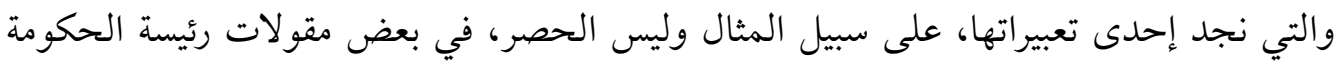

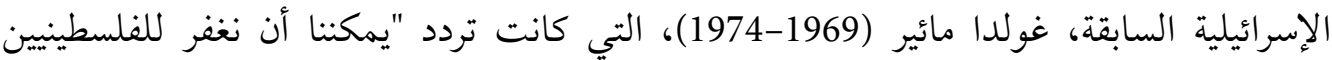

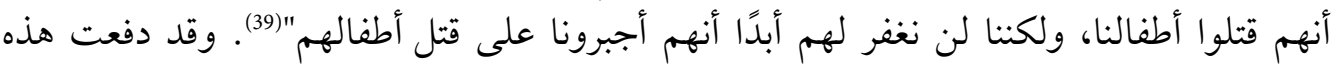

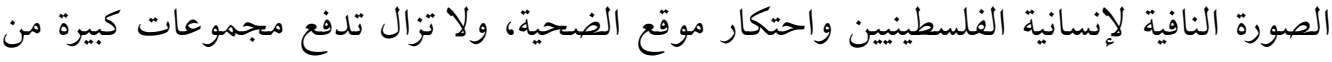

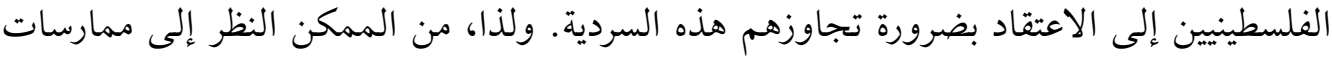

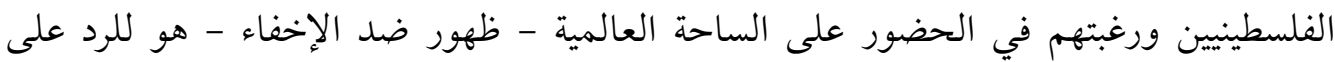

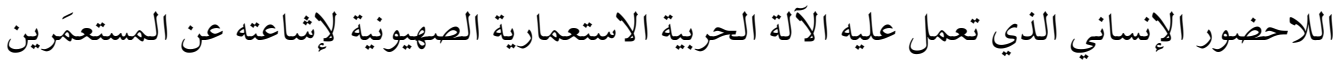

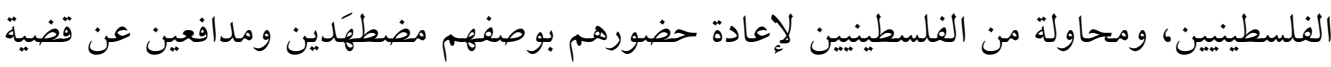

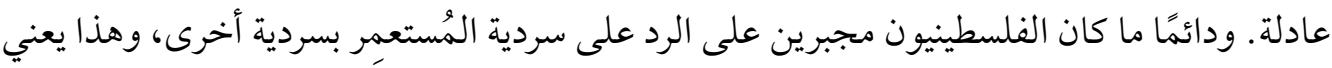

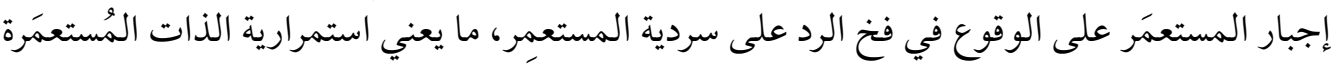

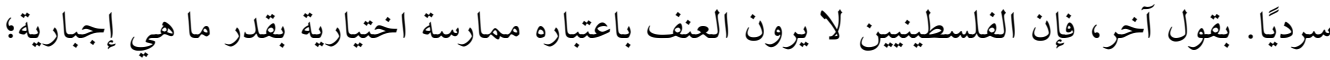

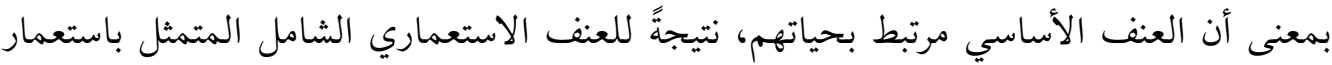

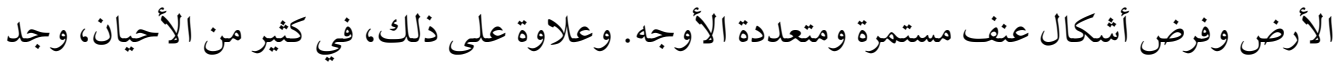

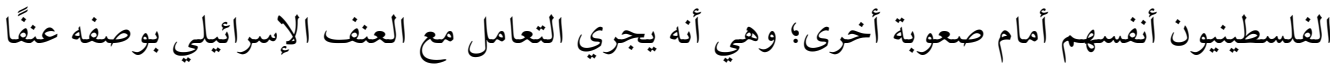

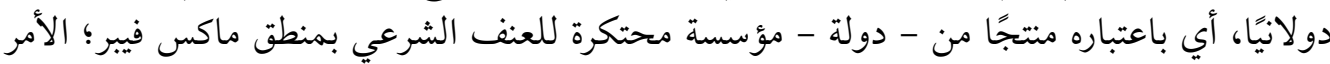

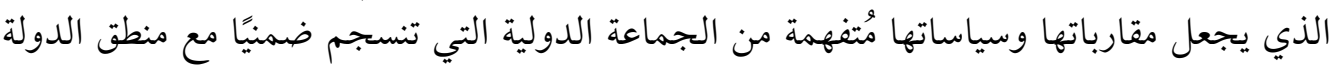

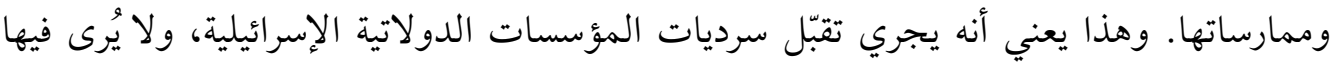

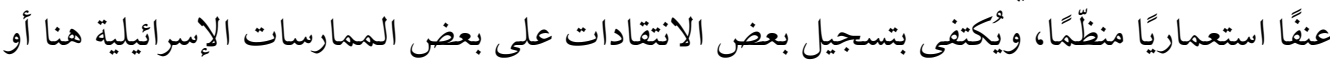

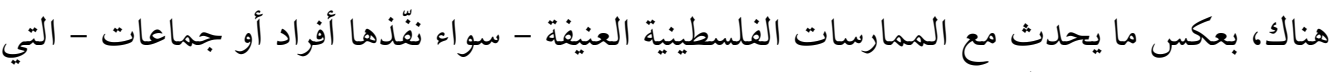
يُنظر إليها باعتبارها عنفًا غير مقبول ماعل المارسات

ويولّد هذا العنف الاستعماري الشامل بدوره عنفًا مُستعمَرِيًا مجتمعيًا متعدد الأشكال، ويعيد

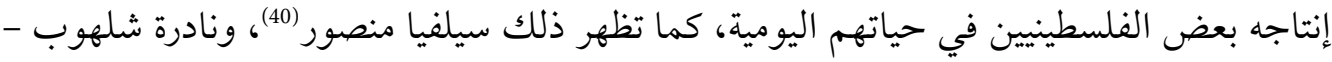

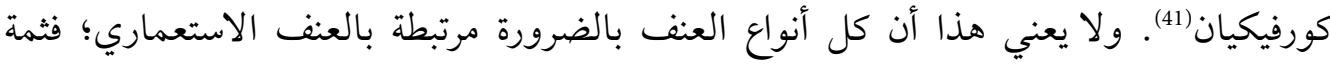

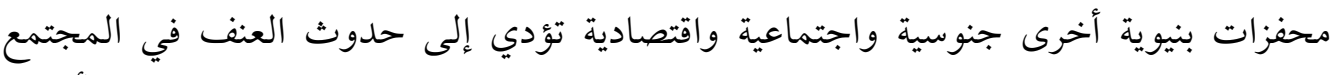

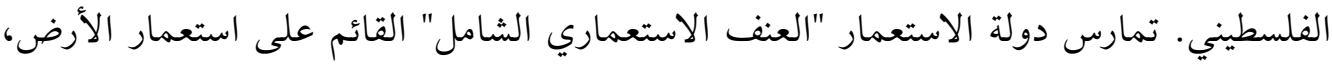

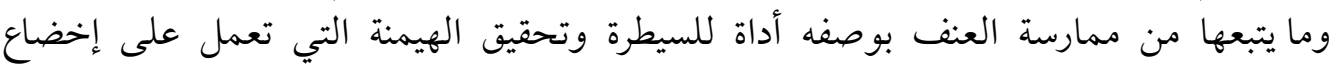

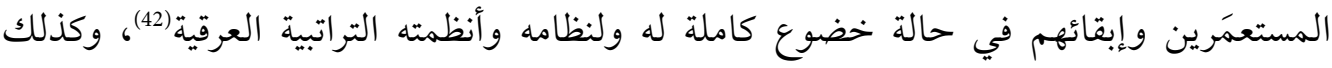

(39) Israel Shanker \& Shanker Mary (eds.), As Good as Golda: The Warmth and Wisdom of Israel's Prime Minister (New York: McCall, 1970).

(40) Sylvie Mansour, "La génération de l'Intifada," Cultures \& Conflits, vol. 2, no. 18 (1995), pp. 63-76.

(41) Nadera Shalhoub-Kevorkian, Militarization and Violence against Women in Conflict Zones: A Palestinian Casestudy (Cambridge: Cambridge University Press, 2009).

(42) Abaher El-Sakka, "Representations of Violence and Non-violence in Palestinian Society," in: Chandra Sudhir (ed.), Violence-Nonviolence across Time: History, Religion and Cultures (London: Routledge, 2018), pp. 204-221. 
التحكم في مواردهم الفيزيائية (الأرض والمياه والطاقة)، وفي السكان أيضًا. وعلاوة على نفي

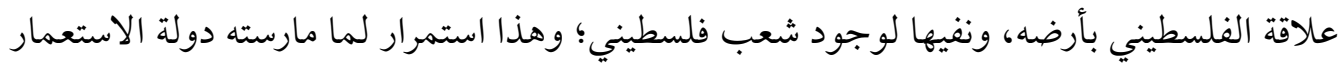

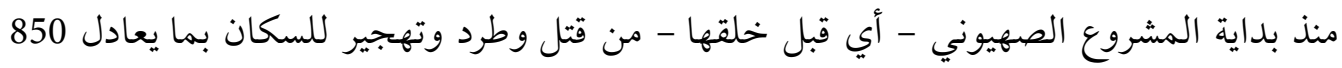

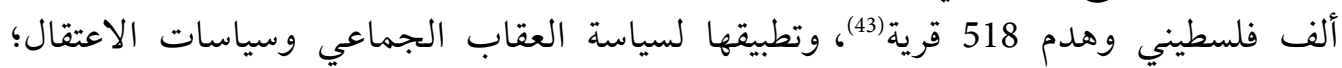

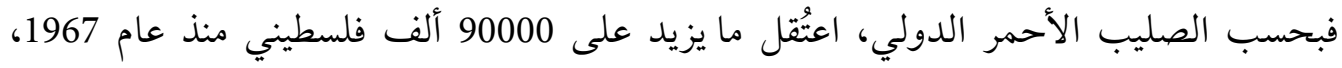

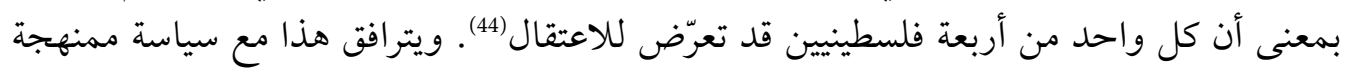

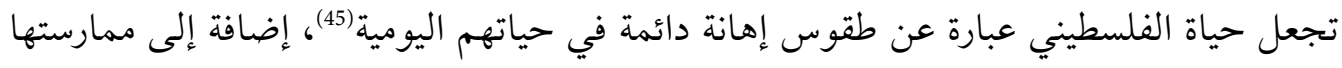

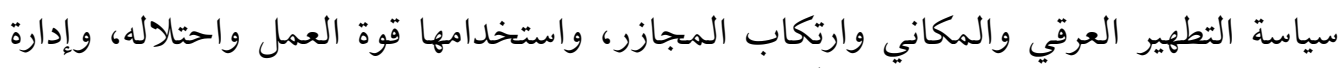

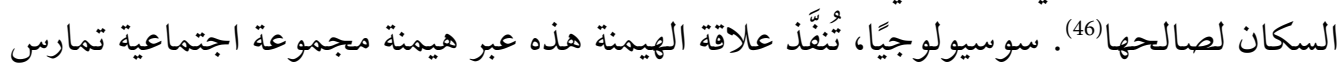

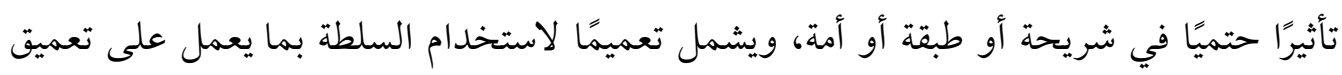

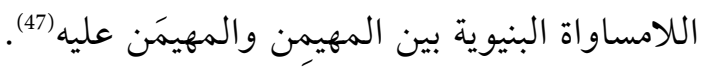

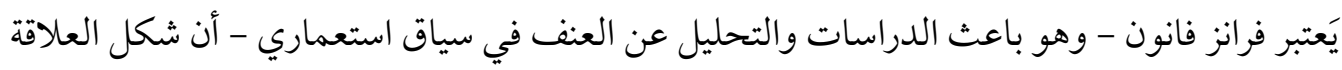

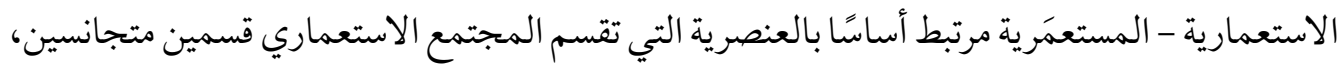

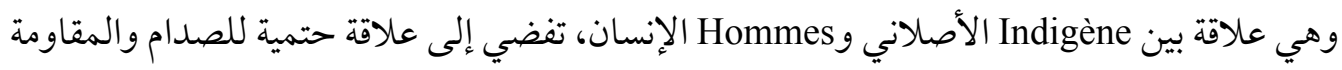

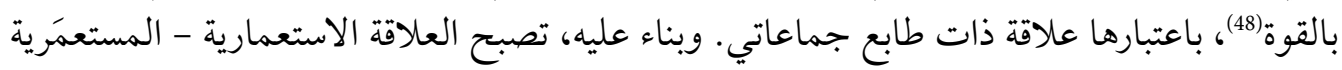

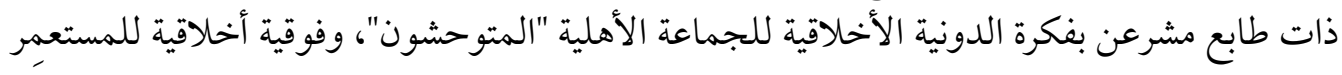

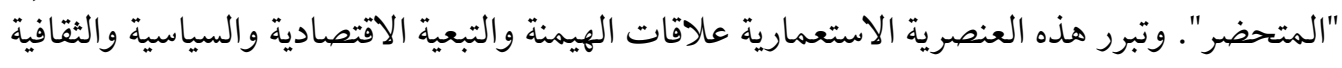

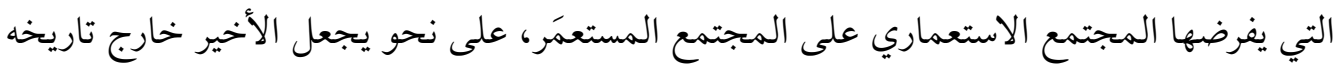

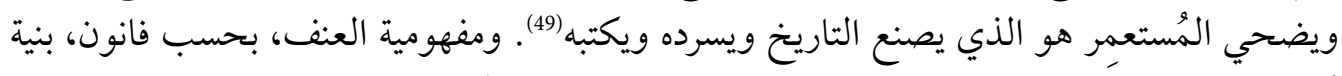

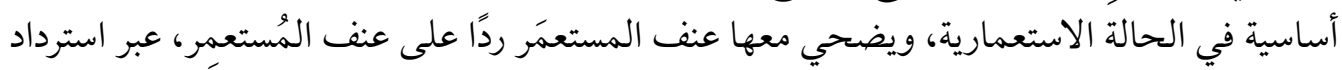

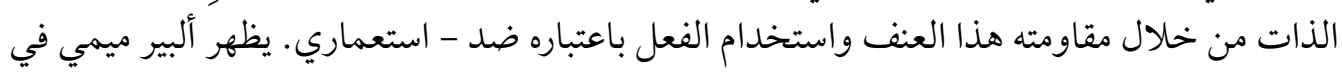

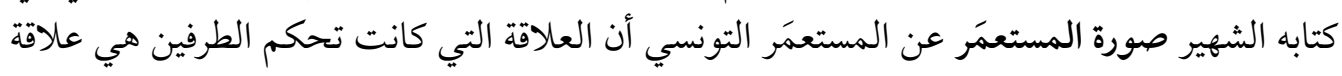

(43) Salman Abu Sitta, The Palestinian Nakba, 1948: The Register of Depopulated Localities in Palestine (London: Palestinian Return Centre, 2000).

(44) نقلاً عن هيئة شؤون الأسرى والمحررين التابعة لمنظمة التحرير الفلسطينية، ينظر : عبير العدوى، "شؤون الأسرى: إسرائيل

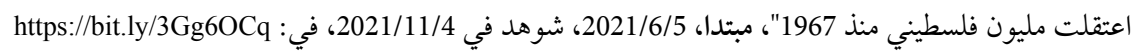

(45) Abaher El-Sakka \& Mehl Sandra, "La cérémonie de l'humiliation, le monde diplomatique," Le monde diplomatique, 25/9/2015, accessed on 1/10/2021, at: https://bit.ly/3ffsOkZ

(46) Neve Gordon, "From Colonisation to Separation: Exploring the Structure of Israel's Occupation," in: Adi Ophir, Michal Givoni \& Sari Hanafi (eds.), The Power of Inclusive Exclusion: Anatomy of Israeli Rule in the Occupied Palestinian Territories (New York: Zone Books, 2009), pp. 239-267.

(47) "Domination," in: André Akoun \& Pierre Ansart (dir.), Dictionnaire de sociologie, Collection Le Robert (Paris: Seuil, 1999).

(48) Frantz Fanon, Les damnés de la terre (Paris: Gallimard, 1991), p. 84.

(49) Ibid., p. 82. 
محددة مسبقًا، يكون فيها المُستعمر حامًا للمستعمَر، وتُعرف بطريقة نمطية استعلائية تنزَع إنسانية

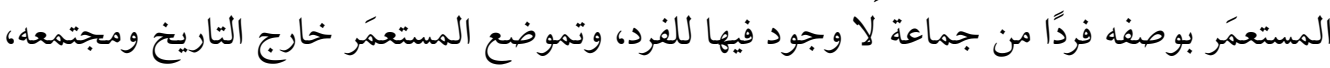

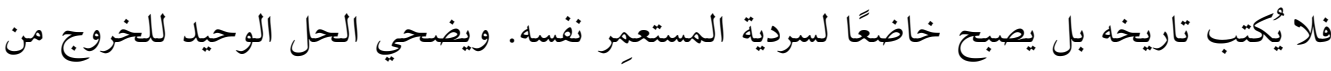

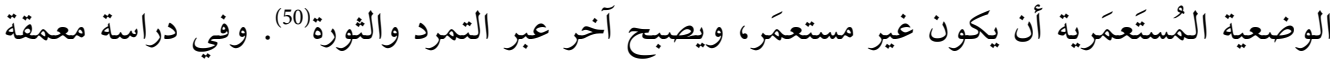

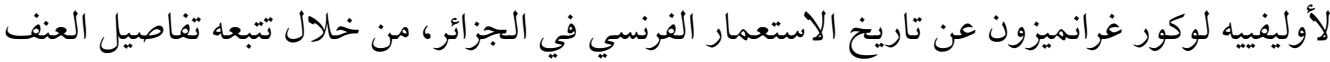

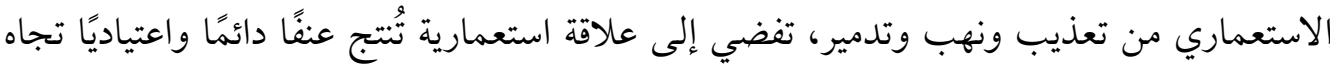
ذوات دونية (51).

ويتصاحب هذا العنف بحالة الاستثاء الذي يستخدمه العديد من الأكاديميين مثل أغامبين، حيث تقوم الدولة على منظومة إجراءات طارئة ومؤقتة ومن ثم تضحي دائمة، وترتكز حالة الاستثناء هذه

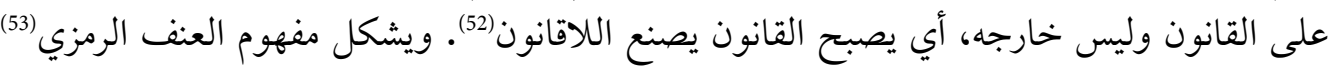
قراءة مهمة لفهم بعض أشكال التشابه في الحالات الاستعمارية التي يقوم بها المستعمر باستبطان ميكانيزمات الهيمنة واستدخالها في الاعتيادي الاستعماري، بوصفها بنى اعتيادية تظهر فئه على أنها طبيعية في السياق الاجتماعي، كما يقول بورديو. ومع ذلك، هذا الفهم له حدوده، لأن الاستبطان

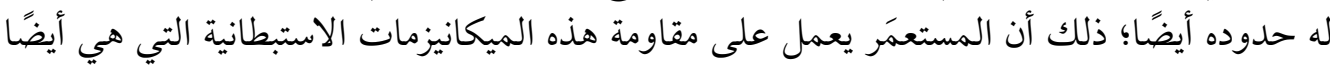
مشتركة في السياقات الاستعمارية - المُستعمَرية.

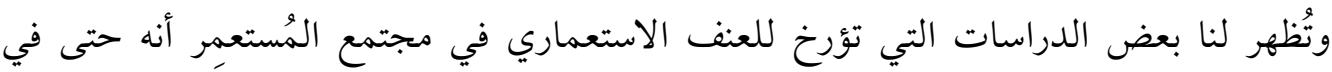
ممارسات الرياضة المقاتلة فيه قد تجد هذه التمثلات تعبيراتها في تصورات كوزمولوجية فئنية "كونية" عن فكرة الحرب الشاملة والرعب(54)؛ الأمر الذي يجعل الفرد، في رأينا، في بعض الته التجمعات

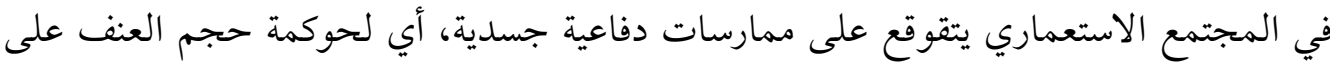

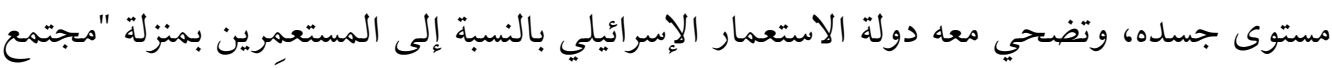
الأمن" بمنطق ميشيل فوكو (55)، أي عبر القبول والسماح بمجموعة من السلوكيات المتعددة التي يقع بعضها على حدود الإجرام، من أجل التخلص من كل ما يصنف على أنه خطير . والخطير هنا

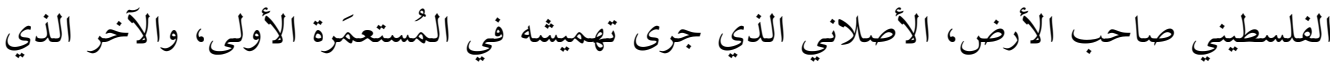

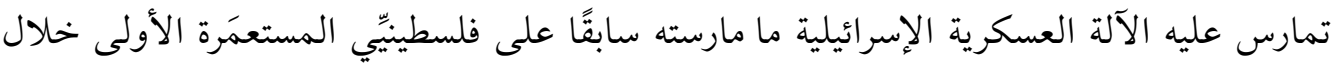
فترة الحكم العسكري.

(50) Albert Memmi, Portrait du colonisé (Paris: Payot, 1973), pp. 115-124.

(51) Olivier Le Cour Grandmaison, Coloniser, exterminer, sur la guerre et l'état colonial (Paris: Fayard, 2005).

(52) Agamben.

(53) Pierre Bourdieu, Langage et pouvoir symbolique (Paris: Seuil, 2001).

(54) Einat Bar-On Cohen, "Globalization of the War on Violence: Israeli Close-combat, Krav Maga and Sudden Alterations in Intensity,"Social Anthropology, vol. 18, no. 3 (2010), p. 269.

(55) Michel Foucault, Dits et écrits (1954-1988), tome II: 1970-1975, Daniel Defert, François Ewald \& Jacques Lagrange (dir.) (Paris: Gallimard, 1978), p. 386. 
وكذلك فرض الجنسية الإسرائيلية التي ينظر إليها بـ"إيجابية"؛ فعلى سبيل المثال يرى بعض المثقفين

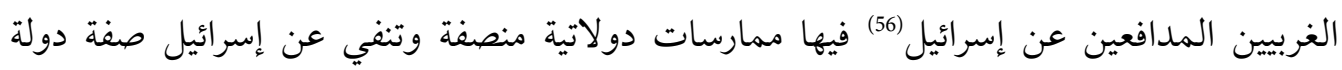

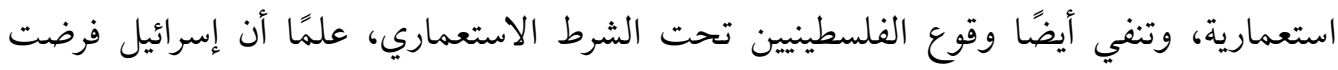

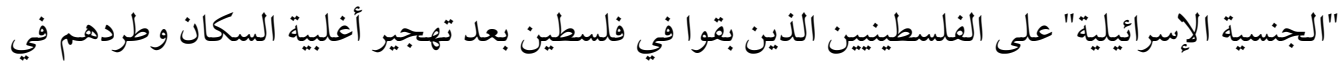

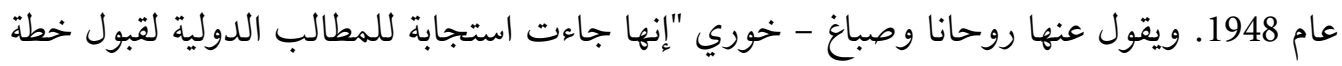

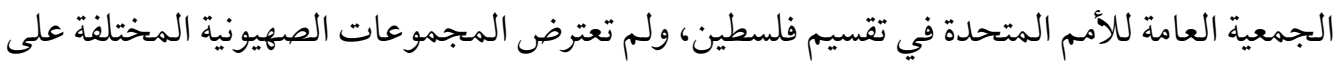

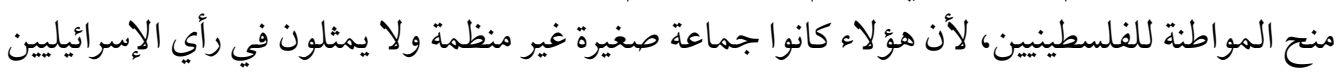

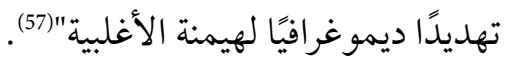

\section{ثُالثًا: فينومينولوجيا التتشُوه المقاهيمي}

يعرض هذا المحور فينومينولوجيا التشوه المفاهيمي لمحاولة فهم تأثيره في الحقلين السياسي

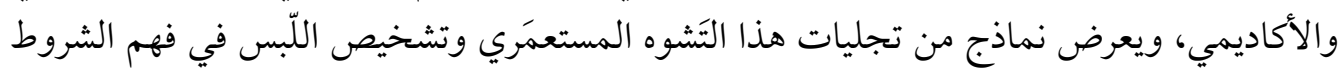

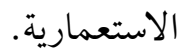

\section{1. هيمنة مغردات الحقل السياسي على الحقل الأكاديمي}

تظهر هيمنة الخطاب السياسي الفلسطيني ومفرداته على الخطاب الأكاديمي السائد وفواعله، عبر

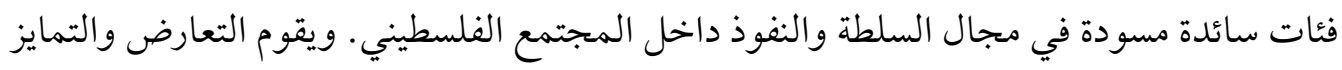

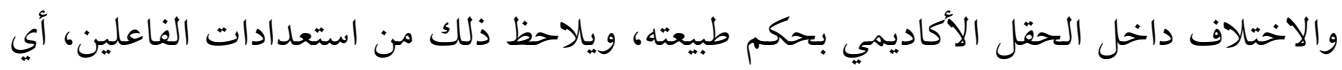

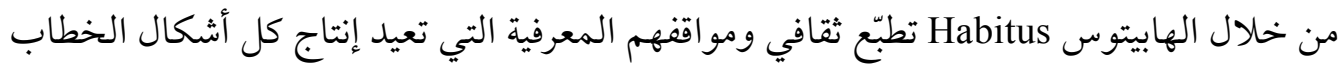

$$
\text { ينظر بيان صدر عن مجموعة من الكتاب والمثقفين والأكاديميين المدافعين عن إسرائيل في فرنسا، في: }
$$

"Israël, éternel exutoire des passions primaires," Le Monde, 3/9/2021, accessed on 10/1/2022, at: https://bit.ly/3teAHQ3; وكذلك بيان آخر أصدره باحثون فرنسيون وآخرون ناطقون بالفرنسية ردًا عليه اعتمادًا على مجموعة من المحاجات التي تؤكد على الى

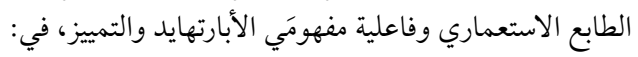

"Le terme 'apartheid' permet de penser dans la durée l'asymétrie des relations israélo-palestiniennes," Le Monde, 28/9/2021, accessed on 10/1/2022, at: https://bit.ly/3HOWG47

مقتطفات من البيان الأخير: "إن البيان السابق هو مقاربة تبسيطية، ومخادعة وخطيرة، ومغايرة للواقع، ويعتبر محاولة لتجريم الباحثين

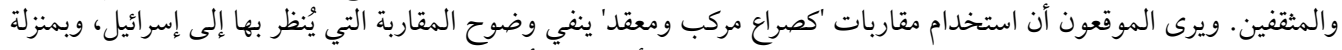

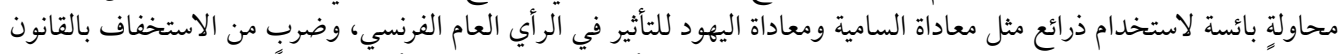

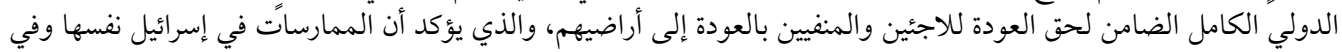

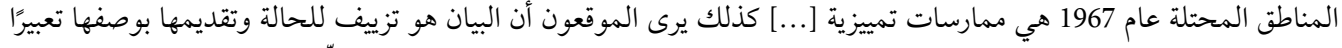

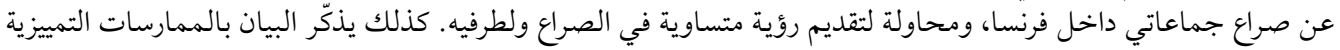

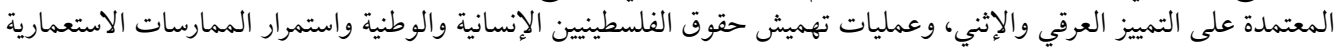

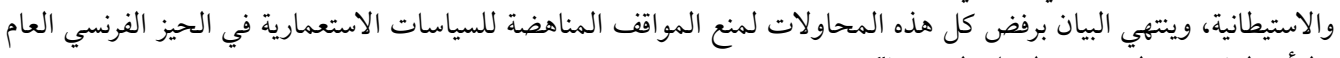

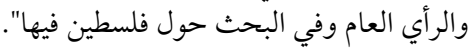

(57) Nadim N. Rouhana \& Areej Sabbagh-Khoury, "Settler-colonial Citizenship: Conceptualizing the Relationship between Israel and its Palestinian Citizens," Settler Colonial Studies, vol. 5, no. 3 (2015), p. 206. 
تبعًا لقواعد اشتغال هذا الحقل Champs من فاعلين اكتسبوا هابيتوس (تطبّعًا ثقافيًا) ملائمًا لبنى الحقل وتاريخ تشكله في السياق الفلسطيني وعبر الانتماء إليه واحتلال مواقع فيه. جُرته، إذّاً،

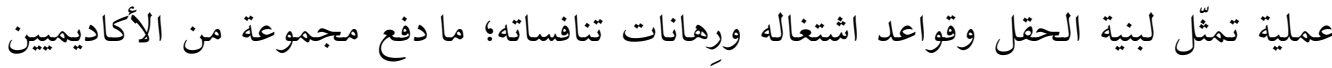

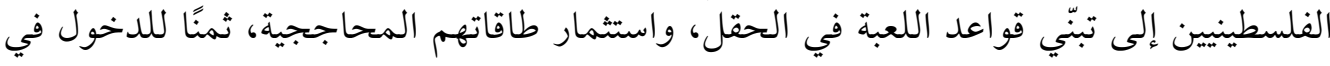
هذا الحقل.

لقد كان الحقل الأكاديمي الفلسطيني امتدادًا للحقل السياسي، وفي حالات كثيرة كان الحقل الأكاديمي يقود الحقل السياسي. وقد رفد الأكاديميون العديد من الأحزاب السياسية بالإطارات

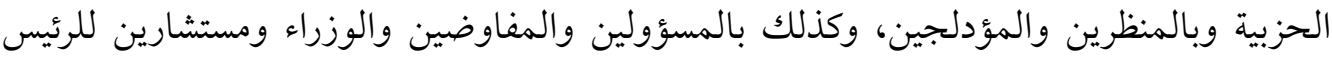

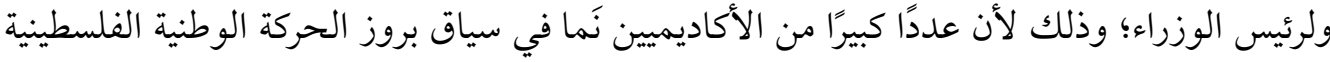

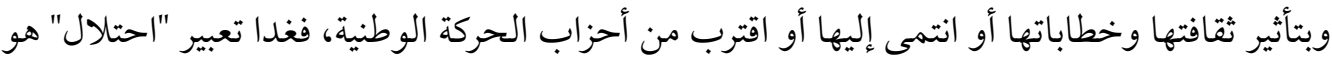

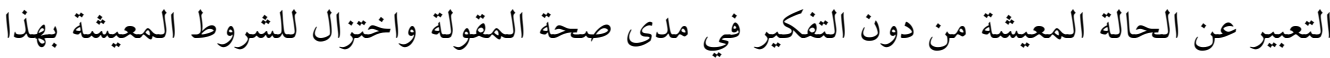
الشق من البنية الاستعمارية.

نرتكز فيما يلي على المقاربة الانعكاسية - الاستفكارية لبورديو وأثرها في المهنة الأكاديمية وفي العين

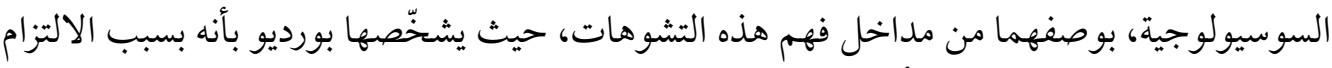

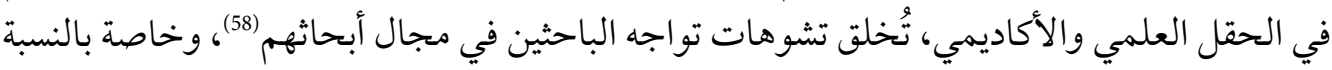

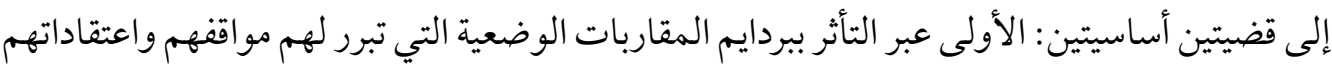

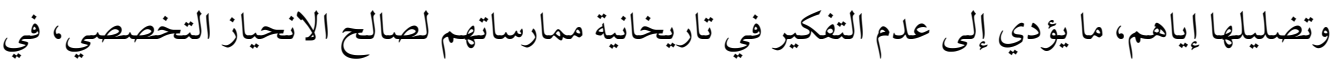

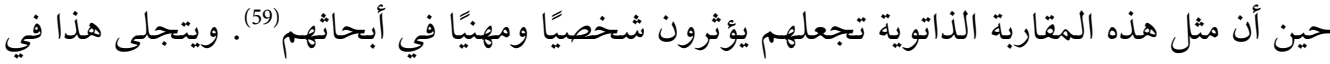

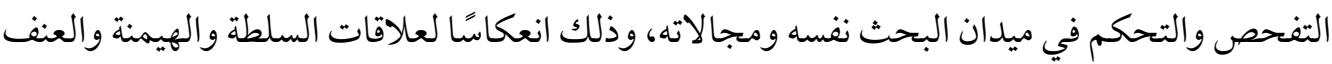

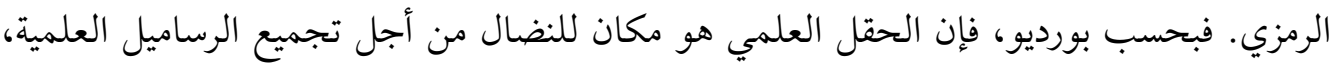

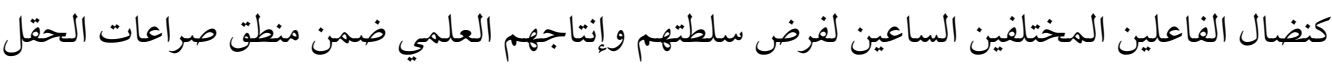

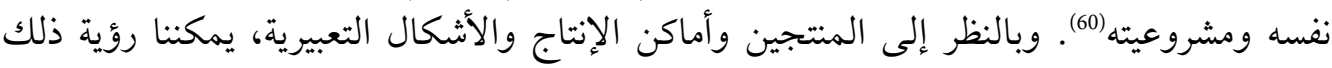

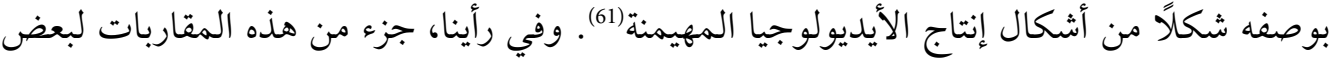
الأكاديميين الفلسطينيين أشبه بعملية استدخال لعقيدة دوكسا Doxa الحقل الأكاديمي، أي إنه في السياق الأكاديمي الفلسطيني السائد تقوم مجموعات من الأكاديني الإيميين

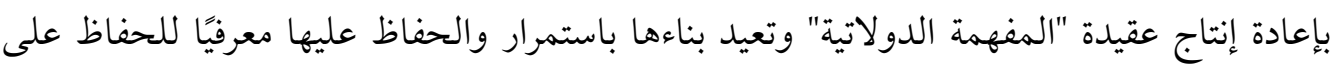

(58) Pierre Bourdieu, La misère du monde: Essais (Paris: Points, 2015 [1993]), p. 1391.

(59) Ibid., p. 1392.

(60) Pierre Bourdieu, "Le champ scientifique," Actes de la recherche en sciences sociales, vol. 2, no. 2-3 (1976), p. 91;

ينظر أيضًا: (Pierre Bourdieu, Homo Academicus (Paris: Minuit, 1984.

(61) Pierre Bourdieu \& Luc Boltanski, "La production de l'idéologie dominante," Actes de la recherche en sciences sociales, vol. 2, no. 2-3 (1976), pp. 4-73.

(62) Pierre Bourdieu, La distinction: Critique sociale du jugement (Paris: Minuit, 1979). 


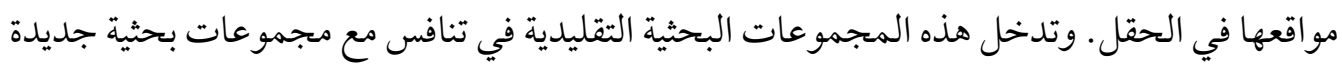

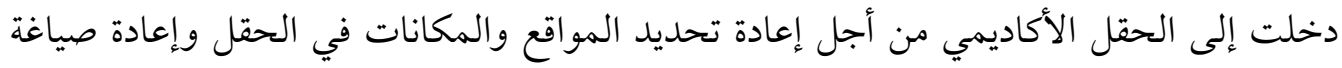

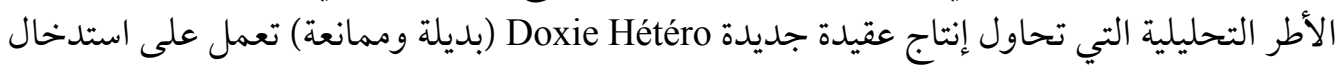
مفهمة الاستعمار لتحليل الوضعية الفلسطينية.

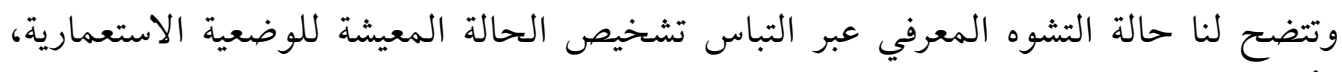

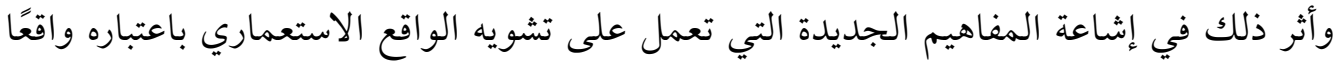

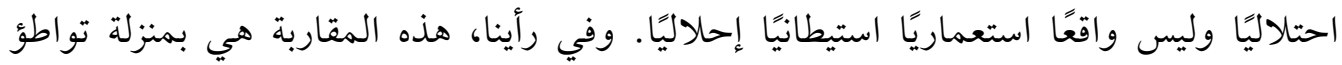

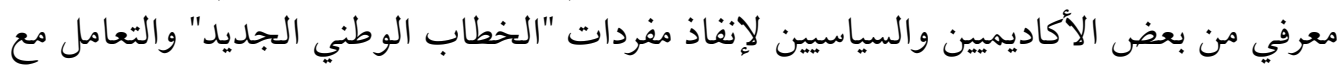

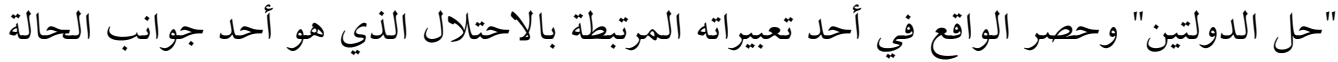

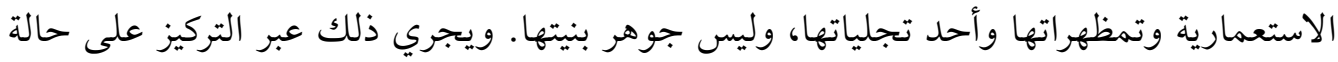

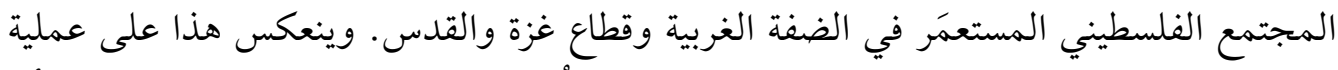

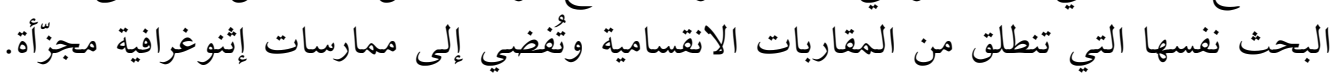

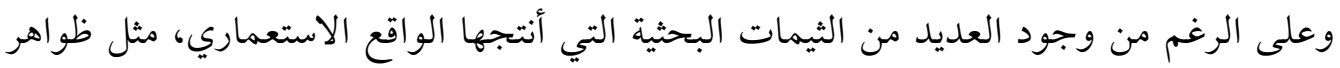

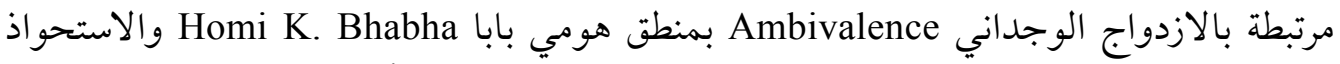
Appropriation

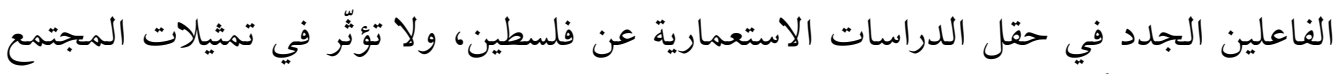
المستعمَر في الأعمال البحثية للأكاديميا السائدة.

أضف إلى ذلك أن بعض الباحثين في العلوم الاجتماعية تواجهرم صعوبات موضوعية، مثل دفعهم

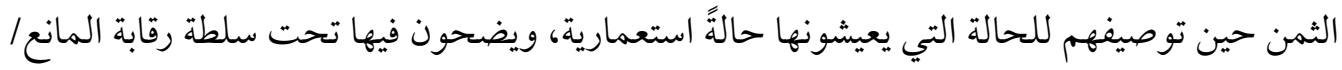

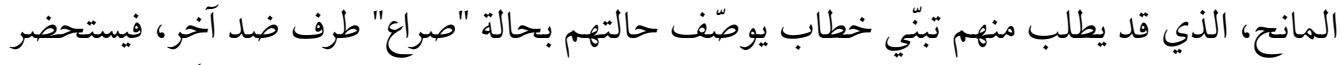

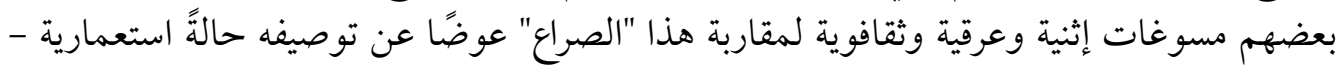

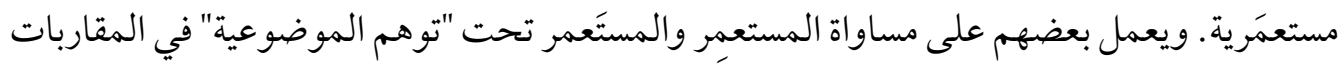

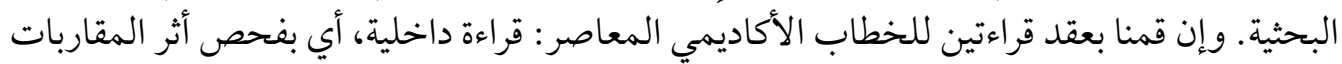

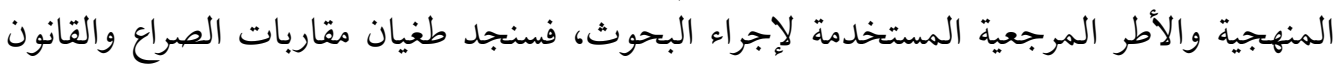

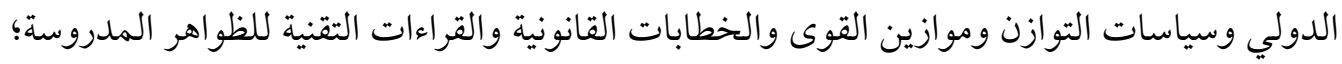

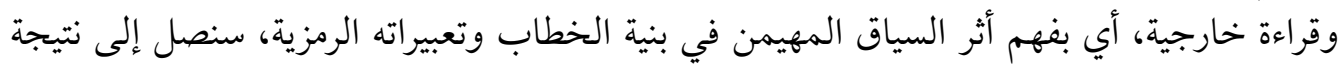

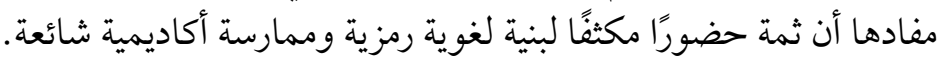

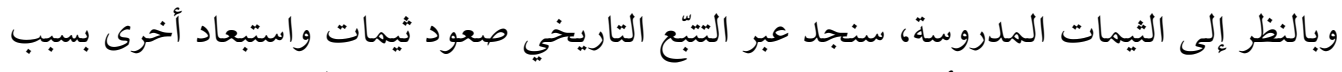

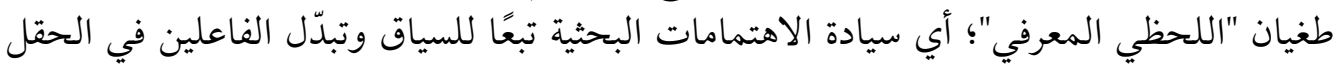

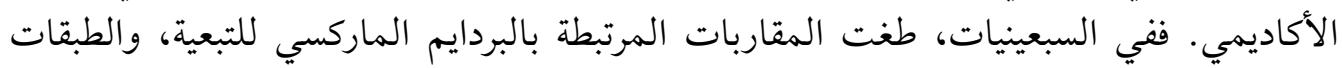

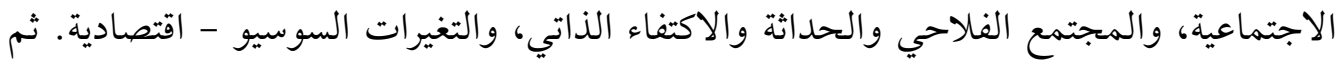

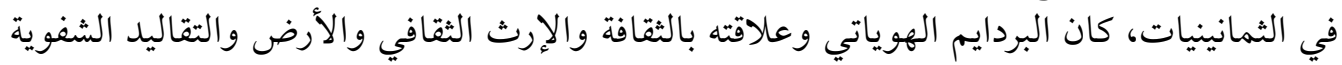


والسير الذاتية محور اهتمام ثيمي مهم. وفي التسعينيات، طرأت تغيرات مهمة على العلوم

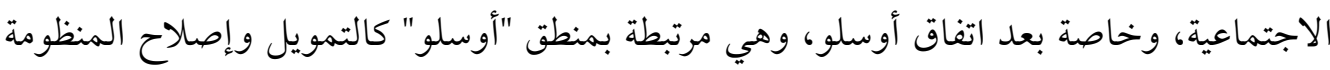

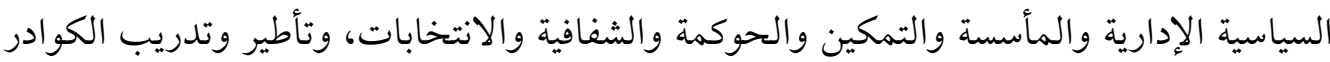

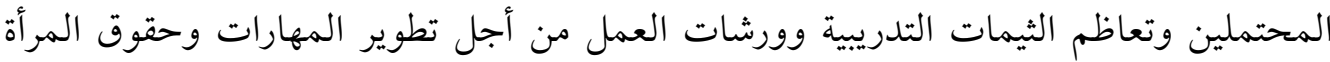
والتنمية الريفية والتفاوض الدولي وقضايا تخص الاقتصاد الفلسطيني المقبل وجاهزيته وبناء المؤسسات والسالام، ليصبح المجال البحثي ملائمًا لدولة. ثم تبعته قضايا العلاقات الدولية وحقوق الإنسان والمواطنة والدبلوماسية الدولية و"الدبلوماسية العامة"، وقضايا أخرى لها علاقة

$$
\text { بمشروع "الدولة المشتهى المبتور". }
$$

والمتتبع لهذه الانعكاسات الثيمية سيجد تمظهرات العقيدة الجديدة في المؤتمرات والورشات والدراسات وثيمات مراكز الأبحاث المحلية التي تبث وتفكر في حل الدولتين ليس بو صفه ثيمة بحثية،

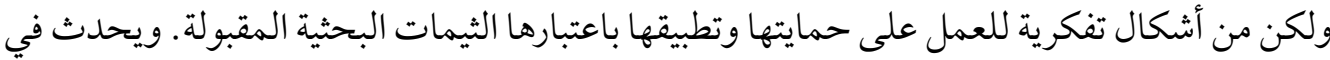
كثير من الأبحاث ممارسة المنع والتهميش لكل المقاربات التي تشخص الحالة الفلسطينية بو صفها حالة استعمارية بذرائع الموضوعية والحياد القيمي/ الأكسيولوجي Axiological Neutrality/ Neutralité Axiologique/ Wertfreiheit فيه عن ضرورة إيجاد مسافة بين الباحث وتصوراته وأحكامه القيمية وبحثه الأكاديمي من أجل إنتاج عمل بحثي مجرد من الأحكام القيمية.

يشكك كثير من المفكرين في هذه المقاربة الفيبرية ويرفضونها، مثل بورديو(64) الذي يبين في العديد

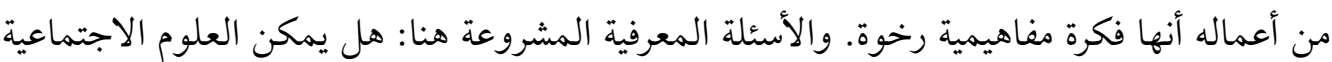
أن تكتفي بدور التوصيف للأشياء، من دون اتخاذ مواقف تجاه الصراعات الأخلاقية والسياسية التي

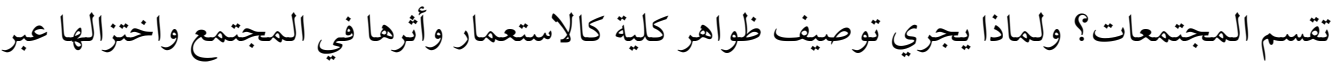

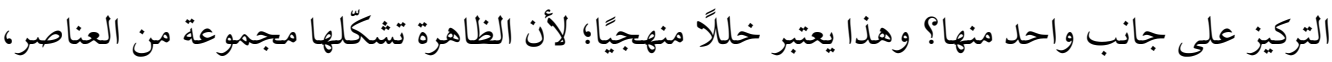

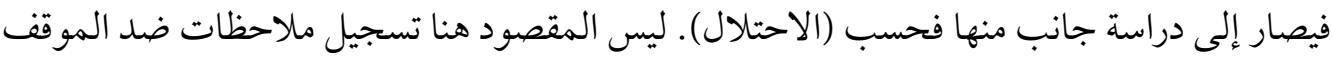

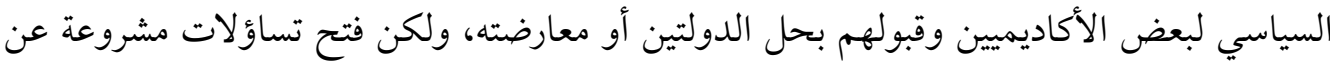
تشويهـم واختزالهم للواقع المعيش عبر عدم البحث في هذه القضايا. يفرض هذا السجال المعرفي

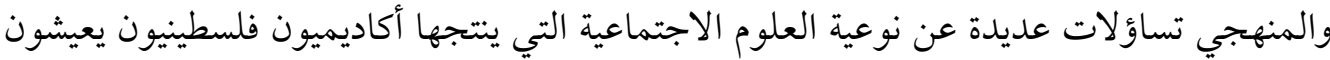

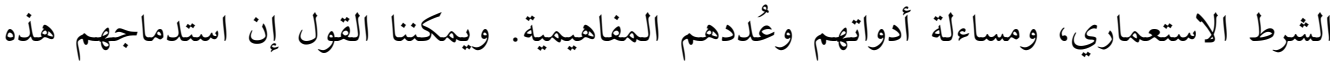
التصورات يقودنا إلى استنتاج مفاده أن عملية رقابة ذاتية يمارسها بعض الأكاديميين تجاه الثيمات التي وعني لا تتناسب مع الخطاب السائد ويجري تهميشها، ويستدخل عبرها بعض الأكاديميين باعتبارهم فواعل

(63) Max Weber, Le savant et le politique, Julien Freund (trad.) (Paris: Plon, 1959).

(64) Pierre Bourdieu, "Pour un savoir engagé," in: Interventions (1961-2001): Sciences sociales et action politique (Marseille: Agone; Montréal: Comeau \& Nadeau, 2002). 
وأدوات "للسلطة المعرفية" بمعنى فوكو (65). بالتأكيد، تنامى الحقل البحثي في الاستعمار الاستيطاني

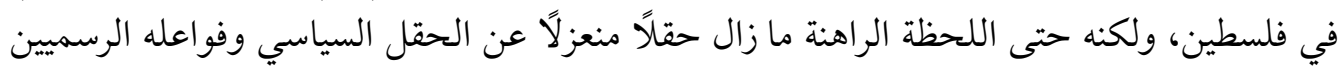
وحتى غير الرسميين.

\section{2. تواطؤ معرفي: الوله بالدولة مجتمعيًا وسياسيًا وأكاديميًا}

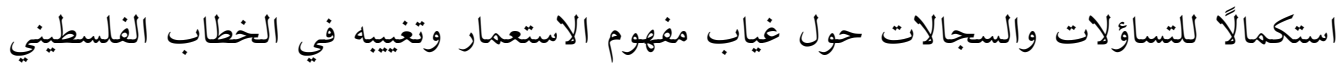

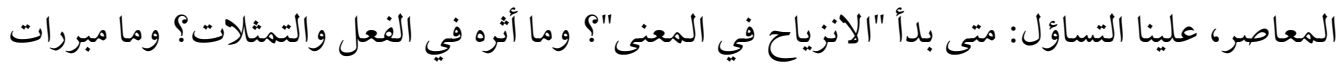

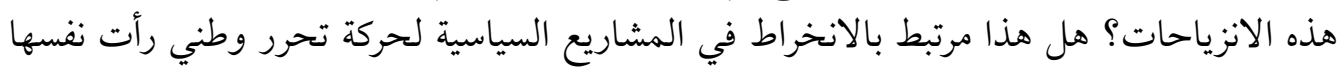

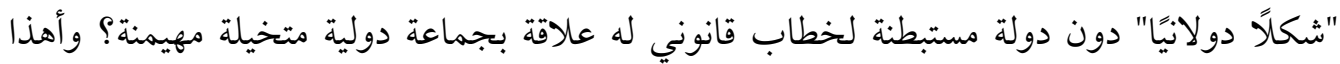

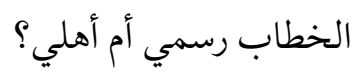

يمكننا استعارة تعبير "الظاهرة الكلية" بمنطق مارسيل موس (66) لتوصيف الوضعية الاستعمارية التي

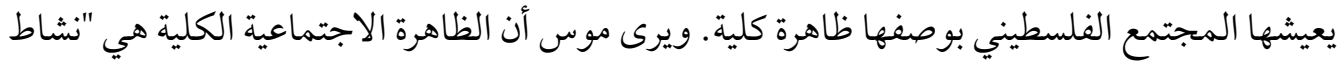

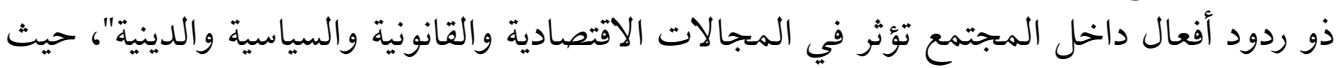

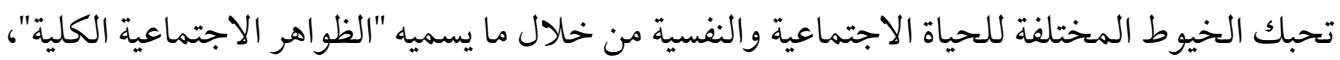

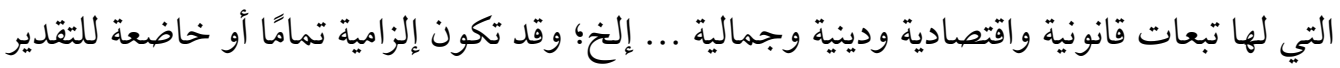

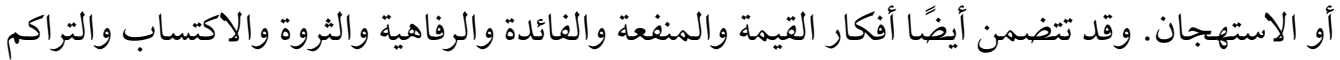

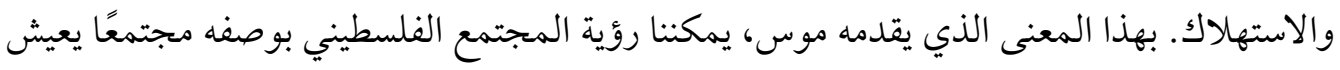

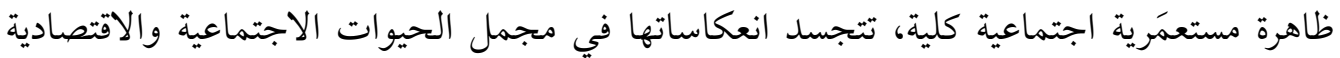
والسياسية والقانونية.

لا يعتبر بورديو التفكير في الدولة خطابًا أو ميتا خطابات Méta Discours (فوق إق خطابي)، أو أنه

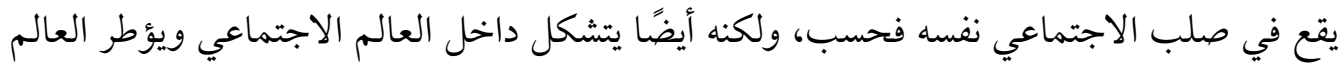

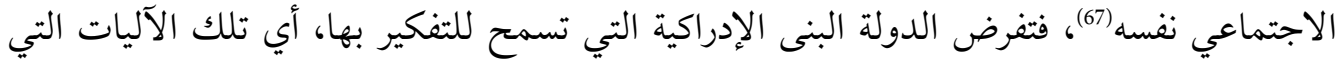

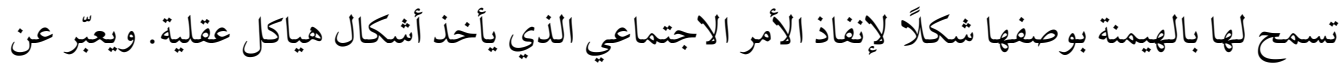

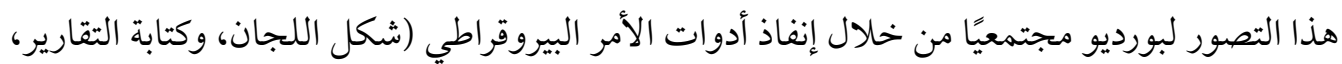

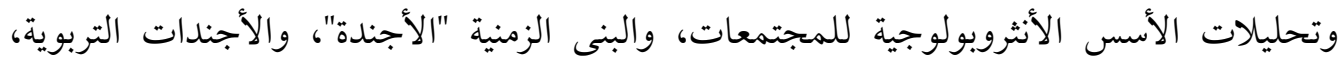

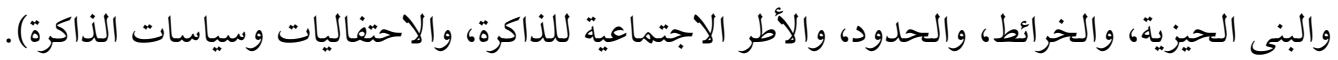

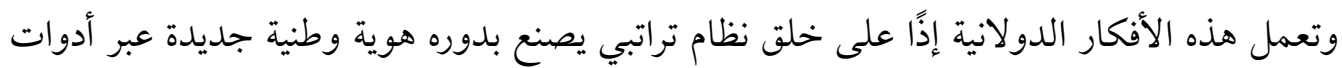

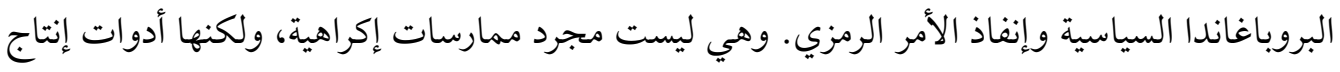

(65) Michel Foucault, Surveiller et punir: Naissance de la prison (Paris: Gallimard, 1975); Michel Foucault, L'Archéologie du savoir (Paris: Gallimard, 1969).

(66) Marcel Mauss, Essai sur le don: Forme et raison de l'échange dans les sociétés archaïques (Paris: PUF, 2007).

(67) Pierre Bourdieu, Sur l'État: Cours au Collège de France (1989-1992) (Paris: Seuil; Raisons d'agir, 2012), p. 291. 
و وإعادة إنتاج تظهر حتى في الحس المشترك (68). كذلك تحتكر التشكيلات الدولانية العنف الرمزي عبر فرض المعايير، لإعادة تصور العالم من خلال الألدوات القات القانونية، والتعبيرات القانونية لإدارة السكان

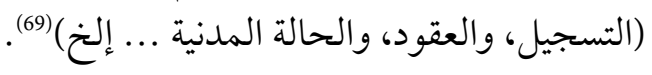

\section{3. استيهـامات مجتمعية}

ندرك تمامًا أن الدولة بالمعنى الكلاسيكي غير حاضرة في السياق الفلسطيني، ولكن لدينا استيهامات خطابية ومجتمعية تعمل على إنفاذ فكرة الدولة على مستوى الخطاب، وكذلك على على مستوى الممارسات

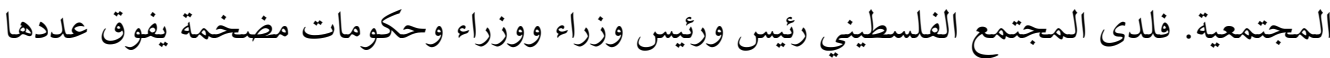

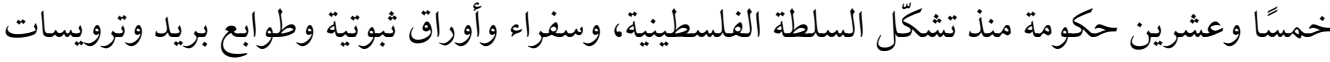

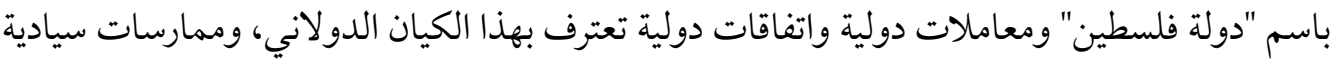

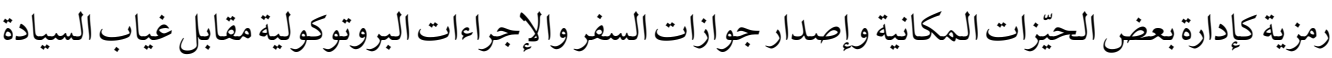

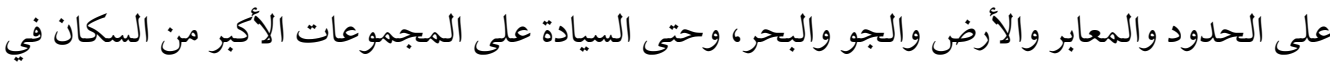

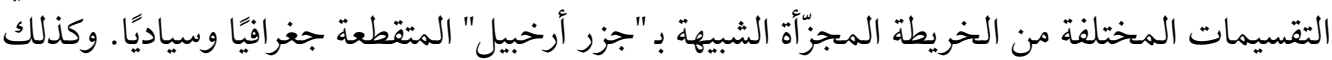
له مجلس تشريعي، وقوانين فلسطينية تتعايش مع قوانين أردنية ومصرية سابقة، وأجهزة شرطية وأمنية،

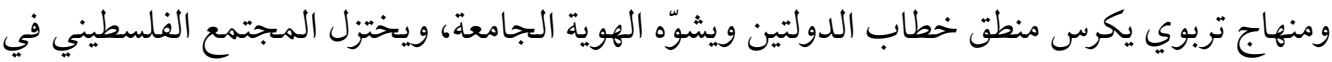

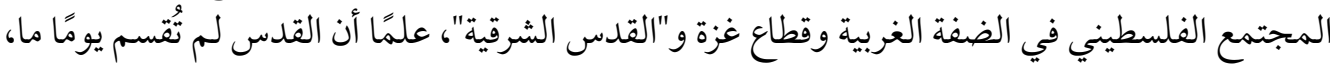

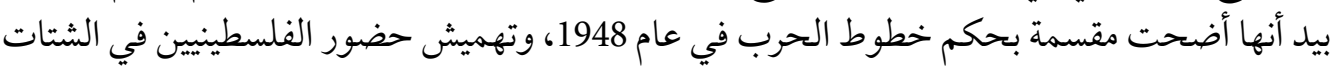

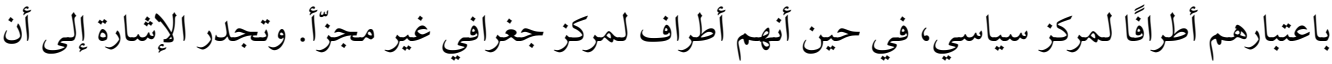

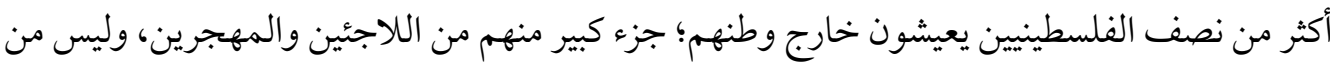

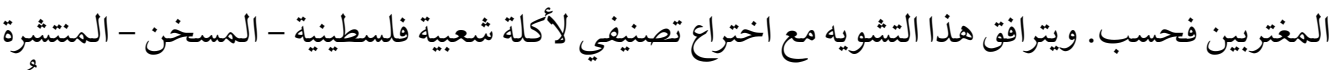
في منطقة وسط الضفة الغربية وشمالها، فيصار إلى اعتبارها "الأكلة الوطنية الفلسطينية"؛ هذا التَمثنّل

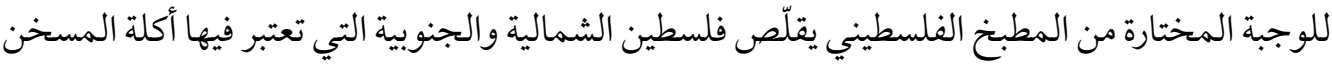

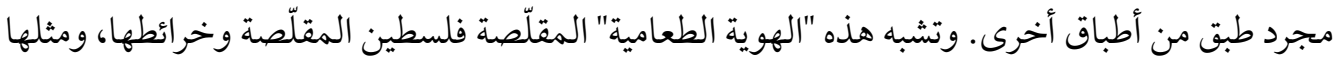

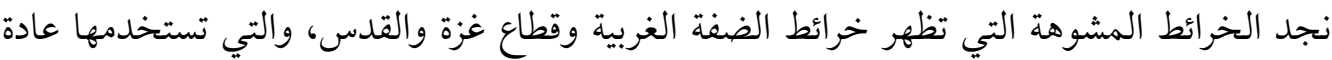

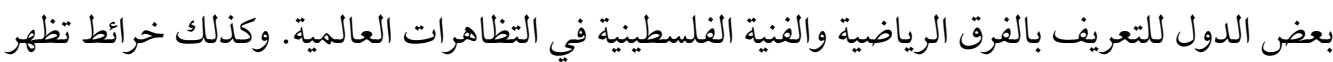

(68) Pierre Bourdieu, Méditations pascaliennes (Paris: Seuil, 1997), p. 209.

(69) Pierre Bourdieu, "Les modes de domination," Actes de la recherche en sciences sociales, vol. 2, no. 2-3 (1976), pp. 122-132;

ينظر أيضًا:

Pierre Bourdieu, La distinction (Paris: Minuit, 1984); Pierre Bourdieu, "Quelques propriétés des champs," in: Questions de sociologie (Paris: Minuit, 1989), pp. 113-120; Pierre Bourdieu, La noblesse d'Etat: Grandes écoles et esprit de corps (Paris: Minuit, 1992); Pierre Bourdieu \& Loïc Wacquant, "La logique des champs," in: Réponses (Paris: Seuil, 1992), pp. 71-90; Pierre Bourdieu, "Esprits d'État: Genèse et structure du champ bureaucratique," Actes de la recherche en sciences sociales, vol. 96-97 (Mars 1993), pp 49-62; Pierre Bourdieu, "'L'État et la construction du marché' et 'Le champ des pouvoirs locaux'," in: Les structures sociales de l'économie (Paris: Seuil, 2000), pp. 113-180; Bourdieu \& Boltanski, pp. 4-73. 


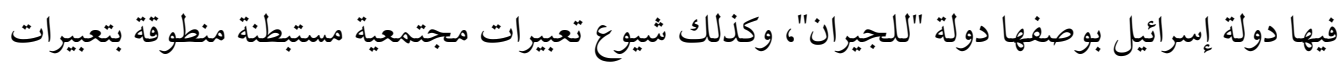

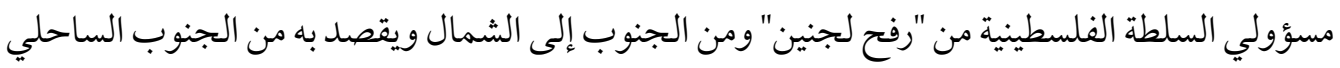

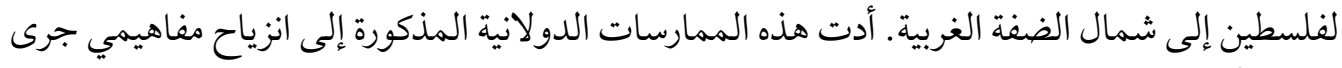

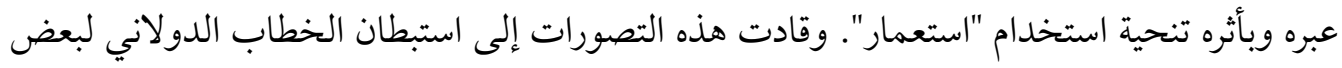

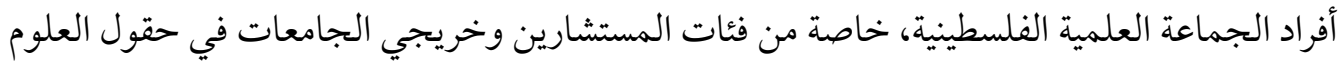

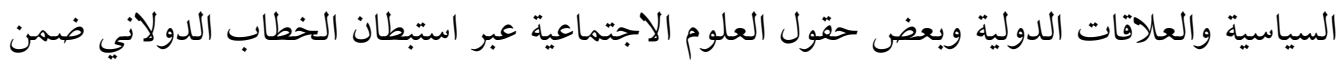
ما يمكن تسميته "صناعة العقول".

فلسطينًا، كان مفهوم الاستعمار مستخدمًا في بداية القرن الماضي لتوصيف الحالات الاستعمارية التي

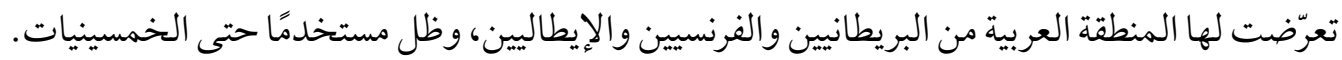

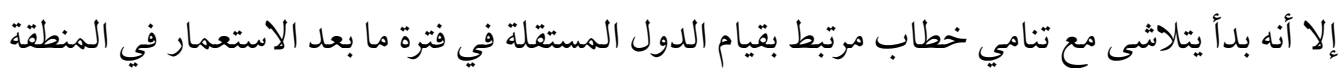

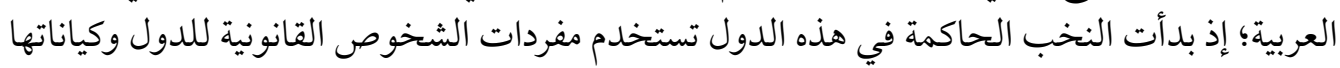

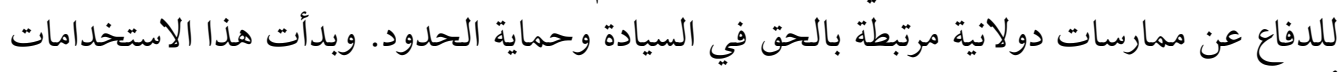

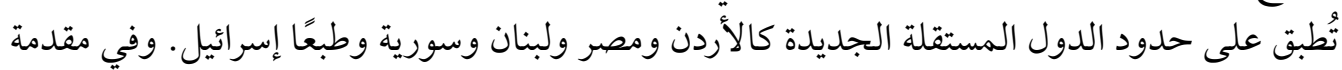

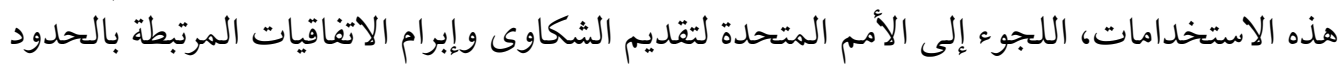

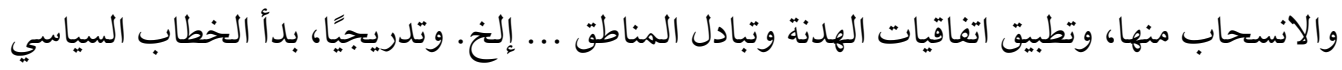

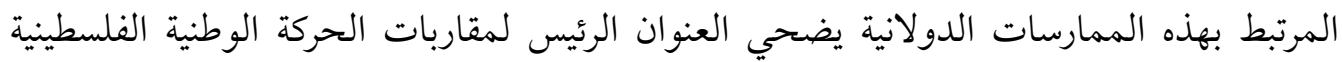

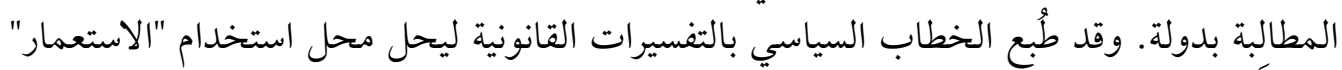

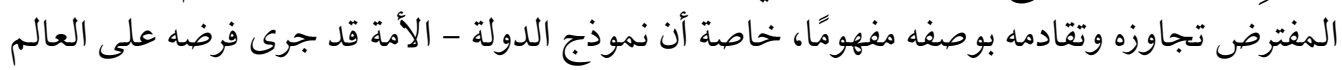

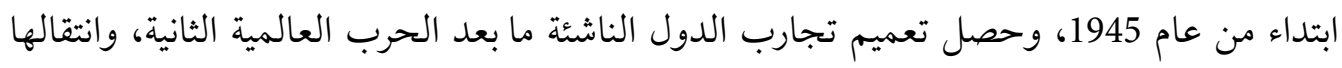

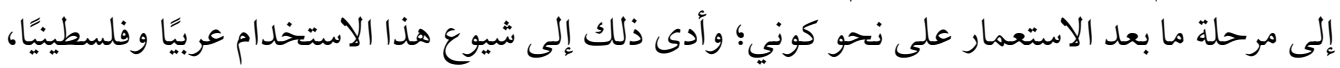

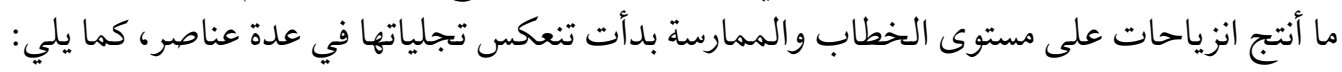

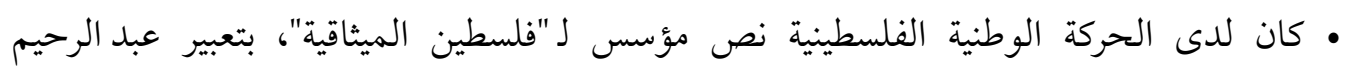

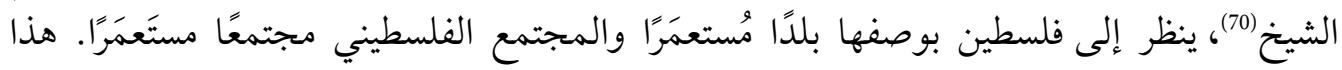

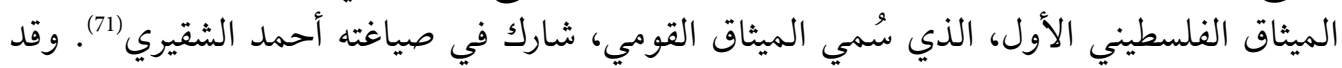

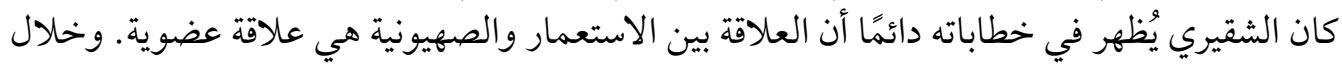

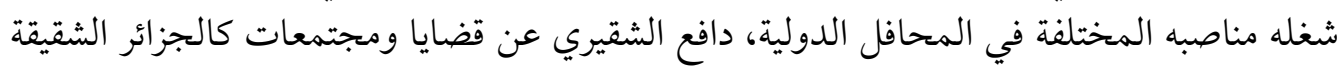

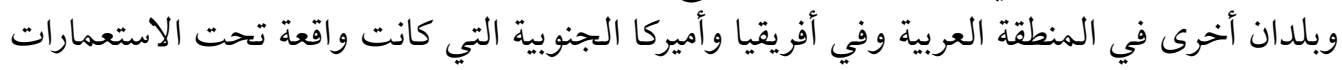

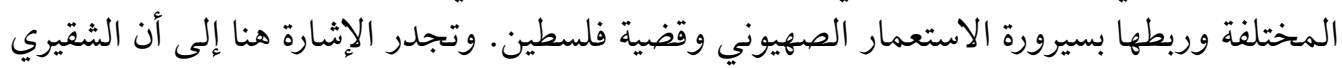

(70) عبد الرحيم الشيخ، "الهوية الثقافية الفلسطينية: المثال والتمثيل والتماثل" في: التجمعات الفلسطينية وتمثلاتها ومستقبل

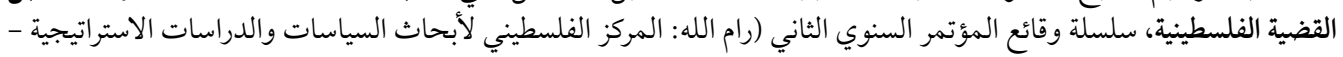
مسارات، 2013)، ص 76.

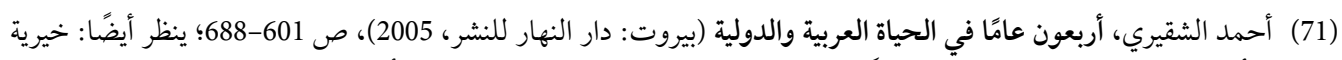

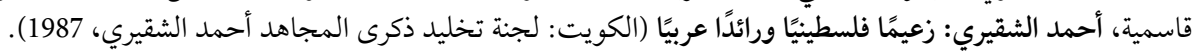




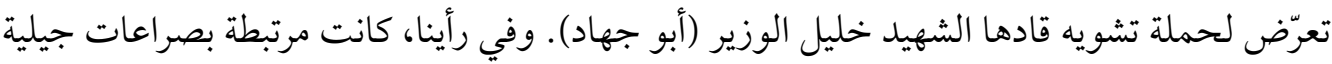
في حينها وحزبية، وكذلك لصراعات وسيرورات اجتماعية مرتبطة بخلفية الشقيري نفسها، "ممثلاً

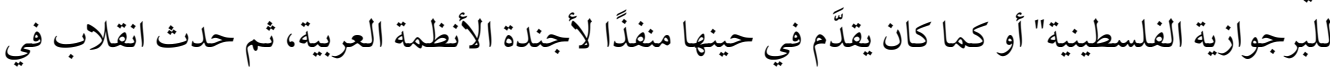

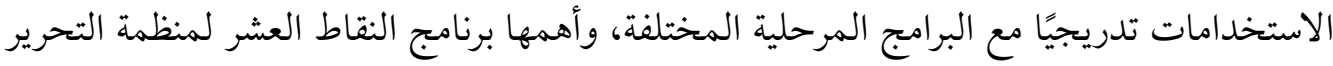

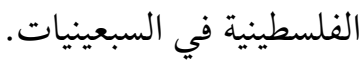

• بسبب تمركز الخطابات الموجهة إلى العالم المهيمن المناصر لدولة الاستعمار الصهيوني،

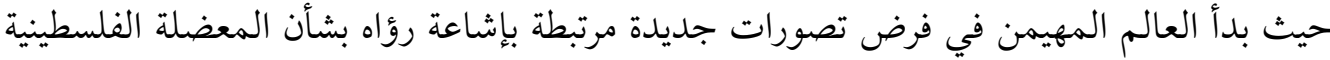

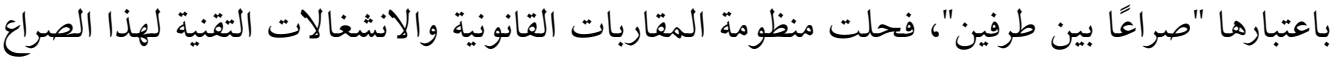

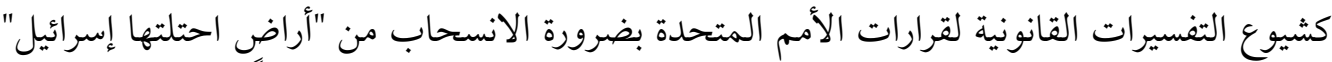

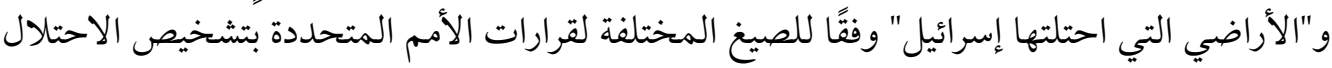

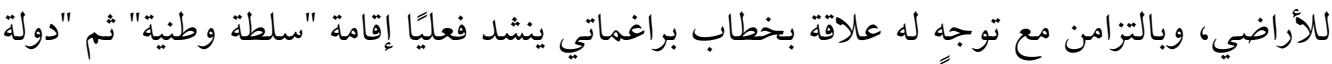

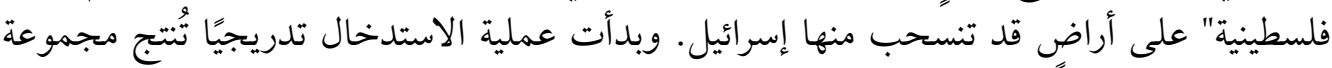

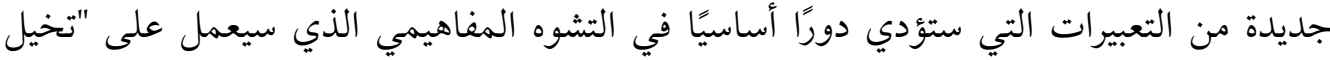

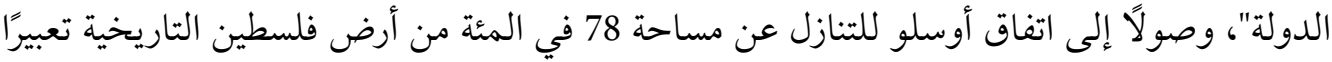

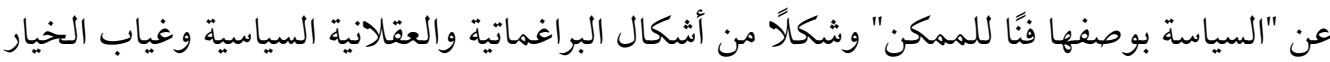

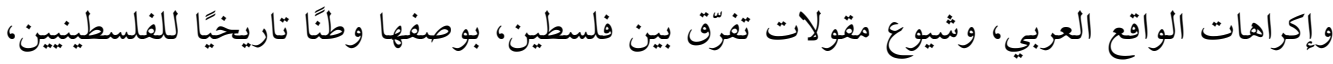

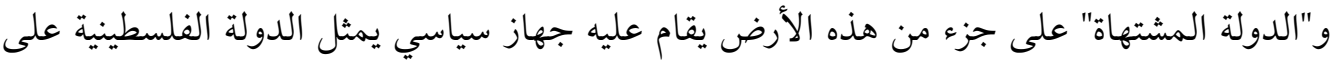

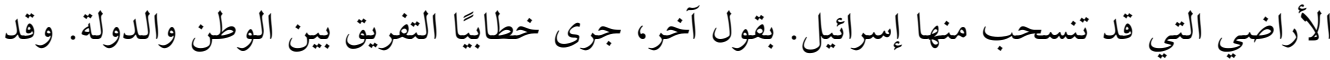

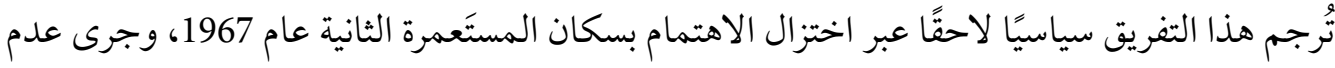

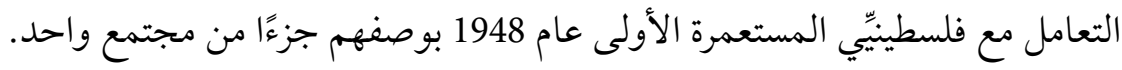

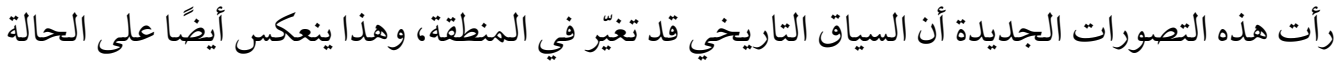

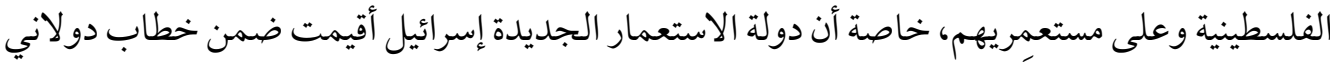

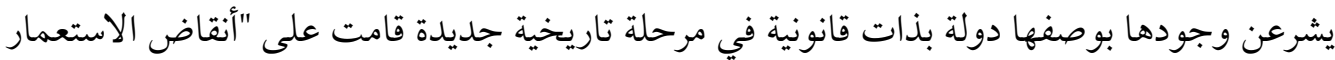

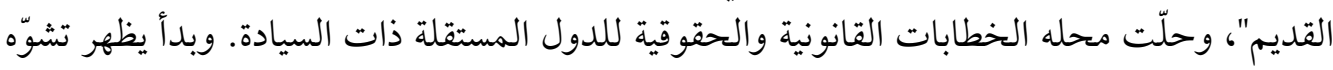

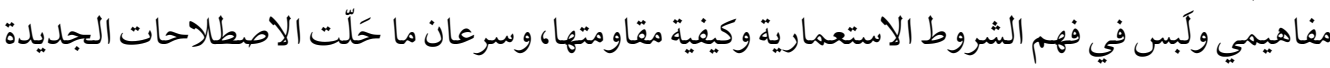

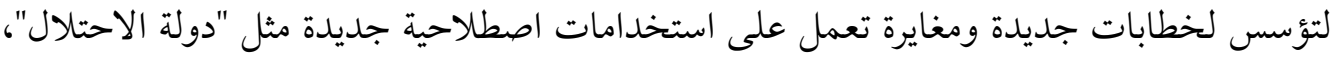

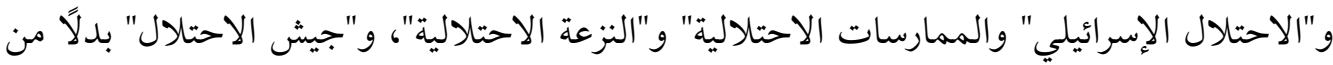

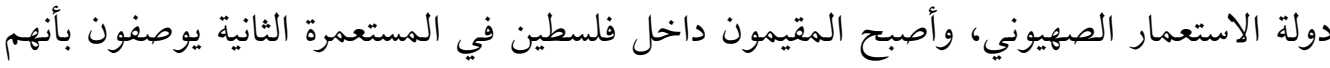

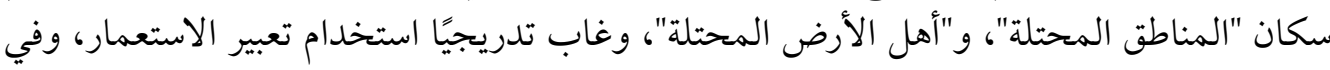

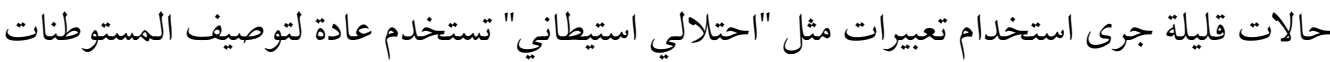

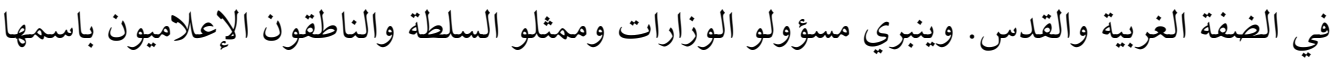

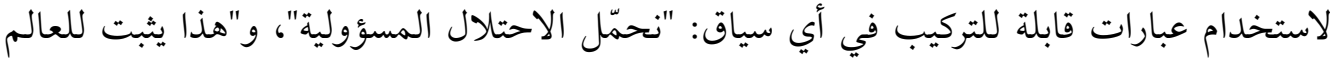


أن الجانب الآخر لا يريد السلام"، و"على المجتمع الدولي دعم حل الدولتين"، و"بتوجيه من السيد

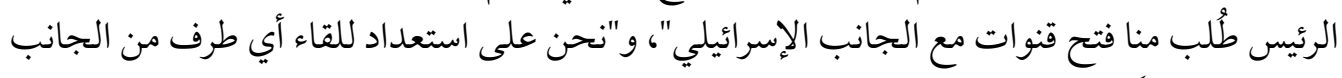

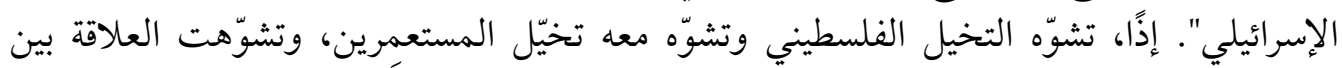

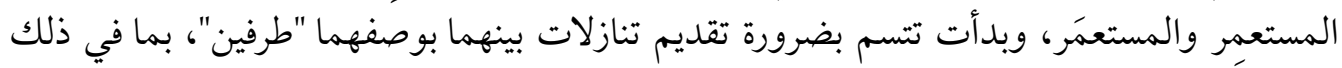

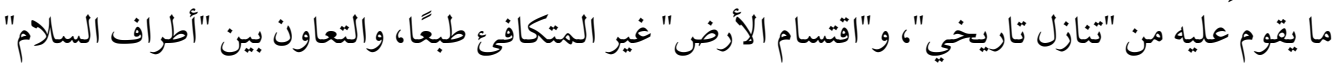

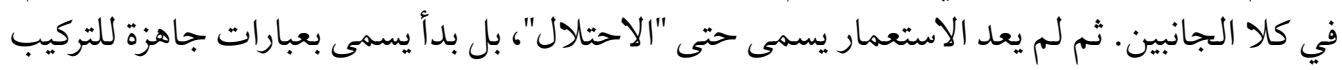

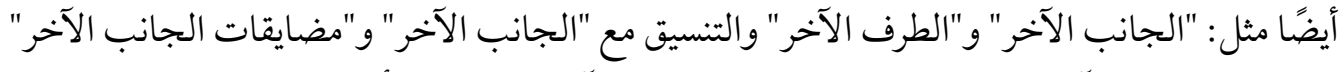

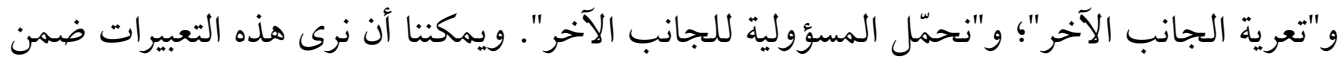

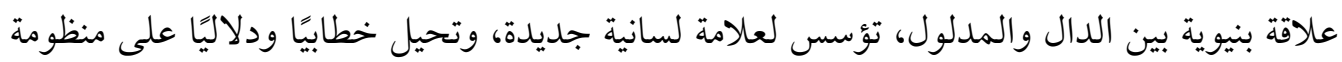

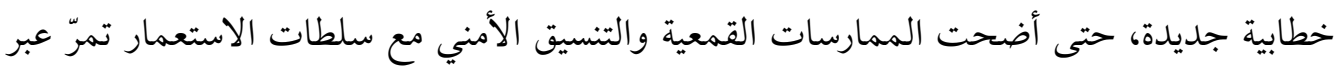

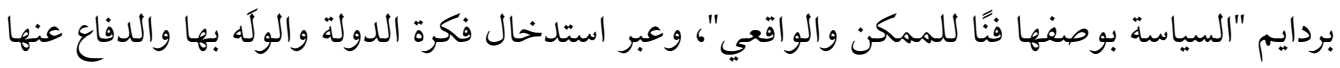

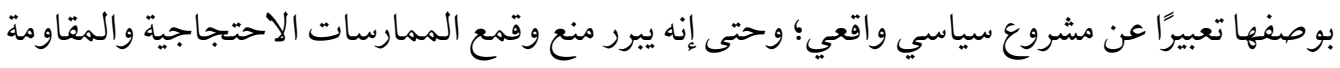

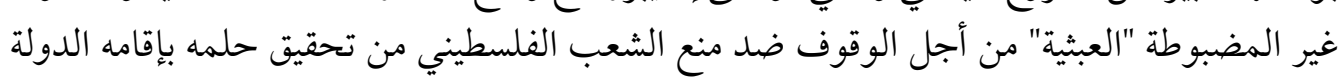

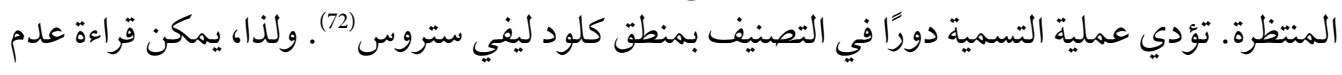

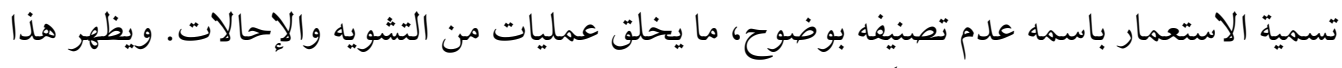

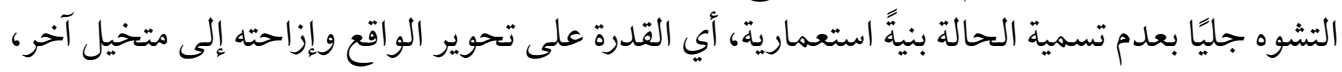

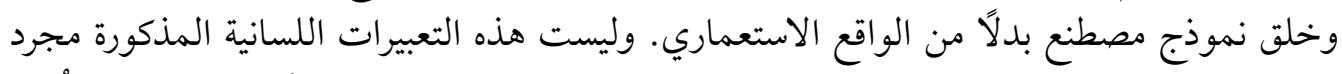

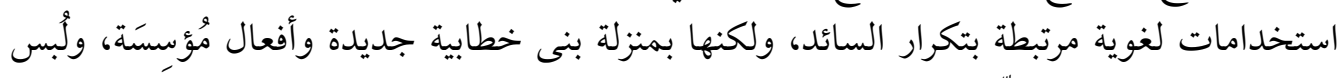

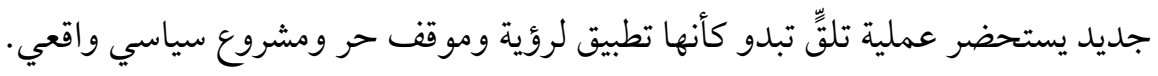

تتمترس جل الخطابات الفلسطينية الرسمية وبعض الخطابات غير الرسمية في علاقتها مع المستعمرين

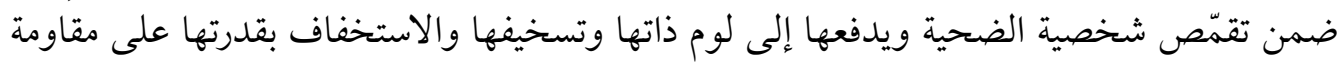

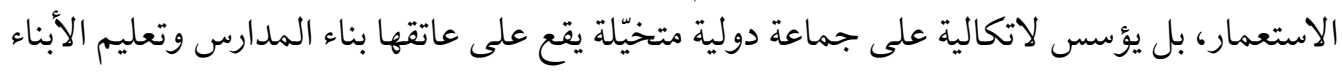

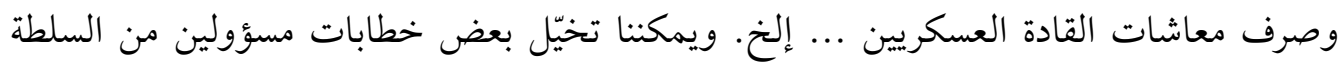

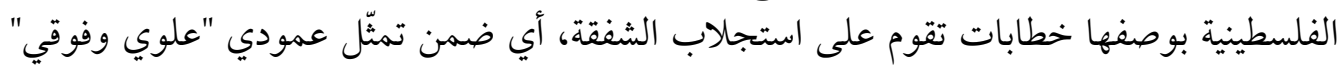
بتعبير لوك بولتناسكي (73).

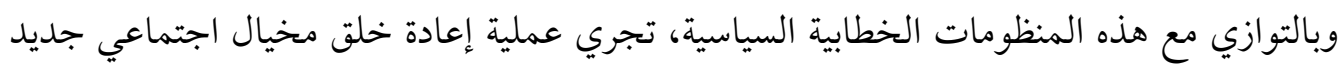

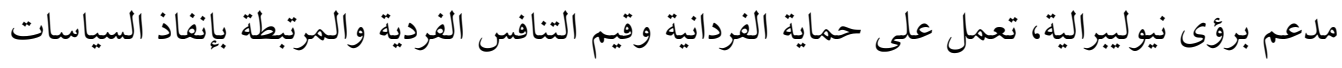

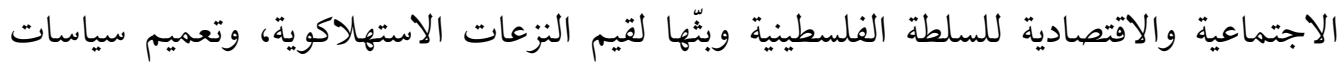

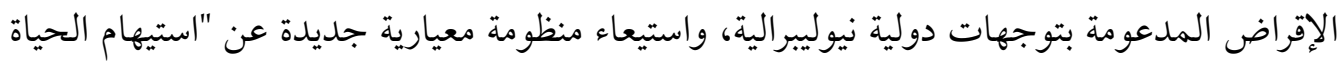

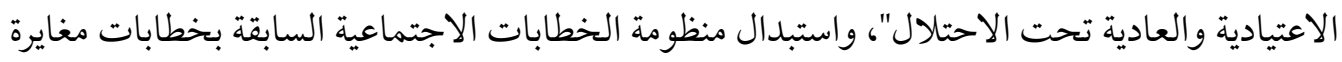

(72) Claude Lévi-Strauss, La Pensée sauvage (Paris: Pocket, 1990 [Paris: Plon, 1962]), p. 222.

(73) Luc Boltanski, La souffrance à distance (Paris: Métailié, 1993), p. 16. 
تقوم على استبدال قيم المشاركة المجتمعية والعمل التطوعي بمنظومة "الريادة" و"التميز الاقتصادي" وسبل النجاح والخلاص الفردية.

\section{4. شرعنة وهم "الدولة تحت الاحتلال"}

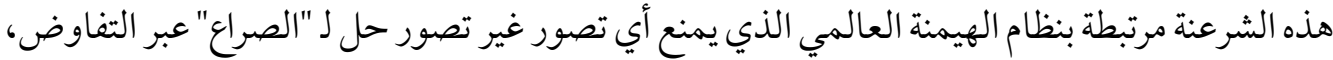

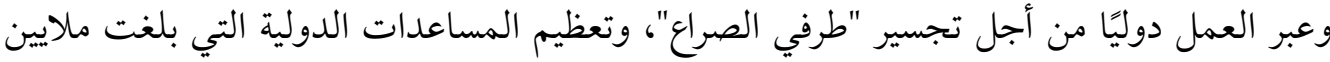

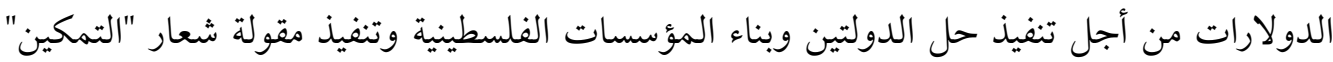

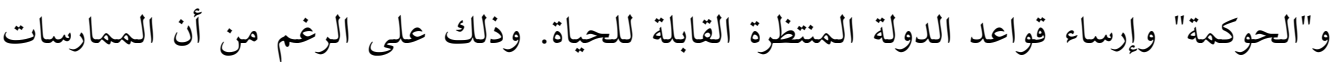

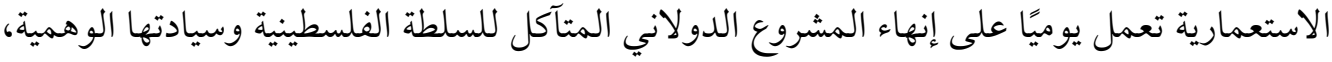

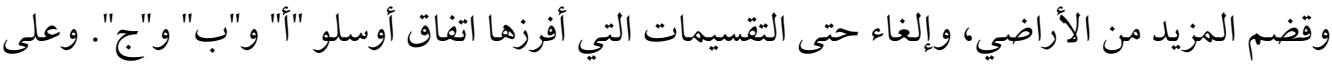

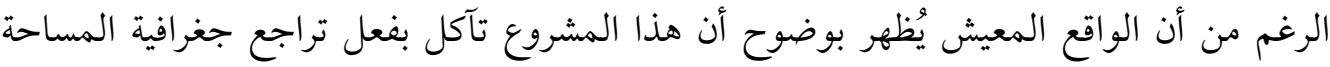

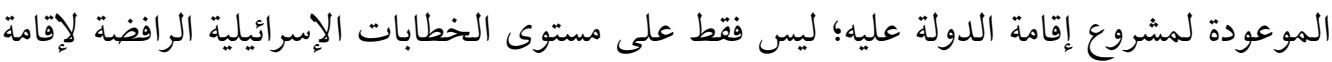

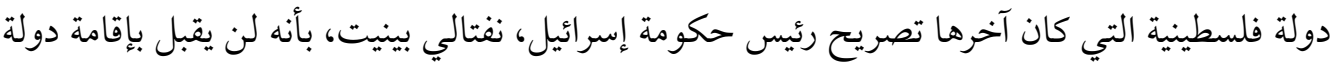

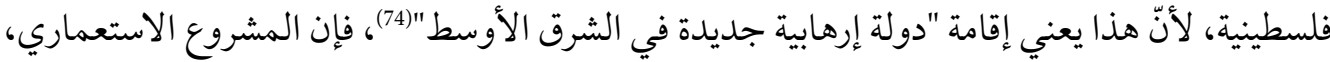

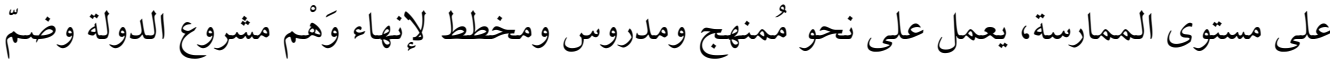

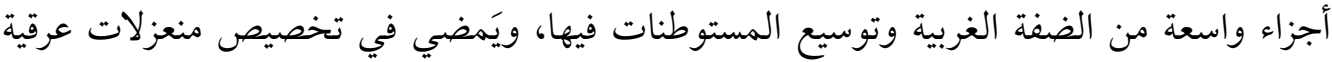

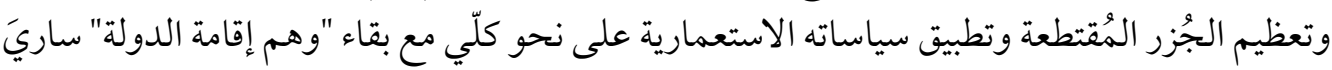
المفعول خطابيًا، وذلك عبر أموال المانحين.

كما أشرنا سابقًا، ثمة خصوصية لكل حالة استعمارية مرتبطة بتغيّر السياق، ولكننا إن حاولنا قراءة

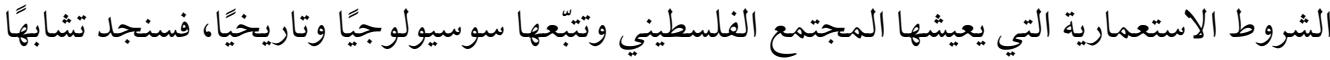

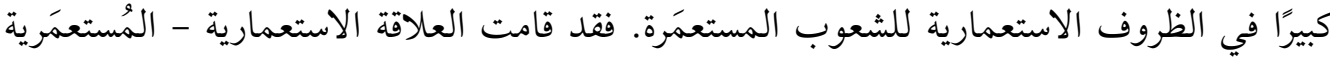

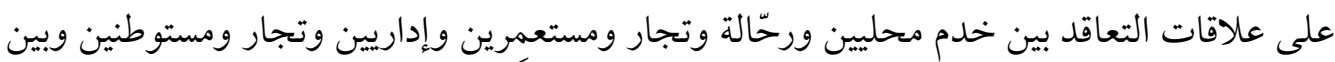

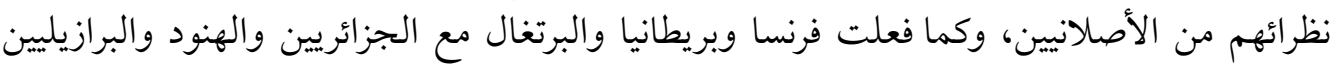

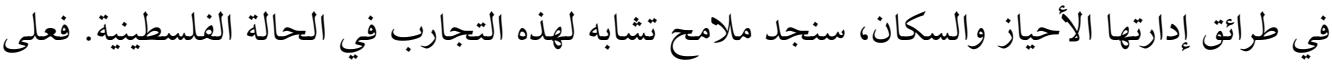

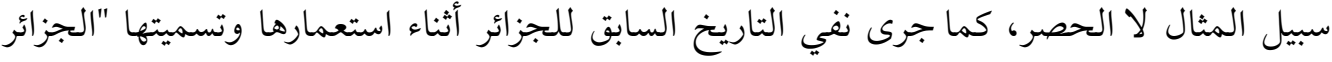

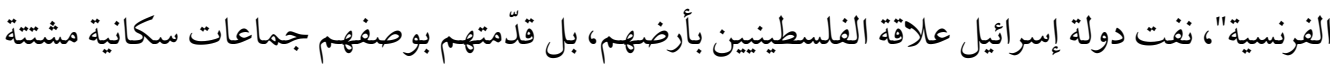

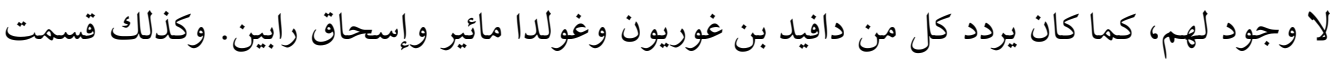

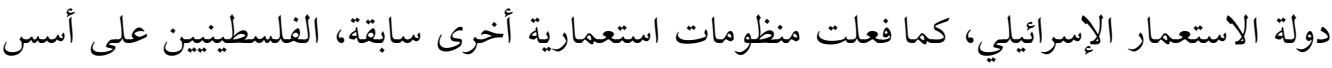

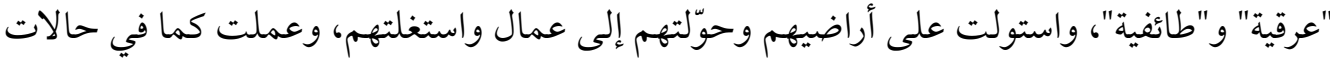
مشابهة أيضًا على تطبيق سياستها الحيوية وسياسات الموت على على الفلسطينيين والتحكم في أجسادهم 
الحية والميتة والشهيدة. وكما فعلت الدول الاستعمارية السابقة، عملت إسرائيل على تجميع الرساميل

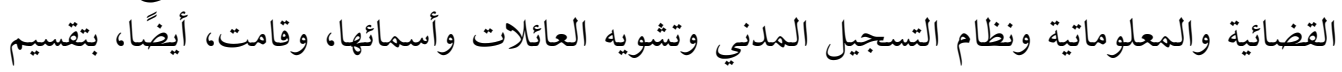

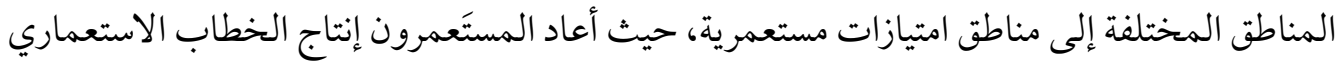

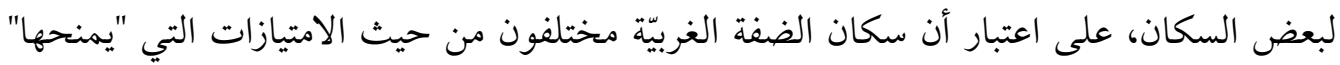

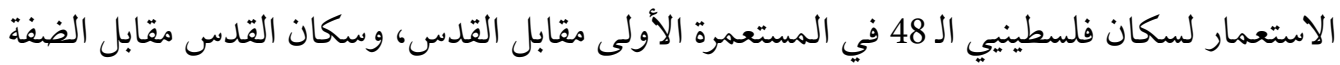

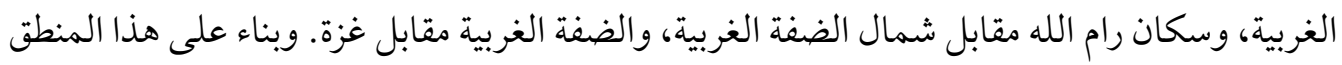

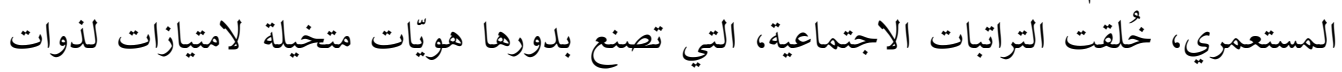
اجتماعية واقتصادية مختلفة تعجّ بتنميط ثقافوي استعماري (75).

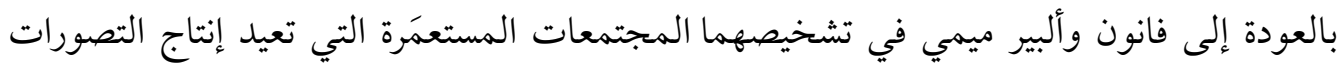

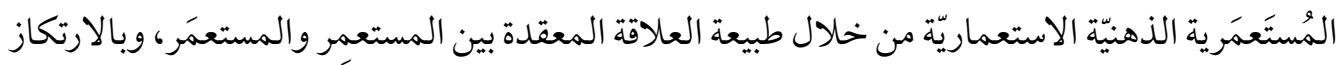

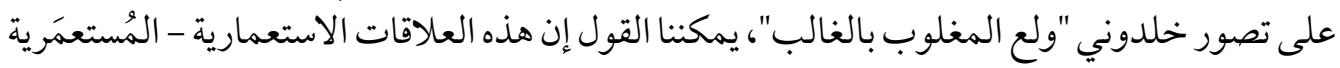

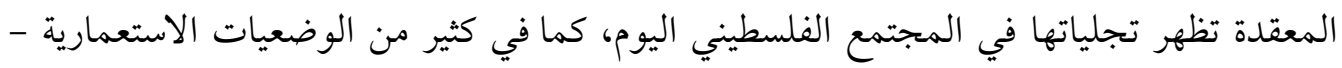

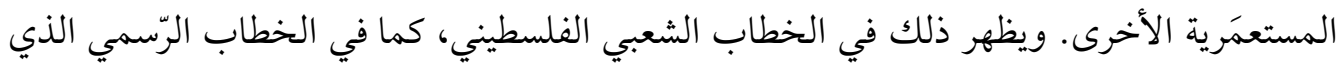

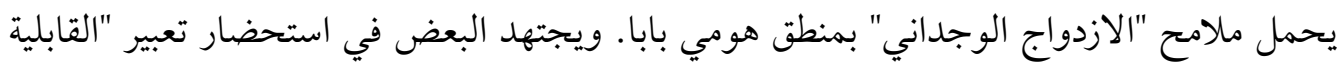

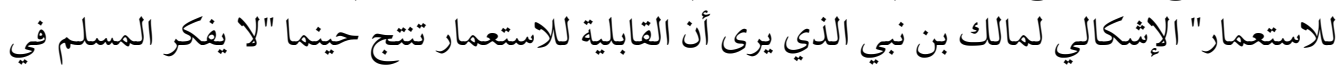

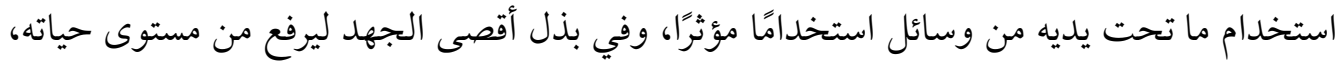

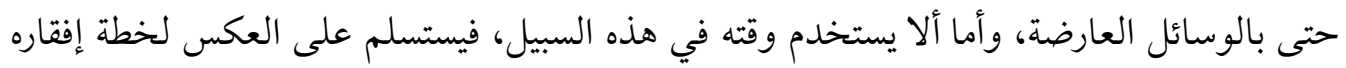

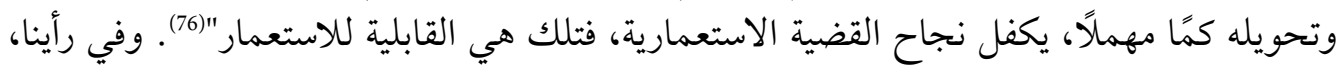

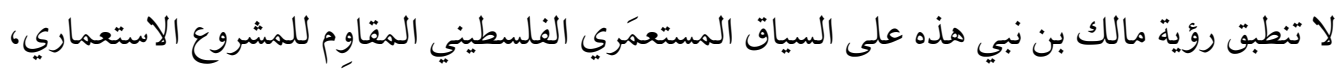

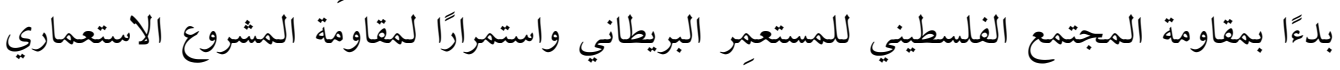

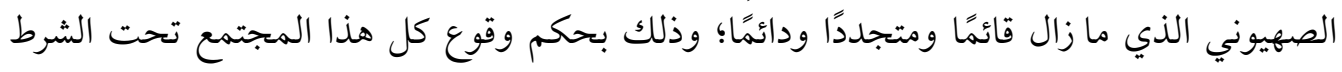

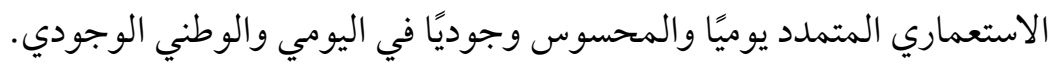

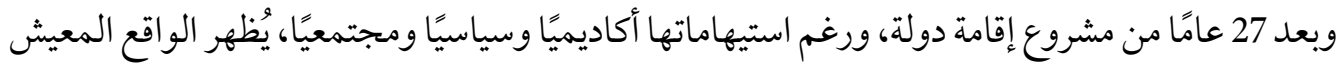

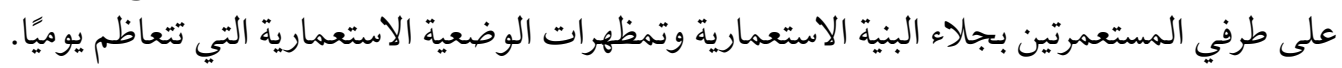

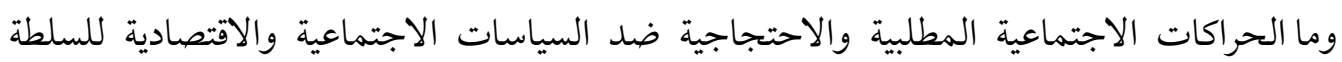

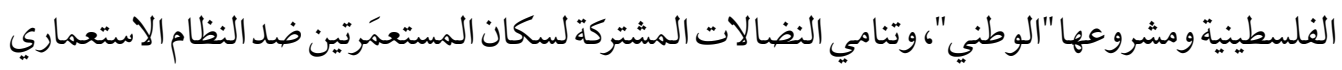

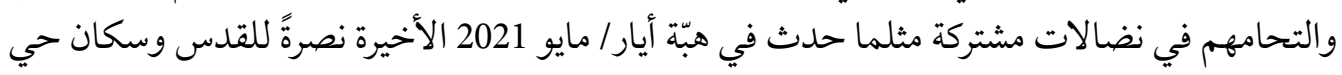

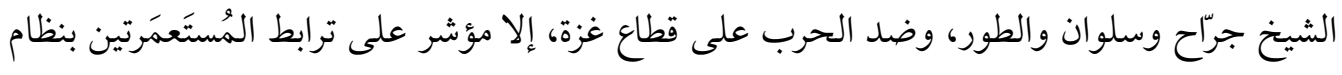

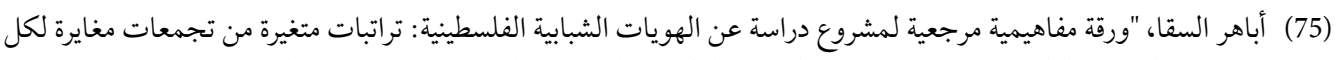

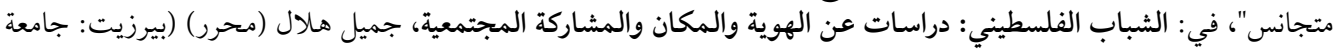

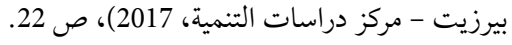
(76) مالك بن نبي، وجهة العالم الإسلامي (دمشق: دار الفكر، 2017)، 1980)، ص 150. 


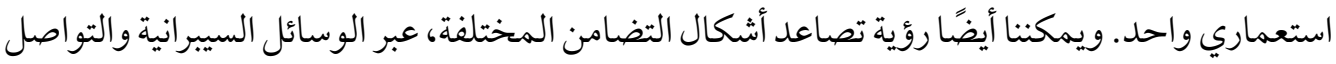

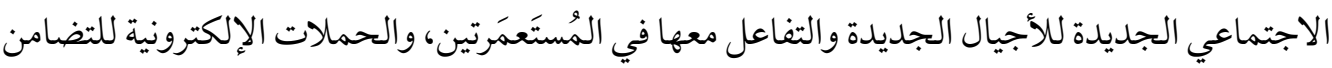

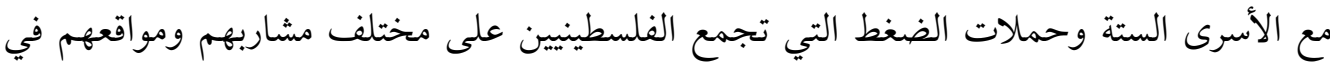

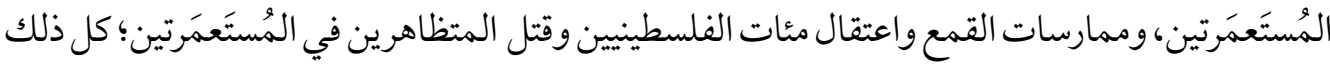

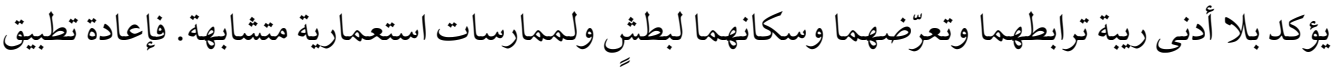

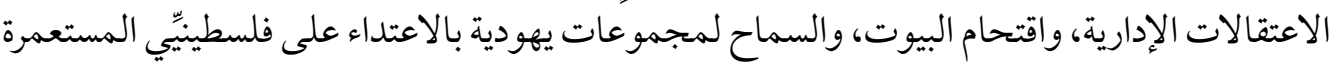

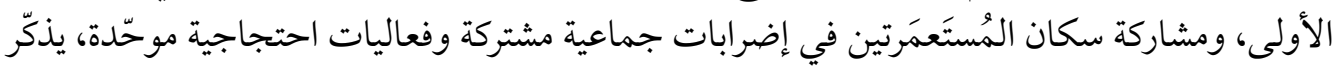

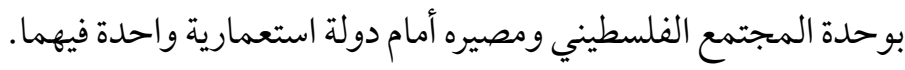

\section{حَاتمة}

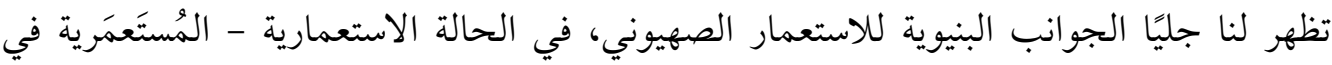

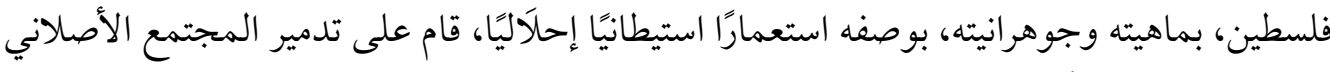

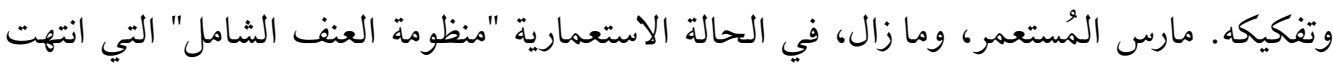

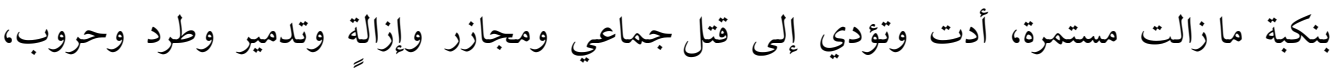

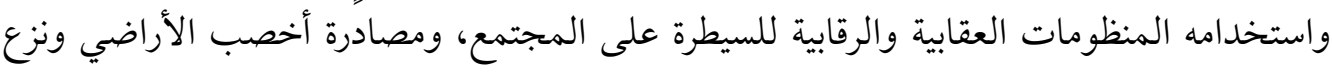

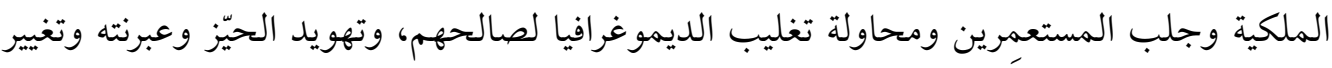

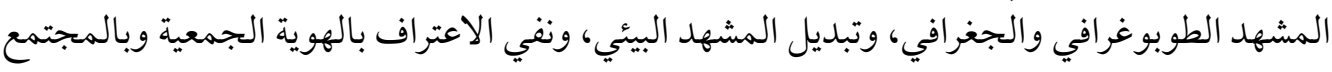

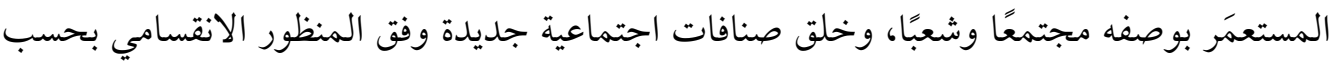

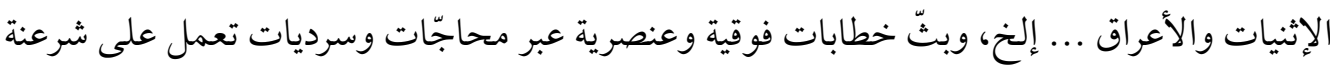

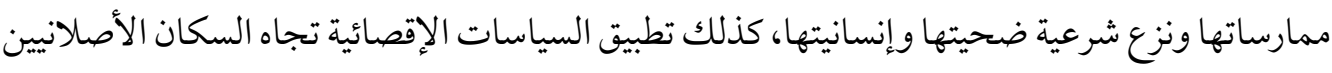

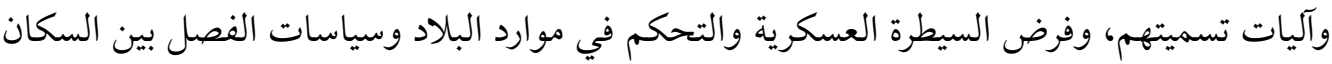

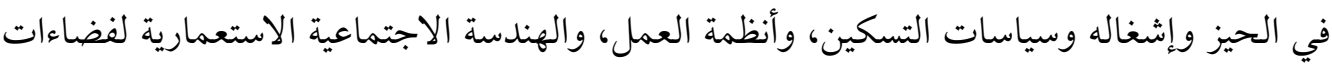

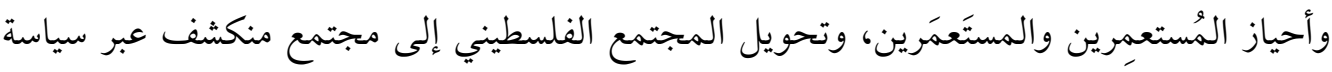

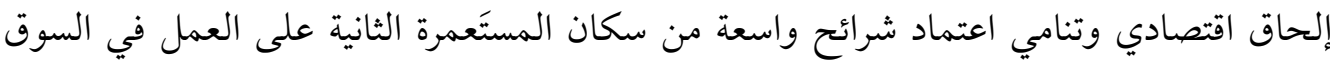

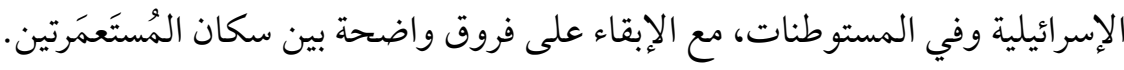

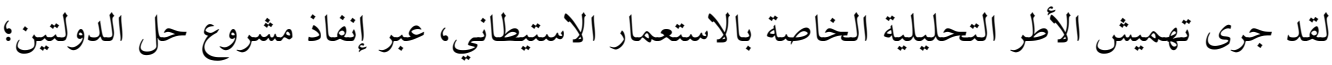

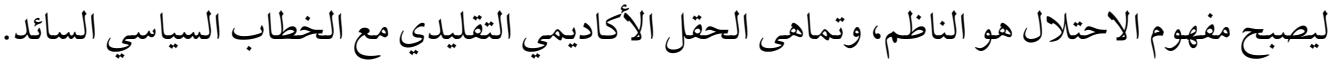

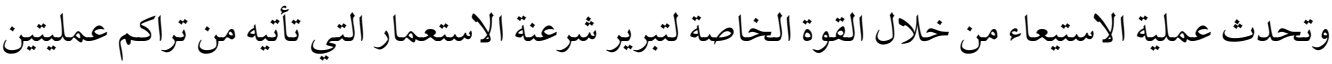

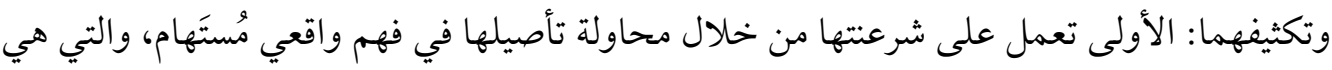

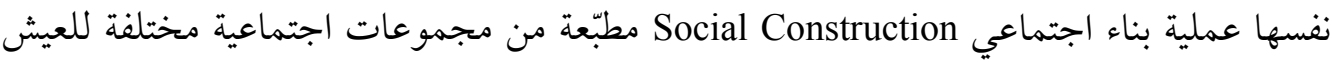

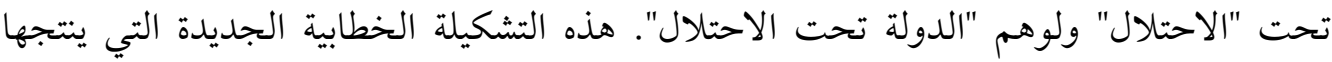

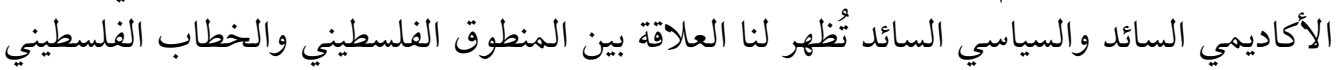


اللذين يظهران جليًا في المجتمع الفلسطيني، طبعًا من دون تهميش استمرارية المقاومة المجتمعية له من شرائح واسعة في المجتمع الفلسطيني.

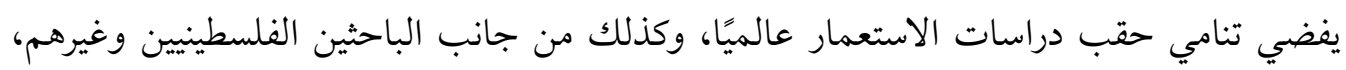

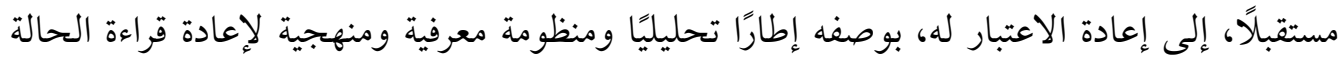
الفلسطينية الاستعمارية وتشخيصها، وقد يفضي إلى ولادة حقل معرفي جديد عن الحالة المُستَعَمرية.

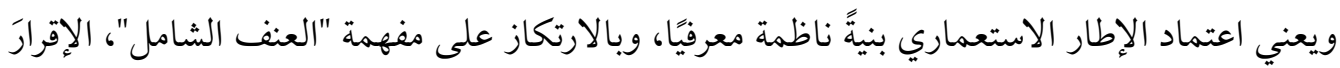

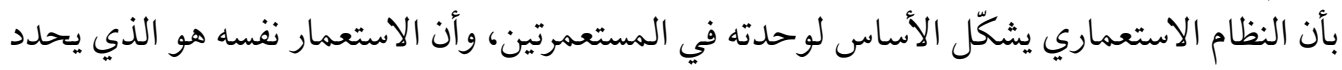

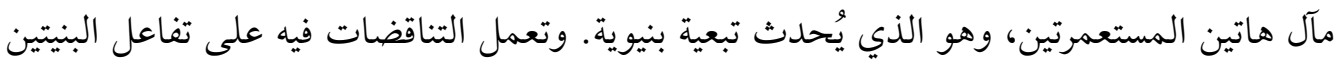

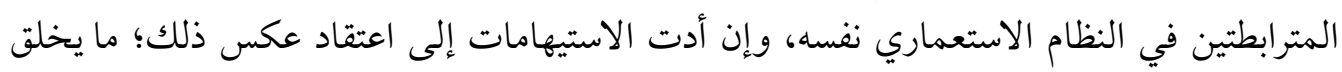

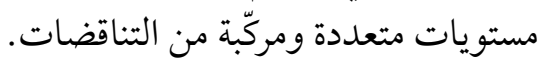

من نافلة القول إن سمات ظاهرة "الاستبدال المفاهيمي" هي ظاهرة اعتيادية في عالم الأفكار

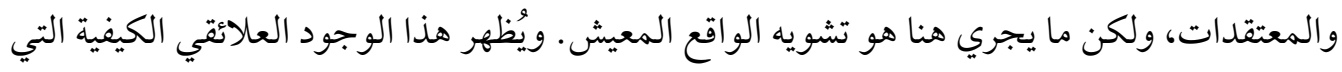

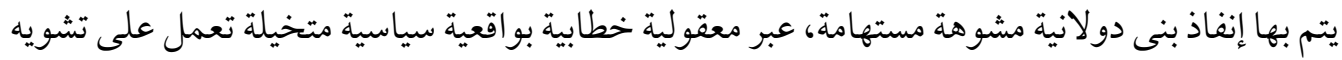

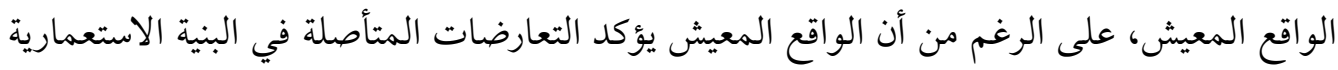

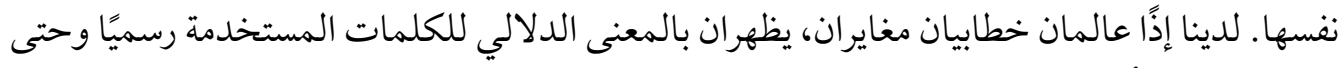

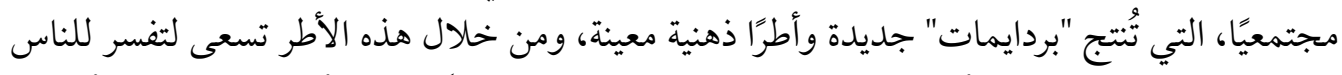

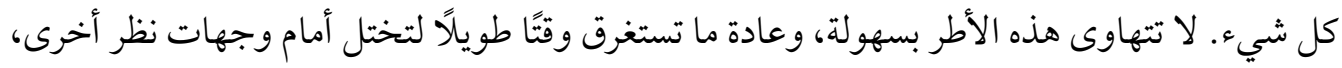

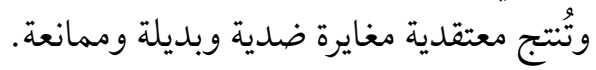

\section{References}

أمارة، أحمد ويارا هواري. "توظيف الأصلانية في النضال التحرّري الفلسطيني". شبكة السياسات الفلسطينية. 2019/8/8. في: https://bit.ly/34E4ffN

بن نبي، مالك. وجهة العالم الإسلامي. دمشق: دار الفكر، 1980.

التجمعات الفلسطينية وتمثلاتها ومستقبل القضية الفلسطينية. سلسلة وقائع المؤتمر السنوي الثاني. رام الله: المركز الفلسطيني لأبحاث السياسات والدراسات الاستراتيجية - مسارات، 2013.

الشباب الفلسطيني: دراسات عن الهوية والمكان والمشاركة المجتمعية. جميل هلال (محرر) . بيرزيت: جامعة بيرزيت - مركز دراسات التنمية، 2017. الشقيري، أحمد. أربعون عامًا في الحياة العربية والدولية. بيروت: دار النهار للنشر، 2005. 


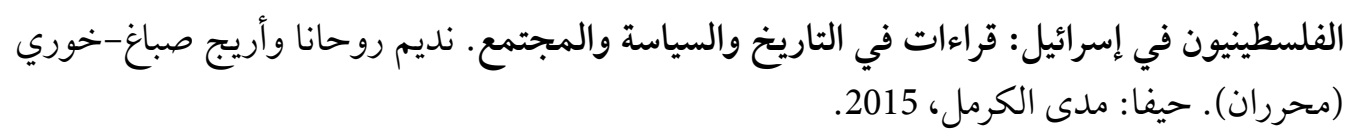

قاسمية، خيرية. أحمد الشقيري: زعيمًا فلسطينًا ورائدًا عربيًا. الكويت: لجنة تخليد ذكرى المجاهد أحمد الشقيري، 1987.

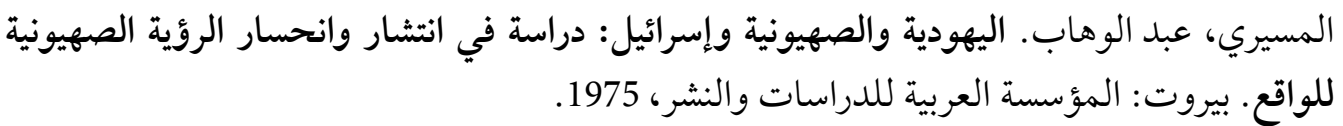

الأحنبية

Abdeljawad, Saleh. "La politique israélienne envers le peuple palestinien." Inprecor. no. 517 (Mai 2006). at: https://bit.ly/3JUy4sx

Abu Sitta, Salman. The Palestinian Nakba, 1948: The Register of Depopulated Localities in Palestine. London: Palestinian Return Centre, 2000.

Abu-Lughod, Ibrahim \& Baha Abu-Laban (eds.). Settler Regimes in Africa and the Arab World: The Illusion of Endurance. Wilmette, IL: Medina University Press International, 1974.

Agamben, Giorgio. État d'exception: Homo Sacer II. Paris: Seuil, 2003.

Akoun, André \& Pierre Ansart (dir.). Dictionnaire de sociologie. Collection Le Robert. Paris: Seuil, 1999.

Arendt, Hannah. Du mensonge à la violence: Essai de politique contemporaine. Guy Durand (trad.). Paris: Calmann-Lévy, 1972.

Balandier, Georges. "La situation coloniale:Approche théorique." Cahiers internationaux de sociologie. vol. 11 (1951).

Balibar, Étienne. "Lénine et Gandhi, Une rencontre manquée?" Alternative Roma. no. 6 (2005).

Ball, Kirstie, Kevin Haggerty \& David Lyon (eds.). Routledge Handbook of Surveillance Studies. London: Routledge, 2012.

Barakat, Rana. "Writing/ Righting Palestine studies: Settler Colonialism, Indigenous Sovereignty and Resisting the Ghost(s) of History." Settler Colonial Studies. vol. 8, no. 3 (2017).

Bell, David. The First Total War: Napoleon's Europe and the Birth of Warfare as We Know it. New York/ Boston: Houghton Miflin Company, 2010.

Bober, Arie (ed.). The Other Israel: The Radical Case Against Zionism. Garden City, NY: Anchor Books, 1972.

Boltanski, Luc. La souffrance à distance. Paris: Métailié, 1993.

Bourdieu, Pierre \& Loïc Wacquant. Réponses. Paris: Seuil, 1992.

Bourdieu, Pierre \& Luc Boltanski. "La production de l'idéologie dominante." Actes de la recherche en sciences sociales. vol. 2, no. 2-3 (1976). 
Bourdieu, Pierre. "Le champ scientifique." Actes de la recherche en sciences sociales. vol. 2, no. 2-3 (1976).

. "Les modes de domination." Actes de la recherche en sciences sociales. vol. 2, no. 2-3 (1976).

. La distinction: Critique sociale du jugement. Paris: Minuit, 1979.

. Homo Academicus. Paris: Minuit, 1984.

. La distinction. Paris: Minuit, 1984.

- Questions de sociologie. Paris: Minuit, 1989.

. La noblesse d'Etat: Grandes écoles et esprit de corps. Paris: Minuit, 1992.

. "Esprits d'État: Genèse et structure du champ bureaucratique." Actes de la recherche en sciences sociales. vol. 96-97 (Mars 1993).

. Méditations pascaliennes. Paris: Seuil, 1997.

. Les structures sociales de l'économie. Paris: Seuil, 2000.

. Langage et pouvoir symbolique. Paris: Seuil, 2001.

. Interventions (1961-2001): Sciences sociales et action politique. Marseille: Agone; Montréal: Comeau \& Nadeau, 2002. d'agir, 2012 .

. Sur l'État: Cours au Collège de France (1989-1992). Paris: Seuil; Raisons . La misère du monde: Essais. Paris: Points, 2015 [1993].

Cohen, Einat Bar-On. "Globalization of the War on Violence: Israeli Close-combat, Krav Maga and Sudden Alterations in Intensity." Social Anthropology. vol. 18, no. 3 (2010).

Davis, Uri. Israel, Utopia Incorporated: A Study of Class, State, and Corporate Kin Control. London: Zed Press, 1977.

. Apartheid Israel, Possibilities for the Struggle Within. London/ New York: Zed Books, 2003.

Deleuze, Gilles. Les Indiens de Palestine Paru dans le recueil Deux régimes de fous. Paris: Minuit, 1983.

Ferro, Marc (dir.). Le livre noir du colonialisme. Paris: Robert Laffont, 2003.

Foucault, Michel. L'Archéologie du savoir. Paris: Gallimard, 1969.

. Surveiller et Punir: Naissance de la prison. Paris: Gallimard, 1975.

. Dits et écrits (1954-1988), tome II: 1970-1975. Daniel Defert, François

Ewald \& Jacques Lagrange (dir.). Paris: Gallimard, 1978.

Frantz, Fanon. Les damnés de la terre. Paris: Gallimard, 1991.

Go, Julian. "The 'New' Sociology of Empire and Colonialism." Sociology Compass. vol. 3, no. 5 (2009).

. "For a Postcolonial Sociology." Theory and Society. vol. 42, no. 1 (2013).

Grandmaison, Olivier Le Cour. Coloniser, exterminer, sur la guerre et l'état colonial. 
Paris: Fayard, 2005.

Gribaudi, Gabriella. Guerra Totale: Tra bombe alleate e violenze naziste: Napoli e il fronte meridionale, 1940-44. Torino: Bollati Boringhieri, 2005.

Guiomar, Jean-Yves. L'Invention de la guerre totale. Paris: Le Félin, 2004.

Hanafi, Sari \& Linda Taber. "Spatio-cide, réfugiés, crise de l'État-nation." Multitudes. vol. 4, no. 18 (2004).

Jamil, Hilal. "Imperialism and Settler-Colonialism in West Asia: Israel and the Arab Palestinian Struggle." Utafiti. vol. 1, no. 1 (1976).

Kayyali, Abdul-Wahhab (ed.). Zionism, Imperialism, and Racism. London: Croom Helm, 1979.

Kervégan, Jean-François. Que faire de Carl Schmitt? Paris: Gallimard, 2011.

Khalidi, Rashid. The Hundred Years' War on Palestine: A History of Settler Colonialism and Resistance, 1917-2017. New York: Metropolitan Books, 2020.

Kimmerling, Baruch. Politicide: Les guerres d'Ariel Sharon contre les Palestiniens. Paris: Éditions Agnès Viénot, 2003.

Labica, Georges. Théorie de la violence. Paris: Vrin; Napoli: La Citta del Sol, 2008.

Lévi-Strauss, Claude. La Pensée sauvage. Paris: Pocket, 1990 [Paris: Plon, 1962].

Mansour, Sylvie. "La génération de l'Intifada." Cultures \& Conflits. vol. 2, no. 18 (1995).

Martin, Jean-Clément. "Révolution française et 'violence totale'." Inflexions. vol. 31, no. 1 (2016).

Masalha, Nur. The Palestine Nakba: Decolonising History, Narrating the Subaltern, Reclaiming Memory. London/ New York: Zed Books, 2012.

The Zionist Bible: Biblical Precedent, Colonialism and the Erasure of Memory. Durham: Acumen, 2013.

Mauss, Marcel. Essai sur le don: Forme et raison de l'échange dans les sociétés archaïques. Paris: PUF, 2007.

Memmi, Albert. Portrait du colonisé. Paris: Payot, 1973.

Mikdashi, Maya. "What is Settler Colonialism? (For Leo Delano Ames Jr.)." American Indian Culture \& Research Journal. vol. 37, no. 2 (2013).

Ophir, Adi, Michal Givoni \& Sari Hanafi (eds.). The Power of Inclusive Exclusion: Anatomy of Israeli Rule in the Occupied Palestinian Territories. New York: Zone Books, 2009.

Raz-Krakotzkin,Amnon. Exil et souveraineté: Judaïsme, sionisme et pensée binationale. Paris: La Fabrique, 2007.

Rochlitz, Rainer (dir.). Walter Benjamin: Critique philosophique de l'art. Paris: Gallimard, 2000 [1921].

Rodinson, Maxime. "Israël, fait colonial?" Les Temps modernes. vol. 22, no. 253 (1967). Peuple juif ou problème juif? Paris: François Maspero, 1981. 
Rouhana, Nadim N. \& Areej Sabbagh-Khoury. "Settler-colonial Citizenship: Conceptualizing the Relationship between Israel and its Palestinian Citizens." Settler Colonial Studies. vol. 5, no. 3 (2015).

Sabbagh-Khoury, Areej. "Tracing Settler Colonialism: A Genealogy of a Paradigm in the Sociology of Knowledge Production in Israel." Politics \& Society (2021).

Said, Edward. The Question of Palestine. New York: Times Books, 1979.

Sand, Shlomo. Comment le peuple juif fut inventé: De la Bible au sionisme. Paris: Fayard, 2008.

Sayegh, Fayez. Zionist Colonialism in Palestine. Beirut: The Palestine Liberation Organization Research Center, 1965.

Shalhoub-Kevorkian, Nadera. Militarization and Violence against Women in Conflict Zones: A Palestinian Case-study. Cambridge: Cambridge University Press, 2009.

. "Human Suffering in Colonial Contexts: Reflections from Palestine." Settler Colonial Studies. no. 4, no. 3 (2014).

Shanker, Israel \& Shanker Mary (eds.). As Good as Golda: The Warmth and Wisdom of Israel's Prime Minister. New York: McCall, 1970.

Shihade, Magid. "Settler Colonialism and Conflict: The Israeli State and Its Palestinian Subjects." Settler Colonial Studies. vol. 2, no. 1 (2012).

Smith, Anthony D. Chosen Peoples: Sacred Sources of National Identity. Oxford: Oxford University Press, 2003.

Sommier, Isabelle. "Du 'terrorisme' comme violence totale?" Revue internationale des sciences sociales. vol. 4, no. 174 (2002).

Sudhir, Chandra (ed.). Violence-Nonviolence across Time: History, Religion and Cultures. London: Routledge, 2018.

Veracini, Lorenzo. Settler Colonialism: A Theoretical Overview. New York: Palgrave Macmillan, 2010.

Wallerstein, Immanuel. L'universalisme européen: De la colonisation au droit d'ingérence. Paris: Demopolis, 2008.

Weber, Max. Le savant et le politique. Julien Freund (trad.). Paris: Plon, 1959.

Wolfe, Patrick. Settler Colonialism and the Transformation of Anthropology: The Politics and Poetics of an Ethnograph Event. London: Cassell, 1999.

. "Settler Colonialism and the Elimination of the Native." Journal of Genocide Research. vol. 8, no. 4 (2006).

Zreik, Raef. "When Does a Settler Become a Native? (With Apologies to Mamdani)." Constellations. vol. 23, no. 3 (2016).

Zureik, Elia. The Palestinians in Israel: A Study in Internal Colonialism. London: Routledge \& Kegan Paul, 1979.

. Israel's Colonial Project in Palestine: Brutal Pursuit. Routledge Studies on the Arab-Israeli Conflict. Abingdon: Routledge, 2015. 